\title{
Structure of the human inner kinetochore CCAN complex and its significance for human centromere organization
}

Marion E. Pesenti ${ }^{1, \$}$, Tobias Raisch $^{2, \$}$, Duccio Conti ${ }^{1}$, Ingrid Hoffmann ${ }^{1}$, Dorothee Vogt ${ }^{1}$, Daniel Prumbaum ${ }^{2}$, Ingrid R. Vetter ${ }^{1, \#}$, Stefan Raunser, ${ }^{2, \#} \&$ Andrea Musacchio, ${ }^{1,3, \#}$

(1) Department of Mechanistic Cell Biology, Max-Planck Institute of Molecular Physiology, Otto-Hahn-Straße 11, 44227 Dortmund, Germany

(2) Department of Structural Biochemistry, Max-Planck Institute of Molecular Physiology, Otto-Hahn-Straße 11, 44227 Dortmund, Germany

(3) Centre for Medical Biotechnology, Faculty of Biology, University Duisburg-Essen, Universitätsstrasse, 45141 Essen, Germany

\$ Equal contribution

\# Correspondence:_andrea.musacchio@mpi-dortmund.mpg.de; stefan.raunser@mpidortmund.mpg.de; ingrid.vetter@mpi-dortmund.mpg.de

Keywords: kinetochore; centromere; chromatin; hemisome; nucleosome; CENP-A; biochemical reconstitution; CENP-N; CENP-C; CENP-TW; constitutive centromere associated network; CCAN; Ctf19; cryo-electron microscopy

Short title: Structure of human CCAN 
Centromeres are specialized chromosome loci that seed the kinetochore, a large protein complex that effects chromosome segregation. The organization of the interface between the kinetochore and the specialized centromeric chromatin, marked by the histone $\mathrm{H} 3$ variant CENP-A, remains incompletely understood. A 16-subunit complex, the constitutive centromere associated network (CCAN), bridges CENP-A to the spindle-binding moiety of the kinetochore. Here, we report a cryo-electron microscopy structure of human CCAN. We highlight unique features such as the pseudo GTPase CENP-M and report how a crucial CENP-C motif binds the CENP-LN complex. The CCAN structure has also important implications for the mechanism of specific recognition of the CENP-A nucleosome. A supported model depicts the interaction as fuzzy and identifies the disordered CCAN subunit CENP-C as only determinant of specificity. A more speculative model identifies both CENP-C and CENP-N as specificity determinants, but implies CENP-A may be in a hemisome rather than in a classical octamer.

\section{Introduction}

The correct distribution of chromosomes from a mother cell to its daughters during mitosis and meiosis is of paramount importance for the stability of intra- and intergenerational genetic inheritance. A specialized proteinaceous complex named the kinetochore mediates the interaction of chromosomes and spindle microtubules and is essential for the success of this process. Kinetochores are complex macromolecular machines, consisting of approximately thirty core subunits, and are regulated at multiple levels to ensure errorless chromosome segregation (McKinley and Cheeseman, 2016; Musacchio and Desai, 2017).

Kinetochores assemble on a specialized chromosome segment known as the centromere. The histone $\mathrm{H} 3$ variant centromeric protein A (CENP-A) is considered the hallmark of centromeres (McKinley and Cheeseman, 2016; Mellone and Fachinetti, 2021; Talbert and Henikoff, 2020). It seeds kinetochores by recruiting the 16-subunit constitutive centromere associated network (CCAN) complex (Foltz et al., 2006; Izuta et al., 2006; Obuse et al., 2004; Okada et al., 2006) (Figure 1A). The CCAN is the heart of the inner (centromere-proximal) kinetochore and plays several crucial functions in kinetochore assembly and centromere maintenance. First, it provides several docking sites for the 
Knl1-Mis12-Ndc80 (KMN) network, a protein assembly of the outer (centromere-distal) kinetochore that mediates microtubules attachment and feedback control of the cell cycle (Musacchio and Desai, 2017). Second, it contributes to the inheritance of centromeres through cell division, which implies the continuous replenishment of CENP-A to compensate for its reduction during DNA replication (Jansen et al., 2007; Schuh et al., 2007). A basic organization comprising a CENP-A-based centromere and a CCANbased inner kinetochore has undergone considerable evolutionary variation, but the general scheme remains recognizable in the vast majority of eukaryotes, including humans (Drinnenberg and Akiyoshi, 2017; Tromer et al., 2019; van Hooff et al., 2017).

In Saccharomyces cerevisiae and related yeasts, centromeres on different chromosomes are built on a conserved $\approx 125$ base pairs (bps) segment of DNA. These centromeres are limited to a single specialized nucleosome defined by the presence of CENP-A (the $S$. cerevisiae's CENP-A ortholog is known as Cse4) and are therefore defined as "point centromeres" (Bloom and Carbon, 1982; Fitzgerald-Hayes et al., 1982; Pluta et al., 1995). Most CCAN subunits are also identified in these organisms, where they are collectively referred to as the Ctf19 complex (henceforth Ctf19 ${ }^{\mathrm{CCAN}}$ ). Recent high-resolution cryoelectron microscopy structures of the S. cerevisiae's Ctf19 ${ }^{\text {CCAN }}$ complex revealed the reciprocal organization of subunits and a possible mode of interaction with an Cse4 ${ }^{\text {CENP-A }}$ nucleosome (Hinshaw and Harrison, 2019, 2020; Yan et al., 2019; Zhang et al., 2020).

Contrary to the point centromere of $S$. cerevisiae, most eukaryotes have regional centromeres that extend over tens of thousands to even millions of DNA bases. These more complex centromeres often feature repetitive DNA sequences, such as the ATrich, 171-base pairs (bps) $\alpha$-satellite DNA repeats found at human kinetochores (McKinley and Cheeseman, 2016; Musacchio and Desai, 2017; Talbert and Henikoff, 2020). However, substantial evidence now supports the view that regional centromere assembly and inheritance is largely independent of DNA sequence. Rather, it is the presence of CENP-A and associated CCAN proteins that allows the propagation of centromeres through the cell-cycle-regulated recruitment of a specialized CENP-A loading machinery in a process that remains incompletely understood (Gambogi and Black, 2019; Mellone and Fachinetti, 2021).

The conservation of CCAN subunits in point and regional centromeres suggests that regional centromeres are modular, and assembled from the repetition of a basic "unit module", similar to that existing in yeast, at multiple docking sites of the regional 
centromeres. Strong support for this idea has come from biochemical work on human proteins, which demonstrated the reconstitution of a discrete CCAN complex with purified components (McKinley et al., 2015; Pesenti et al., 2018; Walstein et al., 2021; Weir et al., 2016). Furthermore, a low-resolution structural by negative-stain electron microscopy provided a first view of the human CCAN complex, revealing a structure that in its outline appears similar to that in S. cerevisiae and related yeasts (Hamilton et al., 2019; Kixmoeller et al., 2020; Pesenti et al., 2018).

The detailed organization of centromeric chromatin has been debated, with models ranging from a right-handed hemisome or a hexasome for the S. cerevisiae centromere to classical left-handed octameric CENP-A containing nucleosome in humans (Black and Cleveland, 2011; Talbert and Henikoff, 2020). Octameric CENP-A mono-nucleosomes assemble in vitro and have been extracted from nuclease-treated chromatin (Hasson et al., 2013; Nechemia-Arbely et al., 2017; Tachiwana et al., 2011). Previous studies, however, have shown that native centromeres may disassemble when chromatin is trimmed to mono-nucleosomes (Ando et al., 2002). Thus, while there is substantial evidence for an octameric left-handed CENP-A nucleosome, it is important to assess the organization of centromeric chromatin in complexes that retain fundamental properties of the native structure. Proteins mediating specific CENP-A recognition by CCAN have a crucial role in this regard. Two CCAN proteins have emerged for specific recognition of CENP-A: CENP-C and CENP-N. CENP-C binds CENP-A nucleosomes through two related motifs, the central region and the CENP-C motif. CENP-N, on the other hand, recognizes the L1 loop of CENP-A, where the sequence of CENP-A diverges from the sequence of H3 (Ali-Ahmad et al., 2019; Allu et al., 2019; Ariyoshi et al., 2021; Carroll et al., 2010; Carroll et al., 2009; Chittori et al., 2018; Guo et al., 2017; Kato et al., 2013; Pentakota et al., 2017; Tian et al., 2018; Walstein et al., 2021)

Here, we report cryo-electron microscopy (cryo-EM) structures of human CCAN assemblies comprising 16 subunits, designated CENP-16, and including the N-terminal region of CENP-C ${ }^{1-544}$ and the subcomplexes CENP-O/CENP-P/CENP-Q/CENPU/CENP-R (CENP-OPQUR complex), CENP-N/CENP-L (CENP-LN), CENPH/CENP-I ${ }^{57-765} /$ CENP-K/CENP-M (CENP-HIKM), and CENP-T/CENP-W/CENPS/CENP-X (CENP-TWSX). We show that the human CCAN structure is similar to the yeast Ctf19 ${ }^{\mathrm{CCAN}}$ structure in its outline, but diverges from it in crucial aspects that have important implications for nucleosome binding. Furthermore, we report that previous structures of the N-terminal region of CENP-N in complex with the octameric CENP-A 
nucleosome (Allu et al., 2019; Chittori et al., 2018; Pentakota et al., 2017; Tian et al., 2018) are incompatible with the structure of human CCAN. We discuss various models of centromere organization that might reconcile these observations and their implications for centromere biology.

\section{Results}

General organization of CCAN We built on our previous biochemical reconstitution of the human kinetochore (Pesenti et al., 2018; Walstein et al., 2021; Weir et al., 2016) to generate CENP-16 from stable individual subcomplexes in preparation for highresolution cryo-EM data collection (Figure 1 - Supplement 1 and Figure 1 - Supplement 2). Two cryo-EM datasets, including one of pure CENP-16 (dataset I) and one of CENP-14 (lacking CENP-SX) with DNA and CENP-A:H4 (dataset II), were processed independently as outlined in Figure 1 - Supplement 3 and Figure 1 - Supplement 4 (see also Table S1 and Methods). We obtained reconstructions for both datasets. However, only the cryo-EM structure derived from dataset I yielded a resolution range $(3.7 \AA$ in the centre with lower resolution in peripheral parts) that allowed reliable model building (Figure 1 - Supplement 3-5).

Molecular models of CCAN subunits were either available from previous structural work (CENP-M, CENP-N), or were generated by homology modelling based on structures of yeast CCAN (Hinshaw and Harrison, 2019, 2020; Yan et al., 2019; Zhang et al., 2020), and in later phases also based on AlphaFold2 in the variants Colabfold and AF2Multimer (Evans et al., 2021; Jumper et al., 2021; Mirdita et al., 2021). Models were fitted in the density using a combination of manual and automated fitting methods (see Methods). The final high-resolution model of CENP-16 obtained with dataset I encompasses 14 of the 16 subunits. CENP-S and CENP-X (CENP-SX), which require CENP-TW for incorporation into CENP-16 (Figure 1 - Supplement 1E-F), could not be modelled as we could not identify a density for these subunits, suggesting they are disordered or absent from the particles). The final model has a molecular mass of $\approx 450$ $\mathrm{kDa}$ and consists of $\approx 25000$ atoms.

The organization of CENP-16 can be rationalized as consisting of two "pillars" connected by a "vault" and a "base" (Figure 1B). Pillars 1 and 2 consist of CENPOPQUR and CENP-HIKM, respectively. The vault consists of CENP-LN. The base consists of CENP-TW, whose position is more clearly defined in the lower resolution 
map from dataset II. This may indicate an effect from the presence of DNA and CENPA:H4 in this sample, but neither was recognizable in density maps. A comparison of human CCAN with the yeast Ctf19 ${ }^{\mathrm{CCAN}}$ reveals overall similarities (Figure 1C-D), further reinforcing the concept that chromatin of regional centromeres consists of a repetitive CCAN unit module resembling the single $\mathrm{Ctf1} 19^{\mathrm{CCAN}}$ of the yeast point centromere. Nonetheless, there are also crucial differences with important implications for our understanding of centromeric chromatin, as described below. Most notably, the angle between pillar 1 and pillar 2 is much wider in the yeast structure than in the human structure, as shown by taking as reference the axis of the CENP-HK coiled-coil (Figure 1E). As discussed below, this difference results from several factors, including the presence of CENP-M and a more closed CENP-LN vault in the human complex relative to the yeast complex (see also Figure 6 below).

The resolution of our maps is highest in the central part of the complex where the vault interacts with pillars 1 and 2, and decreases in more peripheral regions (Figure 1 Supplement 4). Nevertheless, there is significant density, especially in maps obtained with dataset II, for the complex of the CENP-I N-terminal domain with the CENP-HK Cterminal domain, which together form a "HIK head domain" connected to the rest of pillar 2 by a short hinge (Figure 1C-D). The HIK head domain, which in the yeast complex is visible in two different conformations in the structures of $\mathrm{Ctf} 19^{\mathrm{CCAN}}$ dimers and in the structure of the $\mathrm{Ctf} 19^{\mathrm{CCAN}}$ complex with the Cse $4^{\mathrm{CENP}-\mathrm{A}}$ nucleosome, associates with the histone fold domains (HFDs) of CENP-T and CENP-I (the "base"). These were modelled with AF2 and also with reference to recent crystal structures of the Cnn $1^{\text {CENP-T }} /$ Wap1 ${ }^{\text {CENP-W }}$ complex bound to the $S$. cerevisiae HIK head (PDB ID 6WUC and 6YPC) (Hinshaw and Harrison, 2020; Zhang et al., 2020) (Figure 1C). A structurebased alignment of yeast and human $\mathrm{CCAN}^{\mathrm{Ctt19}}$ subunits is supplied in Figure 1 Supplement 6.

CENP-R, CENP-C, and CENP-M CENP-R caps the "northern" globular head of pillar 1 (Figure 1C and Figure 2A). Density for CENP-R is limited to a region comprising residues Phe86-Gln149 as assigned by the AF2 model, consisting of two $\alpha$-helices and a short helical connector (Figure 2B). The rest of the structure is predicted as intrinsically disordered. The CENP-R helices pack closely against a short pair of helices at the Cterminus of the CENP-QU sub-complex. Overall, their position is roughly equivalent to 
that of $\alpha$-helices of Nkp1 and Nkp2 in the related structure of the S. cerevisiae Ctf19 ${ }^{\text {CCAN }}$ complex (Hinshaw and Harrison, 2019; Yan et al., 2019) (Figure 1D), possibly suggesting a distant evolutionary relationship. However, Nkp1 and Nkp2 accompany the entire length of pillar 1 in Ctf19 $9^{\text {CCAN }}$, tightly interacting with Okp1 ${ }^{\text {CENP-U }}$ and Ame1 ${ }^{\text {CENP-Q }}$, whereas the interaction of CENP-R is limited to the head of pillar 1. As a result, pillar 1 is thinner in human CCAN (Figure 1C-D).

Most of the 943-residue protein CENP-C is predicted as intrinsically disordered. Previous work rationalized CENP-C as a blueprint for kinetochore assembly, as the protein contains, from the $\mathrm{N}$ - to the C-terminus, a succession of linear binding motifs for other kinetochore proteins ordered along the outer to inner kinetochore axis (Klare et al., 2015; Walstein et al., 2021). The motifs begin near the N-terminus with an interaction motif for the outer kinetochore MIS12 complex (Gascoigne et al., 2011; Screpanti et al., 2011), followed by binding motifs for the CCAN subunits CENP-LN and CENP-HIKM (comprised between residues 259 and 326 and highlighted in green in Figure 2C) (Klare et al., 2015; Pentakota et al., 2017), and further down for the CENP-A nucleosome, with two related CENP-A binding motifs in humans, the central region (residues 515-535) and the CENP-C motif (735-755) (Ariyoshi et al., 2021; Guo et al., 2017; Kato et al., 2013; Walstein et al., 2021). Finally, CENP-C dimerizes through its only sizable folded region, the C-terminal cupin domain (Chik et al., 2019; Cohen et al., 2008; Medina-Pritchard et al., 2020; Walstein et al., 2021).

CENP-16 incorporates CENP-C residues 1-544 (CENP-C $\left.{ }^{1-544}\right)$, but there is no discernible CENP-C density except for a Phe-Ile-Ile-Asp-Glu (303-FIIDE-307) fragment. In previous work, we found biochemically that this motif is crucial for CENP$\mathrm{LN}$ recruitment to human kinetochores and that it may bind near the CENP-LN dimerization domain (Pentakota et al., 2017). This prediction is fully confirmed by the structural analysis (Figure 2D). The sequence assignment of CENP-C into this short stretch of density was based on a highly significant AF2 prediction for this interaction. Supported by AF2 predictions, we also tentatively assigned a predicted single $\alpha$-helix at the N-terminus of CENP-O to an unaccounted density at the interface of CENP-HK, CENP-I, and CENP-M (Figure 2E). The region containing the 265-LFL-268 motif of CENP-C found to interact with CENP-HIKM (Klare et al., 2015) is also predicted as $\alpha$ helix by AF2 and could in principle also fit in the unaccounted helical density, but AF2 did not predict any significant interactions between this CENP-C region and the CENPHIKM subcomplex. 
The pseudo GTPase CENP-M, which is unable to bind and hydrolyse GTP (Basilico et al., 2014), binds near the CENP-LN dimerization domains at the vault's apex (Figure 1C). Using conserved interfaces, CENP-M also wedges against CENP-I and CENP-HK, generating a very robust network of interactions that bury collectively more that $3300 \AA^{2}$ and greatly stabilizes CENP-16 (Figure 2E-G and Figure 2 - Supplement 1A). As CENP-M resides at the kinetochore throughout the cell cycle (Figure $2 \mathrm{H}$ and Figure $2-$ Supplement 2), we suspect its stabilizing function is constitutive and unregulated. Thus, collectively, pillar 2 is much more deeply connected to the CENP-LN vault of CCAN in the human complex than in the Ctf19 $9^{\mathrm{CCAN}}$ complex, where the trimer of Ctf3 ${ }^{\text {CENP-I }}$, $\mathrm{Mcm} 16^{\mathrm{CENP}-\mathrm{H}}$, and Mcm22 $2^{\mathrm{CENP}-\mathrm{K}}$ connects to the rest of Ctf19 ${ }^{\mathrm{CCAN}}$ exclusively through a small interface $\left(\sim 550 \AA^{2}\right)$ between $\mathrm{Ctf}^{\mathrm{CENP}-\mathrm{I}}$ and $\mathrm{Iml} 3^{\mathrm{CENP}-\mathrm{L}}$ (Figure 2 - Supplement $1 \mathrm{~B}$ ).

CENP-16 binds DNA A surface representation of CENP-16 demonstrates the presence of a central tunnel surrounded by the CENP-TW base and the CENP-LN vault domains, and further extended by pillar 2 on the front and pillar 1 on the back of the structure (Figure 3A). Several considerations, some of which discussed more extensively below, converge on identifying the central tunnel of CENP-16 as a DNA-binding interface. Lined with several positively charged residues from CENP-L and CENP-N, and with an internal diameter of $\approx 27 \AA$, the vault seems ideally suited to surround the negatively charged backbone of a double-stranded (ds) DNA filament with a diameter of $\approx 20 \AA$. CENP-TW in the CCAN base also expose the DNA-binding interface of the histone fold domains (HFDs), which flank positive patches on CENP-I in the HIK head domain in the front (Figure 3B, left) and on CENP-QU in the back (Figure 3B, right). Another positive patch on CENP-N, contributed by residues in the $\alpha 6$ helix, including K102, K110, and R114 (Figure 3B, middle) has been recently implicated in CENP-A nucleosome stacking by the CENP-N N-terminal domain (Zhou et al., 2021).

To gather evidence for a DNA-binding activity in CENP-16, we immobilized on amylose beads a fusion of CENP-TW with maltose binding protein (MBP), and monitored binding of the remaining CCAN subunits in absence or presence of 75 -bp or 165-bp DNA. Both DNAs increased the amounts of the CCAN subunits bound to the immobilized ${ }^{\mathrm{MBP}}$ CENP-TW (Figure 3C). Similarly, in size-exclusion chromatography (SEC) experiments, where the elution volume is inversely related to size and elongation, the presence of DNA promoted earlier elution of the CENP-16 CCAN complex and a 
sharper elution profile, indicative of complex formation and possibly of a stabilization of the complex (Figure 3D). In size-exclusion chromatography experiments with individual CCAN sub-complexes, we found CENP-TW to be a very strong DNA binder (Figure 3 - Supplement 1A), in agreement with previous observations (Nishino et al., 2012; Takeuchi et al., 2014). We have previously reported DNA binding by CENP-HIKM in an EMSA assay at low salt concentrations (Weir et al., 2016), but CENP-HIKM did not appear to bind DNA with sufficient affinity in our SEC assay, nor did CENP-NL (Figure 3 - Supplement 1B-C). Both CENP-C ${ }^{1-544} \mathrm{HIKM}$ and CENP-OPQUR bound DNA in SEC assays, albeit weakly (Figure 3 - Supplement D-E). Thus, multiple individual CENP-16 sub-complexes interact with DNA, as reported previously for individual complexes (Carroll et al., 2010; Carroll et al., 2009; Nishino et al., 2012; Weir et al., 2016), which predicts a substantial binding affinity of CCAN for DNA. Indeed, the combination of CENP-LN, CENP-C ${ }^{1-544} \mathrm{HIKM}$, and CENP-OPQUR in the sample defined as CENP-12 demonstrated strong DNA binding (Figure 3 - Supplement 1F), suggesting additive effects. We anticipate that the different domains of CCAN may form contiguous contacts over a fragment of $65-70$ bps of DNA spanning from the front to the back of the complex.

The CENP-LN vault as a DNA-binding clamp for a single DNA gyre CENP-L and CENP-N, the proteins that form the vault domain, are paralogs that share a $\approx 130$ residue CENP-LN homology domain (LNHD) and that interact through a distinct Cterminal dimerization domain (Hinshaw and Harrison, 2013; Pentakota et al., 2017) (Figure 4A). The CENP-N ${ }^{\mathrm{LNHD}}$ and CENP-L ${ }^{\mathrm{LNHD}}$ lean rigidly against pillars 1 and 2, respectively (Figure 1C). Previously reported structures of a CENP-A nucleosome core particle (CENP-A $\mathrm{A}^{\mathrm{NCP}}$ ) in complex with an N-terminal construct of CENP-N (approximately encompassing residues 1-210 of CENP-N) (Allu et al., 2019; Chittori et al., 2018; Pentakota et al., 2017; Tian et al., 2018) demonstrated that CENP-N ${ }^{\mathrm{LNHD}}$ forms extensive interactions with the nucleosome's DNA, without major contacts with the proteinaceous nucleosome core (Figure 4B, top two panels).

Preceding the CENP-N ${ }^{\mathrm{LNHD}}$, the 80-residue pyrin domain is also part of the $\mathrm{N}$-terminal region of CENP-N (Figure 4A). In the structures of the CENP-N:CENP-A nucleosome complexes, the CENP-N pyrin domain recognizes the exposed L1 loop of CENP-A (Allu et al., 2019; Chittori et al., 2018; Pentakota et al., 2017; Tian et al., 2018) (Figure 
4B). The sequences of CENP-A and H3 diverge significantly in this loop, with important implications for epigenetic centromere inheritance (Black et al., 2004; Black et al., 2007). Mutation of CENP-N residues implicated in L1 loop recognition in vitro also prevent CENP-N kinetochore recruitment (Carroll et al., 2009; Chittori et al., 2018; Pentakota et al., 2017), supporting the interaction mode demonstrated by the structural work.

Given this previous evidence, we asked if the nucleosome-binding mode demonstrated with the CENP-N N-terminal region is compatible with CENP-N binding in the context of the entire CCAN complex. To assess this, we superposed the N-terminal regions (pyrin domain and LNHD) of CENP-N in CCAN and in complex with CENP-A ${ }^{\text {NCP }}$ (PDB ID 6COW) and monitored the fit of the nucleosome on the CCAN structure (Figure 4B, bottom pane). This demonstrated unequivocally that an octameric CENP-A ${ }^{\text {NCP }}$ cannot be accommodated within CENP-16 after superposition of CENP-N, as this would result in a dramatic steric clash of the NCP's second DNA gyre (i.e. the one distal from CENP-N) with CENP-L and with the HIK head.

This prediction is expected if one considers that our analysis has already identified CENP-LN as being ideally suited to surround a dsDNA filament, but not two adjacent filaments. Indeed, a single dsDNA filament is predicted to fit snugly into the deep, narrow, and positively charged CENP-LN vault (Figure 4 - Supplement 1A). That the vault surrounds a single filament of dsDNA not embedded in a classical nucleosome finds additional support in evolutionary considerations. CENP-L and CENP-N are related to the bacterial protein $\mathrm{RdgC}$, a DNA-binding homodimer that forms a full, closed circle for DNA binding (Ha et al., 2007; Tromer et al., 2019) (Figure 4C). The distant relationship with $\mathrm{RdgC}$ seems to imply that CENP-LN originated from the duplication of a DNA binding homo-dimeric singleton (Tromer et al., 2019). This interpretation is further supported by the observation that the CENP-L ${ }^{\mathrm{LNHD}}$ and CENP$\mathrm{N}^{\mathrm{LNHD}}$ in CENP-16 are related, even in the absence of bound DNA, by a 2-fold pseudosymmetry axis (Figure 4D-E and Figure 4 - Supplement 1A, right). With DNA from the proximal gyre of the CENP-N:CENP-A ${ }^{\mathrm{NCP}}$ complex modelled in the vault after superposition of CENP-N, the DNA's own 2-fold pseudosymmetry axis aligns with the 2-fold pseudosymmetry axis of the LNHDs of CENP-L and CENP-N (Figure 4D-E). Thus, CENP-NL in human CCAN is poised to recognize a chromatin structure different from that observed in a classical octameric nucleosome with two adjacent turns of DNA. This conclusion raises a crucial conundrum regarding the effective recognition target of CENP-N. Previous work has implicated CENP-N in specific CENP-A binding at the L1 
loop, but our observations now argue that if the CENP-A L1 remains the target of CENP-N in CCAN, it can't be presented to CENP-N with CENP-A embedded in an octameric nucleosome.

Nucleosome binding by yeast and human CCAN An alternative possibility is that CENP-N, at least when incorporated within CCAN, binds only DNA, or that it binds DNA and a different protein target, possibly a different histone-like protein. To shed further light on this question, we continued by analysing the implications for the human complex of a recent structure of the $S$. cerevisiae $\mathrm{Ctf} 19^{\mathrm{CCAN}}$ in complex with a classical octameric Cse4 ${ }^{\text {CENP-A }}$ nucleosome (PDB ID 6QLD; Figure 5A) (Yan et al., 2019). In this structure, the CENP-LN vault is seen to interact with a loose end of dsDNA unwrapped from the Cse $4^{\mathrm{NCP}}$ core (Figure 4 - Supplement 1C-D). Unwrapping of DNA on one side of the nucleosome causes the normally symmetric distribution of DNA on the two sides of the nucleosome to become greatly asymmetric (Figure 5B, top, where the red arrows mark the two ends of the DNA, and the vertical bar marks the position of the core's 2-

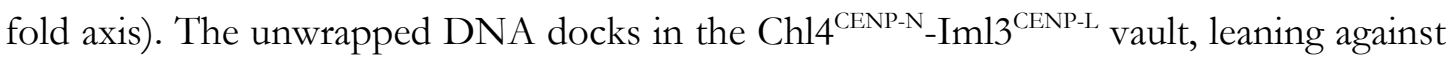
Chl4 and making essentially no contacts with Iml3 or more generally with pillar 2 (Figure 5C-D and Figure 4 - Supplement 1C-D). The position of Chl4 ${ }^{\mathrm{CENP}-\mathrm{N}}$ and of CENP-N relative to the NCP in the Ctf19 ${ }^{\mathrm{CCAN}}: \mathrm{NCP}$ and CENP-N:CENP-A ${ }^{\mathrm{NCP}}$ structures (PDB ID $6 \mathrm{COW}$ ) are therefore entirely unrelated, to the point that in the yeast structure CENP$\mathrm{N}$ does not contact the L1 loop of CENP-A at all, contrary to the human CENP$\mathrm{N}:$ CENP-A ${ }^{\mathrm{NCP}}$ structure, where CENP-N directly faces the L1 loop (Figure 5B). In fact, there are almost no visible contacts of $\mathrm{Ctf1} 9^{\mathrm{CCAN}}$ and the proteinaceous Cse4 ${ }^{\mathrm{CENP}-\mathrm{A}}$ nucleosome core in PDB ID 6QLD. This perplexing observation suggests that Ctf19 ${ }^{\mathrm{CCAN}}$ connects to the centromeric nucleosome almost exclusively through the intrinsically

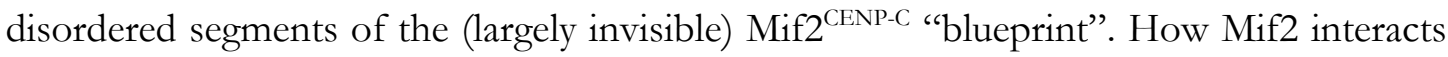
with yeast CCAN remain elusive.

We asked if the structure of the Ctf19 ${ }^{\mathrm{CCAN}}$ :Cse $4^{\mathrm{CENP}-\mathrm{A}}$ nucleosome complex provides a plausible model for the human complex. To assess this, we superposed Chl $4^{\mathrm{CENP}-\mathrm{N}}$ in 6QLD with CENP-N in our structure of human CENP-16, and observed if the nucleosome in PDB ID 6QLD could be accommodated in the human structure without major steric clashes. This procedure evidenced a dramatic clash of the yeast nucleosome with the HIK head of human CCAN (Figure 5D, bottom), with an additional but less 
dramatic predicted overlap between CENP-L and one of the two H2A:H2B dimers. The main clash could be resolved through a hypothetical rotation of the HIK head about a hinge (Figure 5C, bottom) and causing the HIK head to be swung out of its observed position, similar to the yeast Ctf19 ${ }^{\mathrm{CCAN}}$, where the HIK head undergoes an approximately $90^{\circ}$ rotation upon binding to the nucleosome (Yan et al., 2019). Due to fundamental differences in the respective orientation of pillar 2 relative to CENP-N (Figure 1E), however, the yeast complex (PDB ID 6QLD) and the human model built on it would appear quite different even after removing the clash with the HIK head (Figure 5E-F): in the Ctf19 ${ }^{\mathrm{CCAN}}: \mathrm{Cse} 4^{\mathrm{CENP}-\mathrm{A}}$ complex (PDB ID 6QLD) pillar 2 does not even contact the Cse $4^{\text {CENP-A }}$ nucleosome (Figure 5C,E). Conversely, in the modelled human complex, pillar 2 is predicted to make multiple contacts with the nucleosome (Figure 5F). Thus, CCAN may bind an octameric CENP-A nucleosome positioned as in the structure of the yeast $\mathrm{Ctf19}{ }^{\mathrm{CCAN}}-\mathrm{Cse} 4^{\mathrm{NCP}}$ complex (PDB ID 6QLD), but to avoid predicted steric clashes a very large rotation of the HIK head about a hinge point (indicated by blue arrowheads in Figure 5E-F), as well as other less significant changes around CENP-L, would have to be enabled. The way pillar 2 and the nucleosome interact in PDB ID 6QLD and in the resulting human structure would still differ substantially, a consequence of the different opening of the vault.

Open and closed vaults in point and regional centromeres The different organization of human and yeast $\mathrm{CCAN}^{\mathrm{Ctt19}}$ might have multiple causes, including the stabilizing presence of CENP-M in the human complex but not in the yeast complex, and a much larger interface of pillar 1 with the vault in the human complex relative to the yeast complex (Figure 2 - Supplement 1B). A superposition of CENP-N with Chl4 ${ }^{\text {CENP-N }}$ shows a reciprocal rotation within the $\operatorname{Iml} 3^{\text {CENP-L }}:$ Chl $4^{\text {CENP-N }}$ dimer that causes the vault to be much shallower and open in comparison to CENP-LN (Figure 6A). As a consequence, the 2-fold pseudosymmetry of the LNHDs identified in the human complex with a modelled DNA (Figure 4D-E and Figure 4 - Supplement 1A) is broken in the yeast Ctf19 ${ }^{\mathrm{CCAN}}$ :Cse $4^{\mathrm{CENP}-\mathrm{A}}$ nucleosome complex (PDB ID 6QLD; Figure 4 Supplement 1B-D). Modelling with AF2 of Iml3:Chl4 orthologs in yeast species featuring point centromeres and in diverse organisms with regional centromeres demonstrated that the complexes cluster into two different groups, with complexes from organisms with point centromeres showing shallow vaults and complexes from species with regional centromeres showing deep vaults (Figure 6B). This result implies that at 
least in part, the structural properties of the vault are moulded by intrinsic sequence features, in addition to influences from its embedding in the $\mathrm{CCAN}^{\mathrm{Ct} 19}$ complex. Thus, the different structural features of $\mathrm{CCAN}^{\mathrm{Ct} 19}$ complexes in point and regional centromeres are conserved, perhaps hinting to a different composition of the fully assembled kinetochore complexes.

\section{Discussion}

The structure of human CCAN is a milestone in the study of the organization of centromeric chromatin. It builds on early proteomic analyses that identified the majority of vertebrate CCAN subunits (Foltz et al., 2006; Izuta et al., 2006; Obuse et al., 2004; Okada et al., 2006) and on subsequent work of biochemical reconstitution and structural analysis (Ali-Ahmad et al., 2019; Allu et al., 2019; Ariyoshi et al., 2021; Carroll et al., 2010; Carroll et al., 2009; Guo et al., 2017; Kato et al., 2013; McKinley et al., 2015; Pentakota et al., 2017; Pesenti et al., 2018; Walstein et al., 2021; Weir et al., 2016). The structure and biochemical work reported here demonstrates the overall organization of human CCAN, with insights on unique subunits, including CENP-M and CENP-R, and fundamental differences with the yeast complex. Our work also provides the best demonstration so far that regional centromeres are assembled from the repetition of an individual structural module related to that of the Saccharomyces cerevisiae Ctf19 ${ }^{\text {CCAN }}$ complex (Hinshaw and Harrison, 2019, 2020; Yan et al., 2019; Zhang et al., 2020). Regretfully, we have been unable to obtain a sufficiently homogeneous complex of CCAN with DNA or nucleosomes for structural analysis (unpublished results), a priority for our future studies. Nevertheless, the structure of human CCAN has important implications for the basic concepts that have accompanied the vertebrate centromere field in recent years.

The most unexpected observation concerns CENP-N, initially identified with CENP-C as the only direct and specific binder of CENP-A nucleosomes (Carroll et al., 2010; Carroll et al., 2009). The structure of human CCAN shows that the CENP-LN dimer is ideally suited to surround a single filament of dsDNA, as also supported by a suggestive 2 -fold pseudosymmetry arrangement of the LNHDs of CENP-L and CENP-N in the vault. As the CENP-LN complex alone does not have high affinity for DNA, its interaction with DNA may be eminently topological. If the CENP-LN vault is designed to bind a single filament of dsDNA, a most pressing question is whether the pyrin 
domain of CENP-N, when embedded in CCAN, can decode the CENP-A L1 loop as implied by previous structural work with isolated CENP-N deletion constructs bound to CENP-A nucleosomes (Allu et al., 2019; Chittori et al., 2018; Pentakota et al., 2017; Tian et al., 2018). Based on 1) direct evidence from the structure of the yeast Ctf19 ${ }^{\mathrm{CCAN}}$ :Cse $4^{\mathrm{CENP}-\mathrm{A}}$ nucleosome complex (PDB ID 6QLD), where the Chl4 ${ }^{\mathrm{CENP}-\mathrm{N}}$ pyrin domain is mainly engaged in DNA binding and does not even face the L1 loop; and 2) indirect evidence from our own work showing that it is not possible to fit an octameric CENP-A nucleosome into the human CCAN structure while concomitantly satisfying the condition that the CENP-N pyrin domain faces the CENP-A L1 loop (Allu et al., 2019; Chittori et al., 2018; Pentakota et al., 2017; Tian et al., 2018), the most immediate answer is 'no'.

If CENP-N does not contribute to the specificity of CENP-A recognition, only CENP$\mathrm{C}$, to the best of our knowledge the only additional specific CENP-A binder in CCAN, remains to explain it. The implications of this conclusion are summarized in Figure 7A, which incorporates related features of the human and yeast $C C A N^{\mathrm{Ct} 19}$. The dsDNA filament that occupies the vault of CCAN is connected to an octameric CENP-A nucleosome (or a dinucleosome (Walstein et al., 2021)). It enters CCAN from the front (like in the yeast Ctf19 ${ }^{\mathrm{CCAN}}$ :Cse $4^{\mathrm{CENP}-\mathrm{A}}$ nucleosome structure, PDB ID 6QLD) (Yan et al., 2019) or from the back. In the "swung-in" conformation of the human complex, CENPTW could be expected to bind and stabilize the dsDNA filament as the "base" under the vault. A possible position of the CENP-A nucleosome is inferred from the structure of the Ctf19 ${ }^{\mathrm{CCAN}}$ :Cse $4^{\mathrm{CENP}-\mathrm{A}}$ nucleosome complex (PDB ID 6QLD) (Yan et al., 2019). If the nucleosome positioned itself in the human complex as in yeast, an intolerable steric clash with the "swung-in" HIK head and base would arise where the complete histone core would have to be replaced by the HIK head (Figure 5C-D). This could be resolved by 1) repositioning the nucleosome in a very different position, or 2) adopting a swung-out conformation of the HIK head and CENP-TW base, making space for a nucleosome positioned like in yeast and allowing CENP-TW to bind linker DNA, which it prefers over nucleosome-wrapped DNA (Takeuchi et al., 2014). With a swung-out HIK head, however, the details of the interaction with the CENP-A $\mathrm{A}^{\mathrm{Cse}}$ nucleosome in yeast and humans would still differ substantially due to the different angle of divergence of pillar 2 (Figure 5E-F).

Emphasis on predicted differences between the human and yeast complexes aims to expose a crucial aspect of the model(s) in Figure $7 \mathrm{~A}$. The structure of the complex of 
Ctf19 ${ }^{\text {CCAN }}$ with the Cse4 ${ }^{\text {CENP-A }}$ nucleosome (PDB ID 6QLD) (Yan et al., 2019) identified too few contacts to account for the exquisite specificity expected of this interaction. CENP-C ${ }^{\text {Mif2 }}$, in the absence of CENP-N the only expected generator of specificity in the interaction of CCAN with CENP-A, is predicted to be mainly intrinsically disordered. It may therefore connect $\mathrm{CCAN}^{\mathrm{Ct} 19}$ and the CENP-A ${ }^{\mathrm{Cse} 4}$ nucleosome with substantial flexibility and conformational freedom. The resulting complexes may be "fuzzy" rather than rigidly sculpted. In such a framework, the predicted and quite substantial differences between the human and yeast complexes discussed above may all be encompassed in the model in Figure 7A and be ultimately compatible with function.

Mif2 $\mathrm{f}^{\mathrm{CENP}-\mathrm{C}}$ is for the most part invisible in the yeast Ctf19 ${ }^{\mathrm{CCAN}}$ :Cse $4^{\mathrm{CENP}-\mathrm{A}}$ nucleosome complex (PDB ID 6QLD) (Yan et al., 2019) (Figure 7A). The only visible segment of Mif2 $\mathrm{f}^{\mathrm{CENP}-\mathrm{C}}$ is the conserved motif (residues 284-305), shown to bind the acidic patch of H2A:H2B and the CENP-A C-terminal tail (Yan et al., 2019), a binding mode previously demonstrated in vertebrates (Ariyoshi et al., 2021; Kato et al., 2013; Yan et al., 2019). Mif2 ${ }^{\text {CENP-C }}$ is also known to interact with $\operatorname{Iml} 3^{\text {CENP-L }}$ Chl $4^{\text {CENP-N }}$ (Hinshaw and Harrison, 2013), an interaction that is conserved in humans, where additional interactions of CENP-C with CENP-HIKM have also been observed (Hinshaw and Harrison, 2013; Hornung et al., 2014; Klare et al., 2015; McKinley et al., 2015; Nagpal et al., 2015; Pentakota et al., 2017). The specific motifs involved in these interactions with CCAN ${ }^{\mathrm{Ct} 19}$ may not be fully conserved: the 303-FIIDE-307 CENP-C motif we describe, previously shown to be instrumental for the recruitment of CENP-LN to the kinetochore (Pentakota et al., 2017), is not recognizable in Mif2 $2^{\text {CENP-C }}$.

The dismissal of CENP-N as a specificity factor for CENP-A recognition should not be taken light-heartedly. Mutations of the CENP-N region in the pyrin domain involved in L1 binding ablate CENP-A binding in vitro and CENP-N localization in vivo (Allu et al., 2019; Carroll et al., 2010; Carroll et al., 2009; Chittori et al., 2018; Pentakota et al., 2017; Tian et al., 2018). If the structure of the yeast Ctf19 ${ }^{\mathrm{CCAN}}$ :Cse $4^{\mathrm{CENP}-\mathrm{A}}$ nucleosome complex did not confirm Chl4 ${ }^{\text {CENP-N }}$ as L1 loop decoder, the structure of human CCAN now at hand prompts us to identify what requirements should be met for the CENP-N pyrin domain to recognize the L1 loop. Two crucial conditions emerge. First, CENP-A:H4 ought to be presented to CENP-LN in a structure different from a classical 2-turn nucleosome, as only the CENP-N-proximal filament of dsDNA, with its associated CENP-A:H4, would be allowed in the CENP-LN vault without major steric clashes. Second, homo-dimerization of CENP-A would likely be prevented (Black et al., 2004; 
Tachiwana et al., 2011), due to a predicted steric clash with the CENP-QU N-terminal domain, contiguous to the CCAN base at the back of the CENP-LN tunnel.

A structure that satisfies these two conditions is the so-called hemisome, a halfnucleosome sequence of histones with the order CENP-A:H4:H2B:H2A (Figure 7B). In CCAN, H2A:H2B could be part of the hemisome only if the HIK head and CENP-TW base adopted a swung-out conformation. In the swung-in conformation of our structure, H2A:H2B would be excluded due to a dramatic steric clash with CENP-TW, which could then pair with CENP-A:H4 (Figure 7C). Models invoking a hemisome as in Figure 7B-C are entirely speculative at this time, and may also seem to impose prohibitive assumptions. There is unquestionable evidence that CENP-A assembles in vitro into classic octameric nucleosomes with adjacent DNA gyres, and that classical octameric nucleosomes are also the predominant form of CENP-A isolated from chromatin after extensive nuclease treatment (Black and Cleveland, 2011; Dunleavy et al., 2013; Hasson et al., 2013; Nechemia-Arbely et al., 2017; Tachiwana et al., 2011). As discussed in the Introduction, however, extensive nuclease treatments may promote the disassembly of centromeric chromatin (Ando et al., 2002), raising the question whether previous studies might have neglected a handful of CENP-A molecules embedded in a different and possibly larger (than a mononucleosome) chromatin structure (see also (Walstein et al., 2021)).

How can the alternative models discussed in Figure 7A-C be tested? Reconstitution experiments exposing $\mathrm{CCAN}^{\mathrm{Ctt19}}$ to a pre-assembled and greatly stable octameric CENPA nucleosome will with some likelihood promote assembly of a complex with sufficient stability for structural analysis. This will not necessarily prove that the resulting structure, aligned with the model in Figure $7 \mathrm{~A}$, is physiologically relevant. The same approach would not be helpful towards testing the speculative models discussed in Figure 7B-C, as they predict a different type of nucleosome organization that may need to be stabilized differently from classical nucleosomes. Two crucial stabilizing factors of octameric nucleosomes are the dimerization of CENP-A (or H3) and the stabilization of the lefthanded helical staircase of histone octamers by the H2A C-terminal docking domain (Eickbush et al., 1988; Shukla et al., 2011). Neither would be at stake in the hemisome structure postulated in Figure 7B. In the model in Figure 7C, also a hemisome model but with CENP-TW replacing H2A:H2B, the C-terminal extension of CENP-T is buried at the interface with HIK (this study and (Hinshaw and Harrison, 2020; Zhang et al., 2020)). These alternative structures will have much reduced stability of their own 
compared to octameric nucleosomes, and ad hoc procedures for their incorporation in, and stabilization by, CCAN may be necessary for successful reconstitution. Enzymes overcoming kinetic barriers large enough to slow down spontaneous execution may even be required. Be that as it may, our attempts at reconstituting a CCAN:chromatin structure with DNA, CENP-TW (with or without H2A:H2B) and CENP-A:H4 bound to the CENP-NL vault were hitherto unsuccessful (unpublished results). Furthermore, we find that at least the hemisome model in Figure $7 \mathrm{C}$ is not supported by predictions of AF2 and related programs (unpublished results). Thus, we cannot claim own experimental evidence supporting models like those in Figure 7B-C. Yet, we cannot rule them out, as we might have failed to identify appropriate conditions for their assembly.

These concerns are especially relevant to interpret recent work on the Ctf19 ${ }^{\mathrm{CCAN}}$ complex and $\mathrm{Cse} 4^{\mathrm{CENP}-\mathrm{A}}$ nucleosome of $S$. cerevisiae. In this organism, Cse $4^{\mathrm{CENP}-\mathrm{A}}$ resides on a central DNA core of 78-86 bps named CDEII (Camahort et al., 2009; Furuyama and Biggins, 2007; Henikoff et al., 2014; Keith and Fitzgerald-Hayes, 2000; Krassovsky et al., 2012; Meluh et al., 1998). Flanking CDEII, two additional regions of 8 and $\approx 25 \mathrm{bps,}$ known respectively as CDEI and CDEIII, bind the additional factors Cbf1 and Cbf3 complex. The question how the $\mathrm{Ctf} 19^{\mathrm{CCAN}}$ complex relates to the centromeric DNA of $S$. cerevisiae should be considered in the context of these fundamental specificities, something that the work so far, limited to a complex with an octameric nucleosome on a 147 bps Widom 601 DNA sequence (PDB ID 6QLD) (Yan et al., 2019), has not yet fully achieved. Cogently, given the small size of CDEII, a centromeric nucleosome with two full turns seems unlikely. A Cse $4^{\text {CENP-A }}: \mathrm{H} 4: \mathrm{H} 2 \mathrm{~B}: \mathrm{H} 2 \mathrm{~A}$ hemisome has been proposed as a possible alternative (Dalal et al., 2007; Furuyama et al., 2013; Henikoff et al., 2014; Talbert and Henikoff, 2020). This hemisome model, illustrated in Figure 7D, has been extensively debated in the last fifteen years (Black and Cleveland, 2011; Dalal et al., 2007; Dunleavy et al., 2013). It remains highly conjectural, but was shown to neatly explain the pattern of H4 S47C-anchored cleavage mapping at S. cerevisiae centromeres (Henikoff et al., 2014). We note that the hemisome model illustrated in Figure 7D is closely reminiscent of the speculative model of human CCAN discussed in Figure 7B, a model that we developed with the question in mind whether specific recognition of CENP-A by CENP-N is compatible with CCAN structure. The coincidence is remarkable and worth reporting, even though its significance is currently unclear.

Further complicating the picture, histone $\mathrm{H} 2 \mathrm{~A}$ and $\mathrm{H} 2 \mathrm{~B}$ have been shown to be depleted from centromeres both in S. cerevisiae and S. pombe (Mizuguchi et al., 2007; Rossi et al., 
2021; Williams et al., 2009; Xiao et al., 2011), opposing observations notwithstanding (Krassovsky et al., 2012; Pinto and Winston, 2000; Westermann et al., 2003). At yeast centromeres, the possible depletion of $\mathrm{H} 2 \mathrm{~A}: \mathrm{H} 2 \mathrm{~B}$ had been discussed in the context of evidence supporting the existence of a hexasome of $\mathrm{Cse} 4^{\mathrm{CENP}-\mathrm{A}}: \mathrm{H} 4$ with $\mathrm{Scm} 3 . \mathrm{Scm} 3$ is a Cse4 chaperone and a stable centromere resident at all cell cycle stages in S. cerevisiae (Mizuguchi et al., 2007; Xiao et al., 2011). Subsequent structural work indicated that $\mathrm{Scm} 3$ binds the $\mathrm{Cse} 4^{\mathrm{CENP}-\mathrm{A}}$ dimerization interface and competes with dimerization (Cho and Harrison, 2011; Dechassa et al., 2011), questioning the hexasome model, which assumed the dimerization of Cse $4^{\mathrm{CENP}-\mathrm{A}}: \mathrm{H} 4$ in a tetrasome. A speculative alternative explanation is that $\mathrm{Scm} 3$, in addition to depositing Cse $4^{\text {CENP-A }}$, stably suppresses Cse $4^{\text {CENP- }}$ A dimerization, an expected and potentially beneficial function if the basic structure of yeast centromeres were a hemisome. How could the depletion of $\mathrm{H} 2 \mathrm{~A}: \mathrm{H} 2 \mathrm{~B}$ be accounted for, however? Our speculative model in Figure $7 \mathrm{C}$, where $\mathrm{H} 2 \mathrm{~A}: \mathrm{H} 2 \mathrm{~B}$ are replaced with CENP-TW, may serve as inspiration to answer this question. H2A:H2B may be replaced with Cnn1 ${ }^{\text {CENP-T }}$ :Wip1 ${ }^{\text {CENP-W }}$ if a "swung-in" conformation of the yeast complex, similar to that observed in humans, were possible (Figure 7E). We predict, however, that this would require a more complex restructuring of pillar 2 towards the conformation it adopts in human CCAN.

In conclusion, our model of human CCAN is in principle compatible with two classes of models for centromeric chromatin. In one class (exemplified by Figure 7A), which is more strongly supported by current experimental evidence but far from being established, the CCAN assembles on dsDNA and flanks a regular octameric CENP-A ${ }^{\text {Cse4 }}$ nucleosome, to which it connects specifically mainly or exclusively through CENP-C ${ }^{\text {Mif2 }}$ (Hinshaw and Harrison, 2013). In the other class (exemplified by Figure 7B-E), CENP$\mathrm{N}^{\mathrm{Chl} / 4}$, in addition to CENP-C $\mathrm{C}^{\mathrm{Mif2}}$, contributes to the specificity of the CCAN ${ }^{\mathrm{Ct} 19}$ :CENP$\mathrm{A}^{\mathrm{Cse}}$ nucleosome interaction by interacting with the L1 loop of CENP-A $\mathrm{A}^{\mathrm{Cse}}$. In this second class of models, the CENP-A chromatin interacting with CCAN cannot be in the form of a regular octameric nucleosome, while hemisomes may be expected. If this alternative chromatin exists at all, its reconstitution may be considerably more challenging in view of different, and currently unknown, stabilization requirements. Future work will have to address systematically the implications and value of these models in vitro and in vivo, testing them with a combination of biochemical reconstitution, structural analysis, and mutational validation. 


\section{Materials and Methods}

Plasmids Plasmids to express recombinant CENP-LN, -OPQUR, -TWSX, -TW, -SX complexes and CENP-A containing nucleosomes were generated as previously described (Pentakota et al., 2017; Pesenti et al., 2018; Walstein et al., 2021). To generate plasmid for expressing CENP-C ${ }^{1-544} \mathrm{HIKM}$ in insect cells, plasmid to express $\mathrm{N}$-terminus 6xHis tagged CENP-C ${ }^{1-544}$ was generated by Gibson cloning method, codon optimized cDNA of CENP-C ${ }^{1-544}$ (GeneArt, Life Technologies) was inserted in a modified pLIB vectors containing sequences for the 6xHis followed by TEV protease. The codon optimized cDNA of CENP-I, -H, -K- and -M were inserted by Gibson cloning method in to unmodified pLIB plasmids. These pLIB plasmids generated so-forth were used to insert the CENP-H, -K, -I, -M and 6His-CENP-C ${ }^{1-544}$ sequences into a baculovirus-based multigene-expressing vectors, pBIGa (Weissmann et al., 2016) by Gibson assembly. To generate plasmids for expressing ${ }^{\mathrm{MBP}} \mathrm{CENP}-\mathrm{TW}$ and ${ }^{\mathrm{mScarlet}} \mathrm{CENP}-\mathrm{TW}$ in bacterial cells, codon optimized cDNA of CENP-T, and -W were inserted by Gibson in a pETDuet plasmid containing a ${ }^{6 \mathrm{His}-\mathrm{TEV}} \mathrm{CENP}-\mathrm{W}$ and a ${ }^{\text {Halo-TEV }}{ }^{-\mathrm{CENP}-\mathrm{T}}$ (Walstein et al., 2021) to generate plasmids co-expressing the following constructs: ${ }^{6 \mathrm{His}-\mathrm{TEV}} \mathrm{CENP}-\mathrm{W} /{ }^{\mathrm{MBP}} \mathrm{CENP}-\mathrm{T}$ and ${ }^{6 \mathrm{His}-\mathrm{TEV}} \mathrm{CENP}-\mathrm{W} /{ }^{\mathrm{mS} \text { carlet }} \mathrm{CENP}-\mathrm{T}$. The plasmids pUC18 containing 165 -bps and 75 bps CEN1 (centromere 1) like sequences GTGGTAGAATAGGAAATATCT'TCCTATAGAAACTAGACAGAATGATTCTCA GAAACTCCTTTGTGATGTGTGCGTTCAACTCACAGAGTTTAACCT'T'TCT'T'T'T CATAGAGCAGTTAGGAAACACTCTGTTTGTAATGTCTGCAAGTGGATATTC AGACGCCCTTTG and ATCCGTGGTAGAATAGGAAATATCTTCCTATAGAAACTAGACAGAATGATTT CTCAGAAACTCCTTTGTGATGGAT were generated as previously described (Walstein et al., 2021).

Protein expression and purification CENP-LN, -OPQUR, -TWSX and -SX complexes were expressed and purified according to previously published protocols (Pentakota et al., 2017; Pesenti et al., 2018; Walstein et al., 2021). Expression and purification of CENP-C ${ }^{1-544} \mathrm{HIKM}$ was performed following a protocol adapted from (Klare et al., 2015). TnAo38 cells infected with a virus:culture ratio of 1:50 and incubated for $72 \mathrm{~h}$ at $27^{\circ} \mathrm{C}$. Cell pellets were harvested, washed in $1 \times$ PBS, and finally resuspended in a buffer containing $50 \mathrm{mM}$ HEPES 7.0, $500 \mathrm{mM} \mathrm{NaCl}, 5 \mathrm{mM} \mathrm{MgCl}$, 5\% glycerol, $10 \mathrm{mM}$ imidazole, $2 \mathrm{mM}$ TCEP, $0.2 \mathrm{mM}$ PMSF, and $10 \mu \mathrm{g} / \mathrm{ml}$ DNase. Cells were lysed by sonication, and cleared for $1 \mathrm{~h}$ at 100,000g. Cleared cell lysate was then applied over a 5 
$\mathrm{ml} \mathrm{His'Trap} \mathrm{FF} \mathrm{column} \mathrm{(Cytiva)} \mathrm{and} \mathrm{washed} \mathrm{first} \mathrm{with} \mathrm{Washing} \mathrm{buffer} \mathrm{(50} \mathrm{mM} \mathrm{HEPES}$ 7.0, $500 \mathrm{mM} \mathrm{NaCl}, 5 \mathrm{mM} \mathrm{MgCl}$, 5\% glycerol, $10 \mathrm{mM}$ imidazole, and $2 \mathrm{mM}$ TCEP), secondly with High salt washing buffer (50 mM HEPES 7.0, $1 \mathrm{M} \mathrm{NaCl}, 5 \mathrm{mM} \mathrm{MgCl}_{2}$, $5 \%$ glycerol, $10 \mathrm{mM}$ imidazole, and $2 \mathrm{mM}$ TCEP) followed by Washing buffer again and thirdly with Imidazole washing buffer (50 mM HEPES 7.0, $500 \mathrm{mM} \mathrm{NaCl}, 5 \mathrm{mM} \mathrm{MgCl}$, $5 \%$ glycerol, $40 \mathrm{mM}$ imidazole, and $2 \mathrm{mM}$ TCEP). CENP-C ${ }^{1-544} \mathrm{HIKM}$ complex was eluted with Elution buffer (50 mM HEPES 7.0, $500 \mathrm{mM} \mathrm{NaCl}, 5 \mathrm{mM} \mathrm{MgCl}, 5 \%$ glycerol, $200 \mathrm{mM}$ imidazole, and $2 \mathrm{mM}$ TCEP). The fractions containing CENP-C ${ }^{1-}$ ${ }^{544} \mathrm{HIKM}$ were pooled, and the His tag cleaved overnight at $4{ }^{\circ} \mathrm{C}$ with TEV protease (in house production). CENP-C $\mathrm{C}^{1-544} \mathrm{HIKM}$ in solution was then adjusted to a salt concentration of $300 \mathrm{mM}$, before loading on a $5 \mathrm{ml}$ HiTrap Heparin HP column (Cytiva), equilibrated in $20 \mathrm{mM}$ HEPES pH 7.0, $300 \mathrm{mM} \mathrm{NaCl}, 5 \%$ glycerol, $2 \mathrm{mM}$ TCEP. Bound proteins were eluted with a gradient of $300-1000 \mathrm{mM} \mathrm{NaCl}$ over 30 column volumes, and peak fractions corresponding to CENP-C ${ }^{1-544} \mathrm{HIKM}$ were pooled and concentrated in a $50 \mathrm{kDa} \mathrm{MW}$ Amicon concentrator (Millipore). CENP-C ${ }^{1-544} \mathrm{HIKM}$ was then loaded onto a Superose 6 16/600 (Cytiva) in $20 \mathrm{mM}$ HEPES 7.0, $500 \mathrm{mM}$ $\mathrm{NaCl}, 5 \%$ glycerol, $3 \mathrm{mM}$ TCEP. The sample was concentrated and flash frozen in liquid $\mathrm{N} 2$ before use. ${ }^{\text {MBP }}$ CENP-TW and ${ }^{\text {mscarlet }}$ TW complexes were purified using the previously described protocol for CENP-TW wild type (Walstein et al., 2021). Preparations of CENP-A-containing nucleosomes were carried out as described (Walstein et al., 2021) modified from the previously published protocol (Guse et al., 2012).

Recombinant proteins fluorescence labeling CENP-SX was labeled using Alexa Fluor 647 Protein Labeling Kit (ThermoFisher Scientific, Waltham, US-MA) according to the manufacturer instructions.

Analytical SEC Analytical size exclusion chromatography was carried out on a Superose 6 5/150 (Cytiva, Marlborough, US-MA) in a buffer containing 20 mM HEPES pH 6.8, $300 \mathrm{mM} \mathrm{NaCl}, 2.5 \%$ (v/v) glycerol and $1 \mathrm{mM}$ TCEP on an ÄKTA micro system (Cytiva). All samples were eluted under isocratic conditions at $4^{\circ} \mathrm{C}$ in SEC buffer $(20 \mathrm{mM}$ HEPES pH 6.8, $300 \mathrm{mM} \mathrm{NaCl}, 5 \%$ (v/v) glycerol and $1 \mathrm{mM}$ TCEP) at a flow rate of $0.15 \mathrm{ml} / \mathrm{min}$. Elution of proteins was monitored at $280 \mathrm{~nm}, 555 \mathrm{~nm}$ and $647 \mathrm{~nm}$ in case of ${ }^{\text {mScarlet }}$ CENP-TW and CENP-SX ${ }^{\text {Alexa647 }} .100 \mu$ fractions were collected and analyzed by SDS-PAGE and Coomassie blue staining. In experiments where fluorescent labeled 
proteins were used, the in-gel detection of the fluorescence was detected using a BioRAD chemiDoc MP Imaging System (BioRAD, Hercules, US-CA). To detect the formation of a complex, proteins were mixed at the concentrations of $5 \mu \mathrm{M}$ in $50 \mu \mathrm{l}$, incubated for at least 1 hour on ice, subjected to SEC then analyzed by SDS-PAGE.

Amylose-resin pull-down assay The proteins were diluted with binding buffer [20 $\mathrm{mM}$ HEPES pH 6.8, $300 \mathrm{mM} \mathrm{NaCl}, 2.5 \%$ glycerol, $1 \mathrm{mM}$ TCEP, and $0.01 \%$ Tween] to $3 \mu \mathrm{M}$ concentration in a total volume of $50 \mu \mathrm{l}$ and mixed with $20 \mu \mathrm{l}$ of amylose beads (New England Biolabs, Ipswich, US-MA). After mixing the proteins and the beads, $20 \mu \mathrm{l}$ were taken as input. The rest of the solution was incubated at $4{ }^{\circ} \mathrm{C}$ for 1 hour on a thermomixer (Eppendorf, Hamburg, Germany) set to $1000 \mathrm{rpm}$. To separate the proteins bound to the amylose beads from the unbound proteins, the samples were centrifuged at $800 \mathrm{~g}$ for $3 \mathrm{~min}$ at $4^{\circ} \mathrm{C}$. The supernatant was removed, and the beads were washed four times with $500 \mu \mathrm{l}$ of binding buffer. After the last washing step, $20 \mu \mathrm{l}$ of $2 \times$ SDS-PAGE sample loading buffer was added to the dry beads. The samples were boiled for $5 \mathrm{~min}$ at $95^{\circ} \mathrm{C}$ and analyzed by SDS-PAGE and Coomassie staining. Gel densitometry was carried out with Image Lab (BioRAD, Hercules, US-CA).

In vitro assembly of CCAN Reconstitution of human recombinant CCAN particles was performed as previously published in Pesenti et al., 2018. In brief, a stoichiometric amount of purified CENP-LN, CENP-CHIKM, CENP-OPQUR and CENP-TWSX complexes were incubated at around $15 \mu \mathrm{M}$ at $4^{\circ} \mathrm{C}$ for minimum 1 hour and purified by SEC using a buffer containing $20 \mathrm{mM}$ HEPES pH 6.8, $300 \mathrm{mM} \mathrm{NaCl}, 2.5 \%$ (v/v) glycerol and $1 \mathrm{mM}$ TCEP.

Sample preparation for electron microscopy The reconstituted CCAN particles were stabilized via the GraFix method (Kastner et al., 2008). Two 4-ml gradients ranging from 20 to $50 \%$ glycerol in $20 \mathrm{mM}$ HEPES pH $6.8,300 \mathrm{mM} \mathrm{NaCl}$ and $1 \mathrm{mM}$ TCEP were set up. In one of the gradients, the $50 \%$ solution contained $0.125 \%$ of glutaraldehyde. Around $100 \mu \mathrm{L}$ of sample at $15 \mu \mathrm{M}$ was applied to each gradient and centrifuged by ultracentrifugation at $45000 \mathrm{rpm}$ at $4^{\circ} \mathrm{C}$ in SW 60 Ti Swinging-bucket rotor (Beckman Coulter, Palo Alto, US-CA) for 16 hours. The samples from both gradients were fractionated in $150 \mu \mathrm{L}$ fractions, and cross-linker containing fractions were quenched by addition of $100 \mathrm{mM}$ Tris $\mathrm{pH}$ 6.8. All fractions were analyzed by SDS-PAGE and Coomassie blue staining. The fractions of interest were dialyzed two times against 21 of $20 \mathrm{mM}$ HEPES pH 6.8, $300 \mathrm{mM} \mathrm{NaCl}$, and $1 \mathrm{mM}$ TCEP buffer for 16 hours and 2 
hours, and concentrated to around $2 \mathrm{mg} / \mathrm{ml}$ using Amicon Ultra $0.5 \mathrm{ml}-100 \mathrm{kDa}$ cutoff (Millipore, Burlington, US-MA).

Negative stain electron microscopy Negative stain specimens were prepared as described previously (Brocker et al., 2012): The cross-linked CCAN samples were diluted in $20 \mathrm{mM}$ HEPES pH 6.8, $300 \mathrm{mM} \mathrm{NaCl}$, and 1mM TCEP buffer to adjust the particle density. 4 $\mu \mathrm{L}$ of the sample were absorbed at $25^{\circ} \mathrm{C}$ for 1 min onto freshly glow-discharged 400 mesh carbon-coated copper grids (G2400C, Plano GmbH, Wetzlar, Germany). Excess sample was blotted by touching a Whatman filter paper and washed with three droplets of water and exposed to freshly prepared $0.75 \%$ uranyl formate solution (SPI Supplies/Structure Probe, West Chester, PA) for about $1 \mathrm{~min}$. Excess negative stain solution was blotted and the specimen air-dried. Specimens were inspected with a JEM1400 microscope (Jeol, Tokio, Japan) equipped with a LaB 6 cathode and operated at an acceleration voltage of $120 \mathrm{kV}$. Digital micrographs were recorded using a $4 \mathrm{k} \mathrm{x} 4 \mathrm{k}$ CMOS camera F416 (TVIPS, Gauting, Germany).

Cryo-EM grid preparation and data acquisition Grids were prepared using a Vitrobot Mark IV (Thermo Fisher Scientific) at $13{ }^{\circ} \mathrm{C}$ and $100 \%$ humidity. $4 \mu \mathrm{l}$ of CENP-16 supplemented with $0.0025 \%$ Triton were applied to glow-discharged UltrAuFoil R1.2/1.3 grids and excess liquid removed by blotting (3.5 seconds at blot force -3 ) before vitrification in liquid ethane. For dataset I, CENP-16 was used at a concentration of 1.5 $\mathrm{mg} / \mathrm{ml}$. For dataset II, CENP-14 (without CENP-SX) was used at $0.9 \mathrm{mg} / \mathrm{ml}$. The CCAN sample used for dataset II also contained a 145-bp DNA and CENP-A:H4. Elongated DNA was visible in the micrographs, but no density for DNA or CENPA:H4 was identifiable in the 2D classes. Dataset I was acquired on a Titan Krios electron microscope (Thermo Fisher Scientific) equipped with a field emission gun. For this first dataset, 1540 movies were recorded on a K3 camera (Gatan) operated in super-resolution mode at a nominal magnification of 130000 , resulting in a super-resolution pixel size of $0.35 \AA$. A Bioquantum post-column energy filter (Gatan) was used for zero-loss filtration with an energy width of $20 \mathrm{eV}$. Total electron exposure of $76.8 \mathrm{e}-\AA^{2}$ was distributed over 80 frames. Data were collected using the automated data collection software EPU (Thermo Fisher Scientific), with two exposures per hole and a set defocus range of -0.6 to $-1.2 \mu \mathrm{m}$. The second dataset was recorded on a Cs-corrected Titan Krios microscope equipped with a K3 camera (Gatan) and a Bioquantum post-column energy filter with a slit width of $14 \mathrm{eV}$ operated in super-resolution mode at a nominal magnification of 
105000, corresponding to a super-resolution pixel size of $0.34 \AA$. A total exposure of $55.8 \mathrm{e}^{-} / \AA^{2}$ was distributed over 60 frames. 2678 movies were collected using EPU (Thermo Fisher Scientific), with two exposures per hole and a set defocus range of -0.6 to $-1.2 \mu \mathrm{m}$. For both datasets, phase contrast was induced by using a volta phase plate in the back focal plane. Details of data acquisition parameters can be found in Table S1.

Cryo-EM data processing On-the-fly data pre-processing, including correction of beaminduced motion and dose-weighting by MotionCor2 (Zheng et al., 2017), CTF parameter estimation using CTFFIND4 in movie mode (Rohou and Grigorieff, 2015), and particle picking using a custom neural network in SPHIRE-crYOLO (Wagner et al., 2019), was performed within TranSPHIRE (Stabrin et al., 2020). For the high-resolution dataset (dataset I in Figure 1 - Supplement 3), template-free particle picking by crYOLO (Wagner et al., 2019) in the 1540 micrographs greatly improved after re-training with 1354 manually picked particles, resulting in 140910 particle coordinates. 2-fold binned particles were extracted in SPHIRE (Moriya et al., 2017) using a box size of 220x220 pixels. 2D classification was performed in ISAC with a class size limit of 500 particles, a particle radius of 105 pixels and using the VPP option. 45 beautified 2D class averages which had been filtered to $8 \AA$ were used to generate an initial 3D model in RVIPER. In parallel, the dataset was processed in RELION 3.1.2 (Fernandez-Leiro and Scheres, 2017; Nakane et al., 2018) using a box size of 384x384 pixels for extraction and 200 classes for 2D classification and initial model generation. The 95522 selected particles and the resulting initial model could be refined both in MERIDIEN and RELION, yielding a $7 \AA$ reconstruction. The centered particles were then re-extracted without binning and using a box size of 384 pixels, and all further processing steps were performed in RELION. 3D classification with four classes yielded one class with 25206 particles which showed high-resolution features in the center of the particle. The quality of the reconstruction was improved by Bayesian polishing, resulting in an increased global resolution of $5 \AA$.

This reconstruction was further improved by multi-body refinement in RELION using two masks covering the majority of the HIKMLN or OPQUR subcomplexes, i.e. omitting the more flexible QU- and HIK-TW-"heads", resulting in focused reconstructions with resolutions of $4.6 \AA$ for HIKMLN and $6.9 \AA$ for OPQUR. Segmenting the volumes further (including e.g. additional maps for the "heads") did not improve the quality of the reconstructions. The multi-body refinement was especially 
important for improvement of the resolution of the OPQUR part. As evident from local resolution estimation with RELION, the quality of the reconstruction varies greatly between the well-ordered CENP-M/L/N interface with local resolution of $3.7 \AA$, and more peripheral parts which are more flexible and less well resolved. The angular distribution showed that the particles had a moderate fraction of preferred orientations along the shortest axis of the particles (Figure 1 - Supplement 4). DeepEMhancer (Sanchez-Garcia et al., 2021) was used to further enhance the maps for model building.

The second dataset (dataset II in Figure 1 - Supplement 3) had lower resolution although the initial 2678 micrographs yielded more particles compared to the first dataset (233598 vs 140910) when picked with the re-trained crYOLO model. DNA strands were visible in the micrographs, but no nucleosomes (no H2A:H2B was present). For extraction, a larger box size of 512 pixels (corresponding to $358.4 \AA$ ) was chosen to potentially detect more different conformations compared to the first dataset. Particles were subjected to 2D classification in RELION, and an initial model was calculated, also in RELION, using 117473 particles assigned to good 2D classes. Subsequent 3D classification into 4 classes yielded one class (with 44216 assigned particles) suitable for 3D refinement. The quality of the refined model could not be improved by further 2D classification, Bayesian polishing, or CTF refinement. Although the overall resolution was lower, this dataset showed much clearer density for the HIK and QU heads, including a tentative density for the CENP-TW complex that fits very well to the position of TW in the X-ray structure of the HIK-TW complex (PDB ID 6WUC). This assignment is corroborated by Alphafold2 predictions that indicate a strong interaction between the HIK head and TW as compared to the CENPA/H4 dimer (I.R.V, unpublished results). RELION multibody refinement with three masks covering HIKTW, MLN, and OPQUR, respectively, resulted in resolutions of $10.2 \AA, 10.2 \AA$ and $10.6 \AA$ for the three maps. Local resolution estimated with RELION ranged between 8-25 $\AA$ (Figure 1 - Supplement 4). The angular distribution showed no pronounced preferred orientations. Since crYOLO picked practically all particles and the $2 \mathrm{D}$ classes did not show any evidence for the presence of DNA or nucleosomes, any stable association of DNA or CENP-A/H4 with the CCAN can be excluded.

Model building and structure refinement Crystal structures of human CENP-M (PDB ID 4WAU), human CENP-N (PDB ID 6EQT) as well as ab initio models for human CENP-H, K, I, L, N, O, P, Q, U, R, T, and W predicted by the Tencent tFold server 
(https://drug.ai.tencent.com) were initially docked as rigid bodies into the reconstruction of dataset I sharpened by DeepEMhancer and then locally adjusted using Coot (Emsley et al., 2010) and Chimera (Yang et al., 2012). The cryo-EM structures of the yeast CCAN (PDB IDs 6QLD and 6QLE) and the yeast CTF3 complex with CNN1-WIP1 (PDB ID 6WUC) were also used to guide the modeling. Subsequently, ab initio models predicted using Alphafold2 were used to further improve the structure model. These Alphafold models ("Colabfold", AF2, and AF2-multimer (Evans et al., 2021; Jumper et al., 2021; Mirdita et al., 2021) greatly facilitated the sequence assignment in regions with lower local resolution. Density for a short helix at the interface of CENP-I and CENP-K was built as a polyalanine model since the sequence could not be assigned reliably. Possible assignments include CENP-C, the N-terminus of CENP-H, CENP-P or CENP-O, the latter slightly more likely since AF2-multimer predicted this interaction with high confidence. In contrast, the extension of the CENP-N $\beta$-sheet by the CENP-C region 303-FIID-306 was reliably predicted by AF2-multimer and allowed unambiguous interpretation of the corresponding electron density for CENP-C. The position of the CENP-TW complex was derived by superposing an AF2-prediction of the CENP-HIK "head" in complex with CENP-TW (which had exactly the same arrangement as the model of the yeast CTF3-CNN1-WIP1 complex (PDB ID 6WUC)) and subsequently docking it into the reconstruction of dataset II. The final model was optimized by geometry minimization and real-space refinement with PHENIX (Adams et al., 2010) and evaluated with COOT, PHENIX and MolProbity (Chen et al., 2010). Figures were prepared using Chimera and PyMOL (Molecular Graphics System, 2.0.3, Schrodinger). Structural sequence alignments were performed with Chimera.

Cell culture and immunofluorence HeLa Flip-In T-REx EGFP-CENP-M (Basilico et al., 2014) were maintained in DMEM with 10\% tetracycline-free FBS (Pan Biotech), supplemented $50 \mu \mathrm{g} / \mathrm{ml}$ Penicillin/Streptomycin (PAN Biotech), and $2 \mathrm{mM}$ L-glutamine (PAN Biotech). For immunofluorence experiments, cells were grown on coverslips precoated with $0.01 \%$ poly-D-lysine (Sigma-Aldrich). Exogenous gene expression was induced by adding $50 \mathrm{ng} / \mathrm{ml}$ doxycycline (Sigma, St. Louis, Missouri, United States) to the media for $24 \mathrm{~h}$ before fixation. Cells were fixed with ice-cold Methanol for 1 minute, then washed 3 times for 5 minutes with 1 X PBS + 0.1\% Tween-20 (PBST). Cells were blocked for 20 minutes at room temperature in PBST $+5 \%$ BSA, and then were incubated in primary antibodies diluted in PBST $+1 \%$ BSA overnight at 4C. The following morning, coverslips were washed 3 times for 5 minutes with PBST and then 
incubated for 30 minutes at room temperature with secondary antibodies diluted in PBST $+1 \%$ BSA. Finally, coverslips were washed 3 times for 5 minutes in PBST and quickly rinsed in distilled water before mounting. The following primary antibodies were used: anti-CyclinB1 (rabbit monoclonal antibody, Abcam, \#ab32053, 1:1000), CREST/anti-centromere antibody (human autoimmune serum, Antibodies Inc., \#15234, 1:1000), anti-PCNA (mouse monoclonal antibody, Cell Signalling, \#2586S, 1:1000), anti-Tubulin (rat monoclonal antibody, Abcam, \#6160, 1:500). The following secondary antibodies were used: donkey anti-human DyLight 405 Jackson ImmunoResearch, 1:000), donkey anti-mouse Alexa Fluor ${ }^{\circledR} 647$ (Invitrogen, 1:1000), donkey anti-rabbit Rhodamine Red (Jackson ImmunoResearch, 1:000), donkey anti-rat Rhodamine Red (Jackson ImmunoResearch, 1:000), GFP-Booster Alexa Fluor® 488 (Chromotek, gb2AF488-50, 1:1000), goat anti-human Alexa Fluor ${ }^{\circledR} 647$ (Jackson ImmunoResearch, 1:000). DNA was stained with $0.5 \mu \mathrm{g} / \mathrm{ml}$ DAPI (Serva) and Mowiol (Calbiochem) was used as mounting media.

\section{Accession codes}

The coordinates and map of the high- and low-resolution CCAN models have been submitted to the Protein data bank with ID 7QOO and to the EMDB with IDs EMD14098 for the high-resolution dataset and EMD-14099 for the low-resolution dataset.

\section{Acknowledgements}

We are grateful to Oliver Hofnagel for help with data collection, to Julia Schweighofer and Sabine Wohlgemuth for help with the production of CENP-LN and CENP-TW, and to Karolin Luger, Keda Zhou, and the Musacchio and Raunser laboratories for helpful discussions and sharing of unpublished results. This work was supported by the Max Planck Society (to A.M. and S.R.). D.C. acknowledges funding by the European Molecular Biology Organization (EMBO) through an EMBO Long-Term Fellowship (ALTF 439-2019). A.M. acknowledges funding by the Marie-Curie Training Network DivIDE (project number 675737), European Research Council (ERC) through Synergy Grant 951439 (BIOMECANET) and formerly AdG 669686 (RECEPIANCE). The authors declare no competing financial interests. 


\section{Author contributions (following CRediT model)}

Conceptualization: Andrea Musacchio

Data curation: $\mathrm{N} / \mathrm{A}$

Investigation

Sample preparation: Marion E. Pesenti

Data collection and processing: Daniel Prumbaum, Tobias Raisch, Ingrid R.

Vetter

Structure determination and model building: Ingrid R. Vetter

\section{Cell Biology: Duccio Conti}

Funding acquisition: Andrea Musacchio, Stefan Raunser

Project Administration: Andrea Musacchio, Stefan Raunser

Resources: Ingrid Hofmann, Doro Vogt

Supervision: Andrea Musacchio, Stefan Raunser, Ingrid R. Vetter

Validation: Andrea Musacchio, Stefan Raunser, Ingrid R. Vetter

Visualization: Duccio Conti, Marion E. Pesenti, Tobias Raisch, Ingrid R. Vetter

Writing - original draft: Andrea Musacchio

Writing - review \& editing: All authors

\section{References}

Adams, P.D., Afonine, P.V., Bunkoczi, G., Chen, V.B., Davis, I.W., Echols, N., Headd, J.J., Hung, L.W., Kapral, G.J., Grosse-Kunstleve, R.W., et al. (2010). PHENIX: a comprehensive Python-based system for macromolecular structure solution. Acta Crystallogr D Biol Crystallogr 66, 213-221.

Ali-Ahmad, A., Bilokapic, S., Schafer, I.B., Halic, M., and Sekulic, N. (2019). CENP-C unwraps the human CENP-A nucleosome through the H2A C-terminal tail. EMBO Rep 20, e48913.

Allu, P.K., Dawicki-McKenna, J.M., Van Eeuwen, T., Slavin, M., Braitbard, M., Xu, C., Kalisman, N., Murakami, K., and Black, B.E. (2019). Structure of the Human Core Centromeric Nucleosome Complex. Curr Biol 29, 2625-2639 e2625. 
Ando, S., Yang, H., Nozaki, N., Okazaki, T., and Yoda, K. (2002). CENP-A, -B, and -C chromatin complex that contains the I-type alpha-satellite array constitutes the prekinetochore in HeLa cells. Mol Cell Biol 22, 2229-2241.

Ariyoshi, M., Makino, F., Watanabe, R., Nakagawa, R., Kato, T., Namba, K., Arimura, Y., Fujita, R., Kurumizaka, H., Okumura, E.I., et al. (2021). Cryo-EM structure of the CENP-A nucleosome in complex with phosphorylated CENP-C. EMBO J 40, e105671.

Basilico, F., Maffini, S., Weir, J.R., Prumbaum, D., Rojas, A.M., Zimniak, T., De Antoni, A., Jeganathan, S., Voss, B., van Gerwen, S., et al. (2014). The pseudo GTPase CENP-M drives human kinetochore assembly. Elife 3, e02978.

Black, B.E., and Cleveland, D.W. (2011). Epigenetic centromere propagation and the nature of CENP-a nucleosomes. Cell 144, 471-479.

Black, B.E., Foltz, D.R., Chakravarthy, S., Luger, K., Woods, V.L., Jr., and Cleveland, D.W. (2004). Structural determinants for generating centromeric chromatin. Nature 430, 578-582.

Black, B.E., Jansen, L.E., Maddox, P.S., Foltz, D.R., Desai, A.B., Shah, J.V., and Cleveland, D.W. (2007). Centromere identity maintained by nucleosomes assembled with histone H3 containing the CENP-A targeting domain. Mol Cell 25, 309-322.

Bloom, K.S., and Carbon, J. (1982). Yeast centromere DNA is in a unique and highly ordered structure in chromosomes and small circular minichromosomes. Cell 29, 305317.

Brocker, C., Kuhlee, A., Gatsogiannis, C., Balderhaar, H.J., Honscher, C., EngelbrechtVandre, S., Ungermann, C., and Raunser, S. (2012). Molecular architecture of the multisubunit homotypic fusion and vacuole protein sorting (HOPS) tethering complex. Proc Natl Acad Sci U S A 109, 1991-1996.

Camahort, R., Shivaraju, M., Mattingly, M., Li, B., Nakanishi, S., Zhu, D., Shilatifard, A., Workman, J.L., and Gerton, J.L. (2009). Cse4 is part of an octameric nucleosome in budding yeast. Mol Cell 35, 794-805.

Carroll, C.W., Milks, K.J., and Straight, A.F. (2010). Dual recognition of CENP-A nucleosomes is required for centromere assembly. J Cell Biol 189, 1143-1155.

Carroll, C.W., Silva, M.C., Godek, K.M., Jansen, L.E., and Straight, A.F. (2009). Centromere assembly requires the direct recognition of CENP-A nucleosomes by CENP-N. Nat Cell Biol 11, 896-902.

Chen, V.B., Arendall, W.B., 3rd, Headd, J.J., Keedy, D.A., Immormino, R.M., Kapral, G.J., Murray, L.W., Richardson, J.S., and Richardson, D.C. (2010). MolProbity: all-atom structure validation for macromolecular crystallography. Acta Crystallogr D Biol Crystallogr 66, 12-21.

Chik, J.K., Moiseeva, V., Goel, P.K., Meinen, B.A., Koldewey, P., An, S., Mellone, B.G., Subramanian, L., and Cho, U.S. (2019). Structures of CENP-C cupin domains at regional centromeres reveal unique patterns of dimerization and recruitment functions for the inner pocket. J Biol Chem 294, 14119-14134. 
Chittori, S., Hong, J., Saunders, H., Feng, H., Ghirlando, R., Kelly, A.E., Bai, Y., and Subramaniam, S. (2018). Structural mechanisms of centromeric nucleosome recognition by the kinetochore protein CENP-N. Science 359, 339-343.

Cho, U.S., and Harrison, S.C. (2011). Recognition of the centromere-specific histone Cse4 by the chaperone Scm3. Proc Natl Acad Sci U S A 108, 9367-9371.

Cohen, R.L., Espelin, C.W., De Wulf, P., Sorger, P.K., Harrison, S.C., and Simons, K.T. (2008). Structural and functional dissection of Mif2p, a conserved DNA-binding kinetochore protein. Mol Biol Cell 19, 4480-4491.

Dalal, Y., Furuyama, T., Vermaak, D., and Henikoff, S. (2007). Structure, dynamics, and evolution of centromeric nucleosomes. Proc Natl Acad Sci U S A 104, 15974-15981.

Dechassa, M.L., Wyns, K., Li, M., Hall, M.A., Wang, M.D., and Luger, K. (2011). Structure and Scm3-mediated assembly of budding yeast centromeric nucleosomes. Nat Commun 2, 313.

Drinnenberg, I.A., and Akiyoshi, B. (2017). Evolutionary Lessons from Species with Unique Kinetochores. Prog Mol Subcell Biol 56, 111-138.

Dunleavy, E.M., Zhang, W., and Karpen, G.H. (2013). Solo or doppio: how many CENP-As make a centromeric nucleosome? Nat Struct Mol Biol 20, 648-650.

Eickbush, T.H., Godfrey, J.E., Elia, M.C., and Moudrianakis, E.N. (1988). H2a-specific proteolysis as a unique probe in the analysis of the histone octamer. J Biol Chem 263, 18972-18978.

Emsley, P., Lohkamp, B., Scott, W.G., and Cowtan, K. (2010). Features and development of Coot. Acta Crystallogr D Biol Crystallogr 66, 486-501.

Evans, R., O’Neill, M., Pritzel, A., Antropova, N., Senior, A., Green, T., Žídek, A., Bates, R., Blackwell, S., Yim, J., et al. (2021). Protein complex prediction with AlphaFoldMultimer. BioRXiv.

Fernandez-Leiro, R., and Scheres, S.H.W. (2017). A pipeline approach to single-particle processing in RELION. Acta Crystallogr D Struct Biol 73, 496-502.

Fitzgerald-Hayes, M., Clarke, L., and Carbon, J. (1982). Nucleotide sequence comparisons and functional analysis of yeast centromere DNAs. Cell 29, 235-244.

Foltz, D.R., Jansen, L.E., Black, B.E., Bailey, A.O., Yates, J.R., 3rd, and Cleveland, D.W. (2006). The human CENP-A centromeric nucleosome-associated complex. Nat Cell Biol $8,458-469$.

Furuyama, S., and Biggins, S. (2007). Centromere identity is specified by a single centromeric nucleosome in budding yeast. Proc Natl Acad Sci U S A 104, 14706-14711.

Furuyama, T., Codomo, C.A., and Henikoff, S. (2013). Reconstitution of hemisomes on budding yeast centromeric DNA. Nucleic Acids Res 41, 5769-5783.

Gambogi, C.W., and Black, B.E. (2019). The nucleosomes that mark centromere location on chromosomes old and new. Essays Biochem 63, 15-27. 
Gascoigne, K.E., Takeuchi, K., Suzuki, A., Hori, T., Fukagawa, T., and Cheeseman, I.M. (2011). Induced ectopic kinetochore assembly bypasses the requirement for CENP-A nucleosomes. Cell 145, 410-422.

Guo, L.Y., Allu, P.K., Zandarashvili, L., McKinley, K.L., Sekulic, N., Dawicki-McKenna, J.M., Fachinetti, D., Logsdon, G.A., Jamiolkowski, R.M., Cleveland, D.W., et al. (2017). Centromeres are maintained by fastening CENP-A to DNA and directing an arginine anchor-dependent nucleosome transition. Nat Commun 8, 15775.

Guse, A., Fuller, C.J., and Straight, A.F. (2012). A cell-free system for functional centromere and kinetochore assembly. Nat Protoc 7, 1847-1869.

Ha, J.Y., Kim, H.K., Kim, D.J., Kim, K.H., Oh, S.J., Lee, H.H., Yoon, H.J., Song, H.K., and Suh, S.W. (2007). The recombination-associated protein $\mathrm{RdgC}$ adopts a novel toroidal architecture for DNA binding. Nucleic Acids Res 35, 2671-2681.

Hamilton, G., Dimitrova, Y., and Davis, T.N. (2019). Seeing is believing: our evolving view of kinetochore structure, composition, and assembly. Curr Opin Cell Biol 60, 44-52.

Hasson, D., Panchenko, T., Salimian, K.J., Salman, M.U., Sekulic, N., Alonso, A., Warburton, P.E., and Black, B.E. (2013). The octamer is the major form of CENP-A nucleosomes at human centromeres. Nat Struct Mol Biol 20, 687-695.

Henikoff, S., Ramachandran, S., Krassovsky, K., Bryson, T.D., Codomo, C.A., Brogaard, K., Widom, J., Wang, J.P., and Henikoff, J.G. (2014). The budding yeast Centromere DNA Element II wraps a stable Cse4 hemisome in either orientation in vivo. Elife 3, e01861.

Hinshaw, S.M., and Harrison, S.C. (2013). An Iml3-Chl4 heterodimer links the core centromere to factors required for accurate chromosome segregation. Cell Rep 5, 29-36.

Hinshaw, S.M., and Harrison, S.C. (2019). The structure of the Ctf19c/CCAN from budding yeast. Elife 8 .

Hinshaw, S.M., and Harrison, S.C. (2020). The Structural Basis for Kinetochore Stabilization by Cnn1/CENP-T. Curr Biol 30, 3425-3431 e3423.

Hornung, P., Troc, P., Malvezzi, F., Maier, M., Demianova, Z., Zimniak, T., Litos, G., Lampert, F., Schleiffer, A., Brunner, M., et al. (2014). A cooperative mechanism drives budding yeast kinetochore assembly downstream of CENP-A. J Cell Biol 206, 509-524.

Izuta, H., Ikeno, M., Suzuki, N., Tomonaga, T., Nozaki, N., Obuse, C., Kisu, Y., Goshima, N., Nomura, F., Nomura, N., et al. (2006). Comprehensive analysis of the ICEN (Interphase Centromere Complex) components enriched in the CENP-A chromatin of human cells. Genes Cells 11, 673-684.

Jansen, L.E., Black, B.E., Foltz, D.R., and Cleveland, D.W. (2007). Propagation of centromeric chromatin requires exit from mitosis. J Cell Biol 176, 795-805.

Jumper, J., Evans, R., Pritzel, A., Green, T., Figurnov, M., Ronneberger, O., Tunyasuvunakool, K., Bates, R., Zidek, A., Potapenko, A., et al. (2021). Highly accurate protein structure prediction with AlphaFold. Nature 596, 583-589. 
Kabsch, W., and Sander, C. (1983). Dictionary of protein secondary structure: pattern recognition of hydrogen-bonded and geometrical features. Biopolymers 22, 2577-2637.

Kastner, B., Fischer, N., Golas, M.M., Sander, B., Dube, P., Boehringer, D., Hartmuth, K., Deckert, J., Hauer, F., Wolf, E., et al. (2008). GraFix: sample preparation for singleparticle electron cryomicroscopy. Nat Methods 5, 53-55.

Kato, H., Jiang, J., Zhou, B.R., Rozendaal, M., Feng, H., Ghirlando, R., Xiao, T.S., Straight, A.F., and Bai, Y. (2013). A conserved mechanism for centromeric nucleosome recognition by centromere protein CENP-C. Science 340, 1110-1113.

Keith, K.C., and Fitzgerald-Hayes, M. (2000). CSE4 genetically interacts with the Saccharomyces cerevisiae centromere DNA elements CDE I and CDE II but not CDE III. Implications for the path of the centromere dna around a cse $4 p$ variant nucleosome. Genetics 156, 973-981.

Kixmoeller, K., Allu, P.K., and Black, B.E. (2020). The centromere comes into focus: from CENP-A nucleosomes to kinetochore connections with the spindle. Open Biol 10, 200051.

Klare, K., Weir, J.R., Basilico, F., Zimniak, T., Massimiliano, L., Ludwigs, N., Herzog, F., and Musacchio, A. (2015). CENP-C is a blueprint for constitutive centromere-associated network assembly within human kinetochores. J Cell Biol 210, 11-22.

Krassovsky, K., Henikoff, J.G., and Henikoff, S. (2012). Tripartite organization of centromeric chromatin in budding yeast. Proc Natl Acad Sci U S A 109, 243-248.

McKinley, K.L., and Cheeseman, I.M. (2016). The molecular basis for centromere identity and function. Nat Rev Mol Cell Biol 17, 16-29.

McKinley, K.L., Sekulic, N., Guo, L.Y., Tsinman, T., Black, B.E., and Cheeseman, I.M. (2015). The CENP-L-N Complex Forms a Critical Node in an Integrated Meshwork of Interactions at the Centromere-Kinetochore Interface. Mol Cell 60, 886-898.

Medina-Pritchard, B., Lazou, V., Zou, J., Byron, O., Abad, M.A., Rappsilber, J., Heun, P., and Jeyaprakash, A.A. (2020). Structural basis for centromere maintenance by Drosophila CENP-A chaperone CAL1. EMBO J 39, e103234.

Mellone, B.G., and Fachinetti, D. (2021). Diverse mechanisms of centromere specification. Curr Biol 31, R1491-R1504.

Meluh, P.B., Yang, P., Glowczewski, L., Koshland, D., and Smith, M.M. (1998). Cse4p is a component of the core centromere of Saccharomyces cerevisiae. Cell 94, 607-613.

Mirdita, M., Schütze, K., Moriqwaki, L., Ovchinnikov, S., and Steinegger, M. (2021). ColabFold - Making protein folding accessible to all. BioRXiv.

Mizuguchi, G., Xiao, H., Wisniewski, J., Smith, M.M., and Wu, C. (2007). Nonhistone Scm3 and histones CenH3-H4 assemble the core of centromere-specific nucleosomes. Cell 129, 1153-1164. 
Moriya, T., Saur, M., Stabrin, M., Merino, F., Voicu, H., Huang, Z., Penczek, P.A., Raunser, S., and Gatsogiannis, C. (2017). High-resolution Single Particle Analysis from Electron Cryo-microscopy Images Using SPHIRE. J Vis Exp.

Musacchio, A., and Desai, A. (2017). A Molecular View of Kinetochore Assembly and Function. Biology (Basel) 6.

Nagpal, H., Hori, T., Furukawa, A., Sugase, K., Osakabe, A., Kurumizaka, H., and Fukagawa, T. (2015). Dynamic changes in CCAN organization through CENP-C during cell-cycle progression. Mol Biol Cell 26, 3768-3776.

Nakane, T., Kimanius, D., Lindahl, E., and Scheres, S.H. (2018). Characterisation of molecular motions in cryo-EM single-particle data by multi-body refinement in RELION. Elife 7.

Nechemia-Arbely, Y., Fachinetti, D., Miga, K.H., Sekulic, N., Soni, G.V., Kim, D.H., Wong, A.K., Lee, A.Y., Nguyen, K., Dekker, C., et al. (2017). Human centromeric CENP-A chromatin is a homotypic, octameric nucleosome at all cell cycle points. J Cell Biol 216, 607-621.

Nishino, T., Takeuchi, K., Gascoigne, K.E., Suzuki, A., Hori, T., Oyama, T., Morikawa, K., Cheeseman, I.M., and Fukagawa, T. (2012). CENP-T-W-S-X forms a unique centromeric chromatin structure with a histone-like fold. Cell 148, 487-501.

Obuse, C., Yang, H., Nozaki, N., Goto, S., Okazaki, T., and Yoda, K. (2004). Proteomics analysis of the centromere complex from HeLa interphase cells: UV-damaged DNA binding protein 1 (DDB-1) is a component of the CEN-complex, while BMI-1 is transiently co-localized with the centromeric region in interphase. Genes Cells 9, 105120.

Okada, M., Cheeseman, I.M., Hori, T., Okawa, K., McLeod, I.X., Yates, J.R., 3rd, Desai, A., and Fukagawa, T. (2006). The CENP-H-I complex is required for the efficient incorporation of newly synthesized CENP-A into centromeres. Nat Cell Biol 8, 446-457.

Pentakota, S., Zhou, K., Smith, C., Maffini, S., Petrovic, A., Morgan, G.P., Weir, J.R., Vetter, I.R., Musacchio, A., and Luger, K. (2017). Decoding the centromeric nucleosome through CENP-N. Elife 6.

Pesenti, M.E., Prumbaum, D., Auckland, P., Smith, C.M., Faesen, A.C., Petrovic, A., Erent, M., Maffini, S., Pentakota, S., Weir, J.R., et al. (2018). Reconstitution of a 26Subunit Human Kinetochore Reveals Cooperative Microtubule Binding by CENPOPQUR and NDC80. Mol Cell 71, 923-939 e910.

Pinto, I., and Winston, F. (2000). Histone H2A is required for normal centromere function in Saccharomyces cerevisiae. EMBO J 19, 1598-1612.

Pluta, A.F., Mackay, A.M., Ainsztein, A.M., Goldberg, I.G., and Earnshaw, W.C. (1995). The centromere: hub of chromosomal activities. Science 270, 1591-1594.

Rohou, A., and Grigorieff, N. (2015). CTFFIND4: Fast and accurate defocus estimation from electron micrographs. J Struct Biol 192, 216-221. 
Rossi, M.J., Kuntala, P.K., Lai, W.K.M., Yamada, N., Badjatia, N., Mittal, C., Kuzu, G., Bocklund, K., Farrell, N.P., Blanda, T.R., et al. (2021). A high-resolution protein architecture of the budding yeast genome. Nature 592, 309-314.

Sanchez-Garcia, R., Gomez-Blanco, J., Cuervo, A., Carazo, J.M., Sorzano, C.O.S., and Vargas, J. (2021). DeepEMhancer: a deep learning solution for cryo-EM volume postprocessing. Commun Biol 4, 874.

Schuh, M., Lehner, C.F., and Heidmann, S. (2007). Incorporation of Drosophila CID/CENP-A and CENP-C into centromeres during early embryonic anaphase. Curr Biol 17, 237-243.

Screpanti, E., De Antoni, A., Alushin, G.M., Petrovic, A., Melis, T., Nogales, E., and Musacchio, A. (2011). Direct binding of Cenp-C to the Mis12 complex joins the inner and outer kinetochore. Curr Biol 21, 391-398.

Shukla, M.S., Syed, S.H., Goutte-Gattat, D., Richard, J.L., Montel, F., Hamiche, A., Travers, A., Faivre-Moskalenko, C., Bednar, J., Hayes, J.J., et al. (2011). The docking domain of histone $\mathrm{H} 2 \mathrm{~A}$ is required for $\mathrm{H} 1$ binding and RSC-mediated nucleosome remodeling. Nucleic Acids Res 39, 2559-2570.

Stabrin, M., Schoenfeld, F., Wagner, T., Pospich, S., Gatsogiannis, C., and Raunser, S. (2020). TranSPHIRE: automated and feedback-optimized on-the-fly processing for cryoEM. Nat Commun 11, 5716.

Tachiwana, H., Kagawa, W., Shiga, T., Osakabe, A., Miya, Y., Saito, K., HayashiTakanaka, Y., Oda, T., Sato, M., Park, S.Y., et al. (2011). Crystal structure of the human centromeric nucleosome containing CENP-A. Nature 476, 232-235.

Takeuchi, K., Nishino, T., Mayanagi, K., Horikoshi, N., Osakabe, A., Tachiwana, H., Hori, T., Kurumizaka, H., and Fukagawa, T. (2014). The centromeric nucleosome-like CENP-T-W-S-X complex induces positive supercoils into DNA. Nucleic Acids Res 42, 1644-1655.

Talbert, P.B., and Henikoff, S. (2020). What makes a centromere? Exp Cell Res 389, 111895

Tian, T., Li, X., Liu, Y., Wang, C., Liu, X., Bi, G., Zhang, X., Yao, X., Zhou, Z.H., and Zang, J. (2018). Molecular basis for CENP-N recognition of CENP-A nucleosome on the human kinetochore. Cell Res 28, 374-378.

Tromer, E.C., van Hooff, J.J.E., Kops, G., and Snel, B. (2019). Mosaic origin of the eukaryotic kinetochore. Proc Natl Acad Sci U S A 116, 12873-12882.

van Hooff, J.J., Tromer, E., van Wijk, L.M., Snel, B., and Kops, G.J. (2017). Evolutionary dynamics of the kinetochore network in eukaryotes as revealed by comparative genomics. EMBO Rep 18, 1559-1571.

Wagner, T., Merino, F., Stabrin, M., Moriya, T., Antoni, C., Apelbaum, A., Hagel, P., Sitsel, O., Raisch, T., Prumbaum, D., et al. (2019). SPHIRE-crYOLO is a fast and accurate fully automated particle picker for cryo-EM. Commun Biol 2, 218. 
Walstein, K., Petrovic, A., Pan, D., Hagemeier, B., Vogt, D., Vetter, I.R., and Musacchio, A. (2021). Assembly principles and stoichiometry of a complete human kinetochore module. Sci Adv 7.

Weir, J.R., Faesen, A.C., Klare, K., Petrovic, A., Basilico, F., Fischbock, J., Pentakota, S., Keller, J., Pesenti, M.E., Pan, D., et al. (2016). Insights from biochemical reconstitution into the architecture of human kinetochores. Nature 537, 249-253.

Weissmann, F., Petzold, G., VanderLinden, R., Huis In 't Veld, P.J., Brown, N.G., Lampert, F., Westermann, S., Stark, H., Schulman, B.A., and Peters, J.M. (2016). biGBac enables rapid gene assembly for the expression of large multisubunit protein complexes. Proc Natl Acad Sci U S A 113, E2564-2569.

Westermann, S., Cheeseman, I.M., Anderson, S., Yates, J.R., 3rd, Drubin, D.G., and Barnes, G. (2003). Architecture of the budding yeast kinetochore reveals a conserved molecular core. J Cell Biol 163, 215-222.

Williams, J.S., Hayashi, T., Yanagida, M., and Russell, P. (2009). Fission yeast Scm3 mediates stable assembly of Cnp1/CENP-A into centromeric chromatin. Mol Cell 33, 287-298.

Xiao, H., Mizuguchi, G., Wisniewski, J., Huang, Y., Wei, D., and Wu, C. (2011). Nonhistone $\mathrm{Scm} 3$ binds to AT-rich DNA to organize atypical centromeric nucleosome of budding yeast. Mol Cell 43, 369-380.

Yan, K., Yang, J., Zhang, Z., McLaughlin, S.H., Chang, L., Fasci, D., EhrenhoferMurray, A.E., Heck, A.J.R., and Barford, D. (2019). Structure of the inner kinetochore CCAN complex assembled onto a centromeric nucleosome. Nature 574, 278-282.

Yang, Z., Lasker, K., Schneidman-Duhovny, D., Webb, B., Huang, C.C., Pettersen, E.F., Goddard, T.D., Meng, E.C., Sali, A., and Ferrin, T.E. (2012). UCSF Chimera, MODELLER, and IMP: an integrated modeling system. J Struct Biol 179, 269-278.

Zhang, Z., Bellini, D., and Barford, D. (2020). Crystal structure of the Cenp-HIKHeadTW sub-module of the inner kinetochore CCAN complex. Nucleic Acids Res.

Zheng, S.Q., Palovcak, E., Armache, J.P., Verba, K.A., Cheng, Y., and Agard, D.A. (2017). MotionCor2: anisotropic correction of beam-induced motion for improved cryoelectron microscopy. Nat Methods 14, 331-332.

Zhou, K., Gebala, M., Woods, D., Sundararajan, K., Edwards, G., Krzizike, D., Wereszczynski, J., Straight, A.F., and Luger, K. (2021). CENP-N promotes the compaction of centromeric chromatin. BioRXiv. 


\section{Figure legends}

\section{Figure 1. General organization of human CCAN}

A) Scheme of kinetochore organization with presentation of CCAN subcomplexes. B) Surface model of CENP-16 complex coloured to identify distinct sub-modules. C) Cartoon model of human CCAN with all visible subunits. D) Cartoon model of the $S$. cerevisiae Ctf19 ${ }^{\mathrm{CCAN}}$ with same colouring scheme as for human subunits, as applicable (Hinshaw and Harrison, 2019; Yan et al., 2019). E) Cartoon models of human and yeast $\mathrm{CCAN}^{\mathrm{Ct} 19}$ were superposed through CENP-N $\mathrm{N}^{\mathrm{Ch} 14}$ and the resulting orientation of pillar 2 compared. This shows that pillar 2 adopts different orientations in the human and yeast complexes, more divergent in yeast, and more parallel to pillar 1 in humans. Only pillar 2 and the vault were displayed, while pillar 1 and the base were removed to enhance clarity.

\section{Figure 2. CENP-C, CENP-M, and CENP-R}

A) Cartoon showing an overall view of human CCAN from above, and displaying the "knob" domain of pillar 1, the dimerization domain of the vault subunits CENP-LN, and the upper domain of pillar 2, where CENP-M resides. B) Close-up view of the two helices of CENP-R with initial and final visible residues, and the connecting helical segment. C) Sequence of HsCENP-C within the CCAN binding region. Two sequences shown in green and italics identify motifs previously shown to interact with CENP-NL and CENP-HIKM (Klare et al., 2015). The FIIDE sequence interacts with the CENPLN dimerization domain. D) Cartoon model of the CENP-LN dimerization domain with the bound FIIDE sequence of CENP-C shown in sticks. E) Embedding of CENP$\mathrm{M}$ in a network of interactions between pillar 2 and the vault. F) A rotated view showing additional CENP-M interactions. G) Sequence of CENP-M with displayed conservation from 12 distant CENP-M orthologs and contacts with neighbouring subunits. The figure was adapted from reference (Basilico et al., 2014). CENP-M residues in contact with other CCAN subunits are indicated with the same colour used for representation of the subunit. H) Localization of an EGFP-CENP-M construct in HeLa cells during the indicated phases of the cell cycle demonstrates continuity of localization.

\section{Figure 3. Human CCAN binds DNA}

A) Three orientations of HsCCAN shown in surface representation. The left panel is 
from the same view already displayed in Figure 1C. B) Surface electrostatics of the HsCCAN complex (red, negative; blue, positive; potential display levels were between 80 and $80 \mathrm{kT} / \mathrm{e}$ ) and positively charged residues contributing to potential DNA-binding interfaces discussed in the main text. C) Left. results from solid phase binding assay on amylose beads, using MBP (negative control) and MBP-CENP-TW as baits. The remaining CCAN subunits were added in solution, with or without the indicated DNA. Beads were recovered by centrifugation, washed, and their content analysed by SDSPAGE. Right: quantified band intensities from three technical replicates normalized to bound CCAN in absence of DNA. Error bars indicate standard deviation. CENP-C/I and CENP-LN comigrated and we report their integrated band intensities. D) Sizeexclusion chromatography of the indicated complexes with or without 165-bp dsDNA (experiments with 75-bp dsDNA gave analogous results, unpublished observations). Proteins separated by SDS-PAGE were visualized with Coomassie (top) or fluorescence (bottom). Absorbance profiles report on the indicated wavelengths.

\section{Figure 4. Properties of the CENP-LN vault}

A) The isolated CENP-LN vault with relevant domains highlighted in different colours. Shown from left to right are the CENP-N pyrin domain ( $\approx 80$ residues), the CENP-N LNHD ( $\underline{\mathrm{LN}}$-homology domain), the dimerization domains of CENP-N and CENP-L, and the CENP-L LNHD. A 2-fold pseudosymmetry axis (interrupted line with red oval at top) relates the CENP-L and CENP-N LNHDs. B) Top: two rotated cartoon model of the structure of the CENP-N terminal region bound to a CENP-A nucleosome core particle (NCP; PDB ID 6COW) (Pentakota et al., 2017). CENP-N binds in front of the L1 loop of CENP-A (coloured light blue) and to the DNA. The H2A C-terminal tails were removed to improve clarity. Bottom: superposition of CENP-N in 6COW to CENP$\mathrm{N}$ in the structure of human CCAN predicts a steric clash of the second DNA gyre (boxed) onto subunits of pillar 2 (CENP-HIKM). There is space for a single gyre of DNA in the vault. C) Cartoon model of the $\mathrm{RdgC}$ homodimer highlighting the LNHDs and other indicated structural elements. D) The LNHDs of CENP-LN are highlighted in absence of other structural domain (dimerization, pyrin) and modelled with a 15-bps segment of DNA, extracted from the $6 \mathrm{COW}$ structure shown in panel $\mathrm{A}$ and positioned identically relative to CENP-N. The 2-fold pseudosymmetry axis linking the LNHDs coincides with the 2 -fold pseudosymmetry axis of the DNA. E) A rotated view of the 
same object displayed in panel F.

Figure 5. A yeast Ctf19 ${ }^{\mathrm{CCAN}}$ :CENP-A nucleosome structure is a poor model for the human CCAN

A) Cartoon view of the S. cerevisiae Ctf19 ${ }^{\mathrm{CCAN}}$ :CENP-A nucleosome complex (PDB ID 6QLD) (Yan et al., 2019). B) Comparison of CENP-N on the yeast and human nucleosome structures demonstrates a different position. The protein cores of the nucleosomes have the same orientation, as shown by the indicated position of the 2 -fold pseudosymmetry axis. Red arrows point to the DNA ends in the two structures, which are different. They are offset in PDB ID 6QLD, due to the unwrapping of the nucleosomal DNA attracted inside the vault. They are instead roughly symmetric around the 2-fold pseudosymmetry axis in PDB ID 6COW. The H2A C-terminal tails were removed to improve clarity. C) Top: A rotated view of the yeast complex (PDB ID 6QLD) already shown in panel A. The rotation between panels A and C is schematized. Pillar 1 was removed to improve clarity. The position of the Chl $4^{\text {CENP-N }}$ was used to superpose the structure to the human CCAN complex (bottom, pillar 1 and the base were also removed for clarity, so that only the vault and pillar 2 are shown). The HIK Head domain is boxed. D) The same objects shown in panel C are now shown as surfaces. Superposition of CENP-N ${ }^{\mathrm{Chl} / 4}$ predicts a dramatic steric clash of the nucleosome with the HIK head domain, indicating that the yeast nucleosome structure is not a good predictor for the complex of human CCAN with a CENP-A nucleosome. E) PDB ID 6QLD is displayed as in panel C, but rotated approximately $180^{\circ}$. There are no contacts of pillar 2 with the $\mathrm{Cse} 4^{\mathrm{NCP}}$. F) Human CCAN was modelled onto PDB ID 6QLD by aligning CENP-N on Chl4 as in panel D. The predicted steric clash of HIK head with the Cse $4^{\text {CENP-A }}$ nucleosome could be solved if the HIK head swung out by rotation about the hinge. There are residual predicted clashes of CENP-L with H2A:H2B. Due to the different direction of pillar 2 relative to CENP-N $\mathrm{N}^{\mathrm{Chl}}$ in the yeast and human complexes, pillar 2 adopts a very different orientation

\section{Figure 6. Deep and shallow vaults in CENP-LN orthologs}

A) Superposition of CENP-N and Chl4 in human CENP-LN (respectively in deepteal and firebrick) and Iml3 $3^{\text {CENP-L }}:$ Chl $4^{\text {CENP-N }}$ (respectively in cyan and pink). The curved arrow emphasizes the relative rotation of CENP-L about a hinge point in the dimerization 
domain. B) Gallery of AF2 predictions of vertebrate and yeast CENP-LN orthologs from the indicated species, represented in pLDDT score (blue, high confidence prediction; red, low confidence prediction).

\section{Figure 7. Models of centromere:chromatin interaction}

A) Common features of the CCAN ${ }^{\mathrm{Ct} 19}$ :CENP-A ${ }^{\text {Cset }}$ interaction in yeast and humans. The CENP-L ${ }^{\mathrm{Im} / 3} \mathrm{~N}^{\mathrm{Ch} / 4}$ vault is occupied by dsDNA that emerges from a CENP-A ${ }^{\text {Cse4 }}$ nucleosome that is otherwise not directly integrated in CCAN ${ }^{\mathrm{Ct} 19}$ and only connected to it through $\mathrm{CENP}-\mathrm{C}^{\mathrm{Mif} 2}$, which acts as the crucial link between the nucleosome and the CCAN $^{\mathrm{Ct} 19}$. CENP-C ${ }^{\mathrm{MIf2}}$ is flexible (dotted line), enabling multiple binding modes observed or predicted in yeast and humans. The conserved motif binds the CENP-A $\mathrm{Cse4}^{\mathrm{A}}$ nucleosome. The FIIDE motif is only detected in human CENP-C, but an equivalent region of Mif2 $2^{\text {CENP-C }}$ binds to $\operatorname{Iml} 3^{\text {CENP-L }}$ Chl $4^{\text {CENP-N }}$ in S. cerevisiae (Hinshaw and Harrison, 2013). In the "swung-in" conformation the HID head positions CENP-T $T^{\mathrm{Cnn} 1} \mathrm{~W}^{\mathrm{Wip} 1}$ in the observed "base" position, which can only be reached in the human complex due to the higher divergence of pillar 2 in the yeast complex. A "swung-out" conformation is also shown. B) In this hemisome model CENP-A:H4 faces the pyrin domain of CENP-N. A single filament of dsDNA is allowed inside the CENP-LN vault. The CENP-TW base connected to the HIK-head is in a swung-out conformation that permits an interaction of CENP-A:H4 with H2A:H2B, with which CENP-TW would otherwise crash. CENPQU may contribute, alone or in complex with other proteins, to prevent CENP-A dimerization. C) The same hemisome complex, but with H2A:H2B replaced by CENPTW as expected for the "swung-in" conformation observed in our structures. D) The CDEII core of the yeast point centromere is $\approx 85$-bps-long, and flanked by CDEI and CDEIII motif that associate with Cbf1 and Cbf3. A hemisome model has been proposed for this organism (see main text). E) Another hemisome model may explain depletion of $\mathrm{H} 2 \mathrm{~A}: \mathrm{H} 2 \mathrm{~B}$ at yeast centromeres as well as a function of $\mathrm{Scm} 3$ in preventing Cse4 ${ }^{\text {CENP-A }}$ dimerization. 


\section{Figure Supplement Legends}

\section{Figure 1 - Supplement 1. Biochemical reconstitution of human CCAN}

Size-exclusion chromatography on a Superose 6 5/150 column of the indicated CCAN complexes and subcomplexes A) CENP-C ${ }^{1-544} \mathrm{HIKM}$. B) CENP-LN. C) CENPOPQUR. D) CENP-TWSX. DNA binding is demonstrated by the modest left shift when samples was incubated with DNA. D) CENP-OPQUR. DNA binding is demonstrated by a left shift when sample was incubated with DNA. E) Comparison of elution profiles of CENP-TWSX, CENP-12, and CENP-16. F) CENP-TW binds CENP-12, but CENP-SX requires CENP-TW to interact with it.

\section{Figure 1 - Supplement 2. Pipeline of sample preparation}

The figure presents an outline of the various steps of sample preparation preceding highresolution cryo-EM data collection.

\section{Figure 1 - Supplement 3. Data processing flowchart for Dataset I}

A) Processing flowchart for the high-resolution dataset I including an exemplary micrograph (scale bar $=20 \mathrm{~nm}$ ) and a subset of selected 2D classes of CENP-16. The last (grey) map shows the final reconstruction and was obtained by combining the two focused maps from multibody refinement (using the 'vop maximum' command in UCSF Chimera). B) Angular distribution of the particles shown in two positions rotated $90^{\circ}$ to each other. C) Fourier shell correlation (FSC) plots between two independent half-maps for each of the two bodies used in the multibody refinement procedure, according to the FSC $=0.143$ criterion. The dashed line indicates the 0.143 FSC criterion. red: phaserandomized map, green: unmasked map, blue: masked map, black: corrected map. D) Local resolution estimates by RELION for dataset I plotted on the two multibody reconstructions in a rainbow-colored gradient from blue $(3.7 \AA)$ to red $(12 \AA)$. The map differs from the final reconstruction depicted in panel A since the latter shows the combined sub-maps, further modified by DeepEMhancer.

\section{Figure 1 - Supplement 4. Data processing flowchart for Dataset II}


A) Processing flowchart for the low-resolution dataset II including an exemplary micrograph and a subset of selected 2D classes of CENP-14. B) Angular distribution of the particles shown in two positions rotated $90^{\circ}$ to each other. C) Fourier shell correlation (FSC) plots between two independent half-maps for each of the three bodies used in the last multibody-refinement, indicating the resolution of the three groups in the multibody refinement according to the FSC $=0.143$ criterion. . The dashed line indicates the 0.143 FSC criterion. red: phase-randomized map, green: unmasked map, blue: masked map, black: corrected map. D) Local resolution estimates by RELION plotted on the multibody reconstructions in a rainbow-colored gradient from blue $(8 \AA)$ to red (25 A). E) Representative density of CENP-QU head (left), the CENP-TW complex (middle) and the HIK head (right), as seen from the "bottom" towards the top of the CCAN complex in D).

\section{Figure 1 - Supplement 5. Close-ups of density maps}

A) Density for CENP-C 303-FIID-306 bound to CENP-N. B) Representative density of the region with highest resolution around CENP-M. C) Density at the CENP-LN $\beta$ sheet interface.

\section{Figure 1 - Supplement 6. Sequence alignments of human and yeast CCAN}

Secondary structure elements of yeast CCAN (PDB ID 6QLE) were aligned to the human CCAN structure by keeping the molecular shapes and relative orientations as similar as possible. Structure-based alignments were computed by Chimera. The secondary structures for the yeast proteins were assigned by DSSP (Kabsch and Sander, 1983) from the original yeast structures with PDB ID 6QLE and 6WUC. $\alpha$-helices are shown in red, $3_{10}$ helices in orange, and $\beta$-sheets in green. Sequences are colored according to the ClustalX coloring scheme.

\section{Figure 2 - Supplement 1. Comparative interaction of pillar 2 with the vault}

A) Cartoon model of pillar 1 and CENP-L in the vault for human CCAN demonstrates extensive interactions, as already illustrated in Figure 2E-F. B) The equivalent region in the $S$. cerevisiae complex shows a much more modest interface that is limited to the 
Iml3 ${ }^{\text {CENP-L. }}{ }^{\text {Ctf }} 3^{\text {CENP-I }}$ pair and that further emphasizes the role of CENP-M as stabilizer of the human complex.

\section{Figure 2 - Supplement 2. Gallery of EGFP-CENP-M cell cycle localization}

Maximum intensity projections of $5 \times 0.2 \mu \mathrm{m}$ Z-stacks. For Early G1 cells, the orange arrowhead indicates the spindle midbody remnant. Tubulin and DNA were the chosen markers to illustrate mitotic figures. PCNA and cytosolic Cyclin B1 were the chosen markers to illustrate S-phase and G2 phase.

\section{Figure 3 - Supplement 1. DNA binding by CCAN subunits}

Size-exclusion chromatography on a Superose $65 / 150$ column of the indicated samples to monitor protein:DNA binding using 75-bps and 165-bps DNA. A) CENP-LN. B) CENP-HIKM. C) CENP-C ${ }^{1-544}$ HIKM. DNA binding is demonstrated by the modest left shift when samples was incubated with DNA. D) CENP-OPQUR. DNA binding is demonstrated by a left shift when sample was incubated with DNA. E) CENP-TWSX bound strongly to DNA. F) The combined CCAN subunits in CENP-12 bound DNA with substantial affinity.

\section{Figure 4 - Supplement 1. 2-fold pseudosymmetry in the human vault}

A) Left. Cartoon model of human CCAN bound to DNA. The DNA fragment was extracted from PDB ID 6COW (CENP-N N-terminal region bound to CENP-A nucleosome (Pentakota et al., 2017)) from the DNA gyre facing CENP-N after superposition of CENP-N. Right. A 2-fold pseudosymmetry axis links the two LNHDs and the modelled DNA. Related views are shown in Figure 4F-G. B) Left. View of the $S$. cerevisiae's Ctf19 ${ }^{\mathrm{CCAN}}$ :nucleosome complex (PDB ID 6QLD (Yan et al., 2019)) with the same orientation from which the human complex is viewed in panel A. Right. In the yeast complex, the 2-fold pseudosymmetry axis relating the LNHDs of CENP-LN is offset relative to the experimentally determined position of the DNA. The LNHD of Chl4 ${ }^{\text {CENP- }}$ $\mathrm{N}$ is displayed with the same orientation as the human's shown in panel A. C) View from PDB ID 6QLD where only the vault and the nucleosome are displayed. D) As in panel C, but from a different orientation to emphasize lack of contacts of $\mathrm{Iml} 3^{\text {CENP-L }}$ with the DNA and nucleosome. 


\section{A}

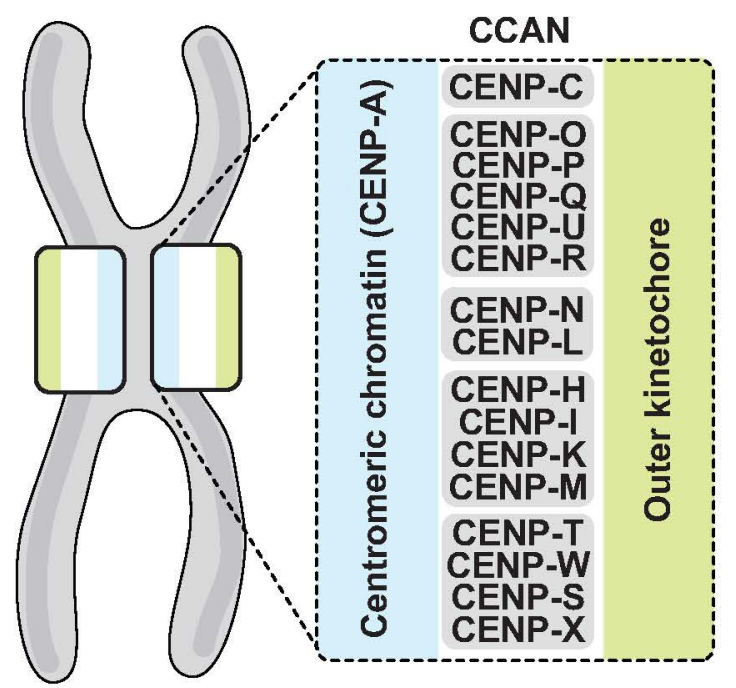

C

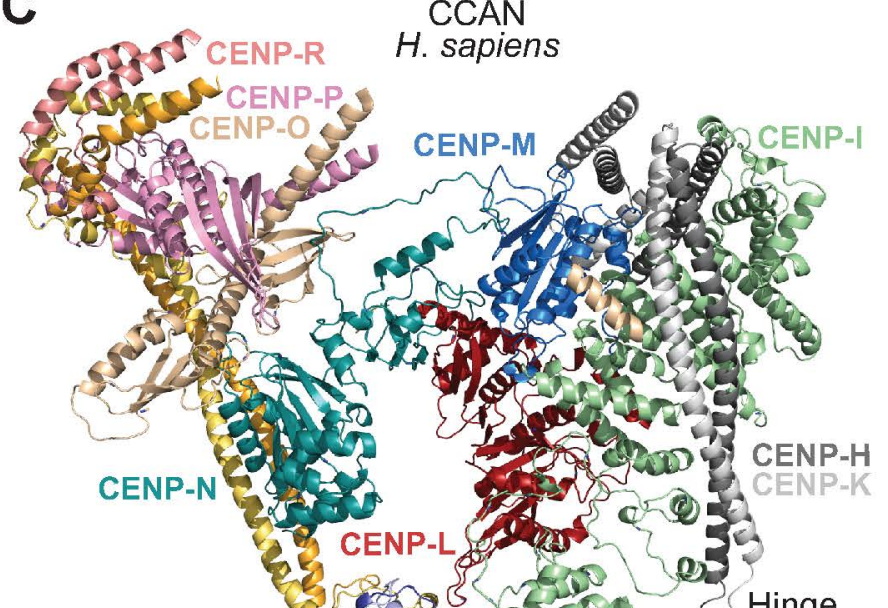

CENP-Q

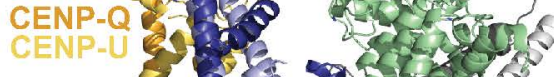
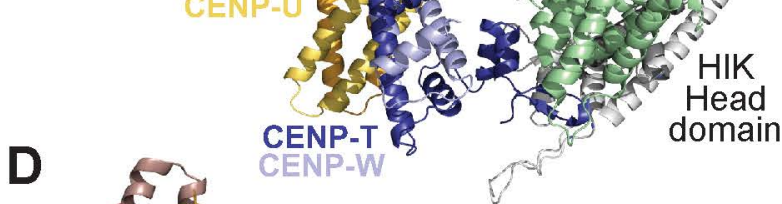

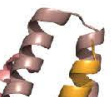
8925

Ctf19

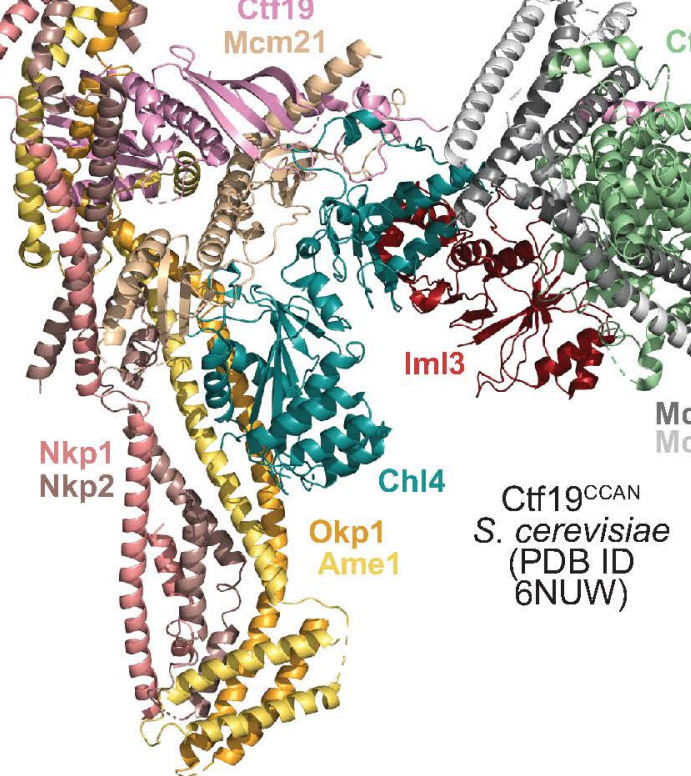

Pillar 1 not displayed

\section{B}

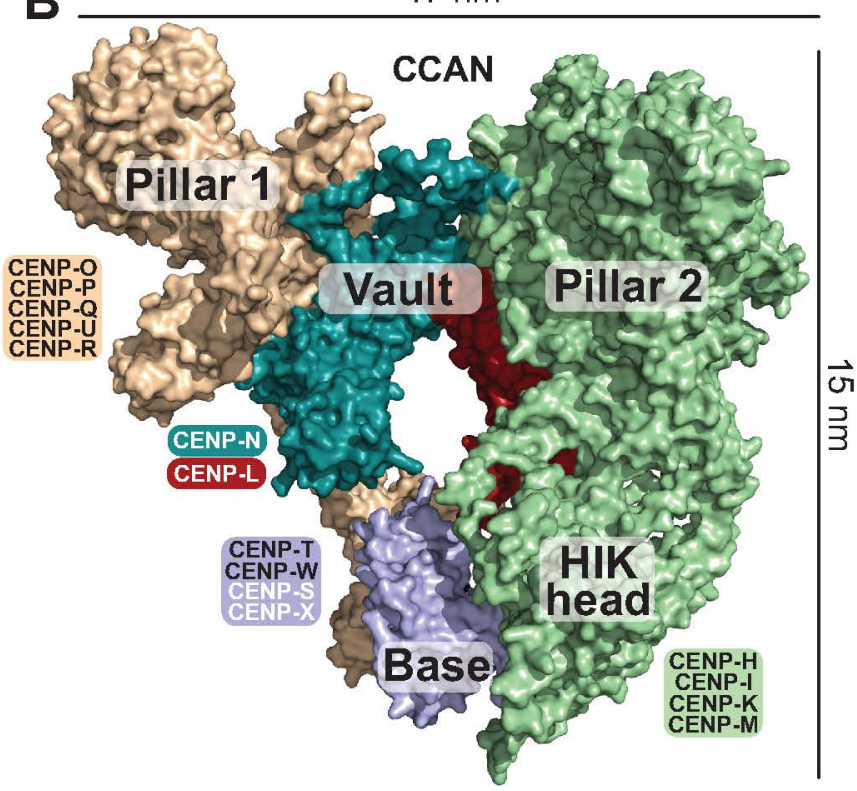
E CCAN
H. sapiens
Pillar 1 and Base

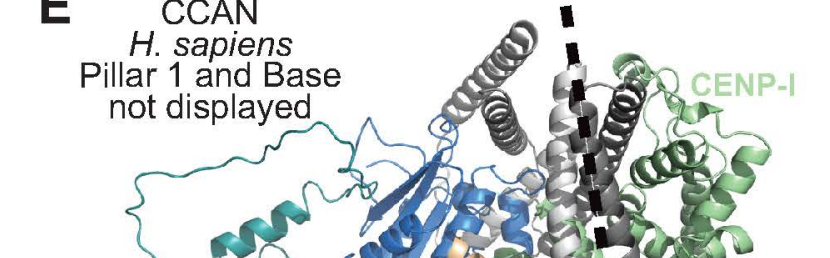

\section{$\vec{r}$}
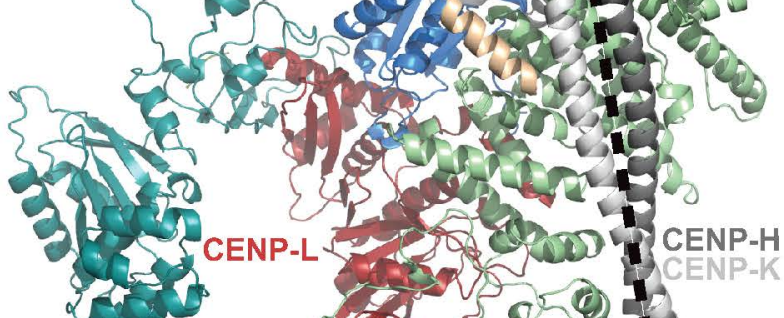

CENP-N

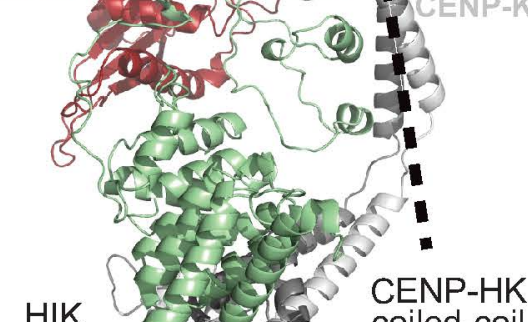

HIK

intic

Head domain

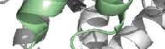
axis
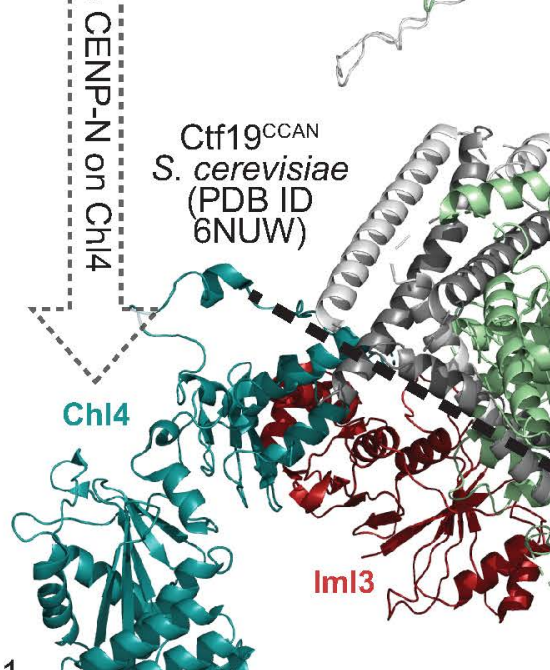

d

tरि
Mcm16-22

coiled-coil axis 


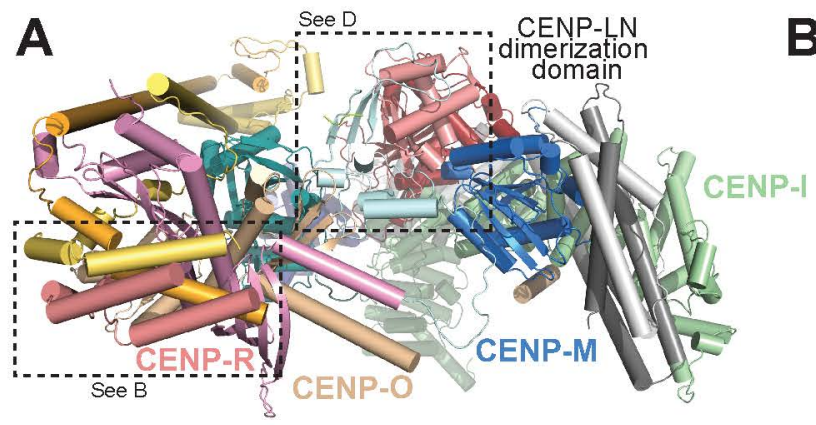

C

259-KKSFSTLFLETVKRKSESSPI VRHAATAPPHSCPPDDTKLIEDEFI IDESDQSFASRS WITIPRKAGS-326
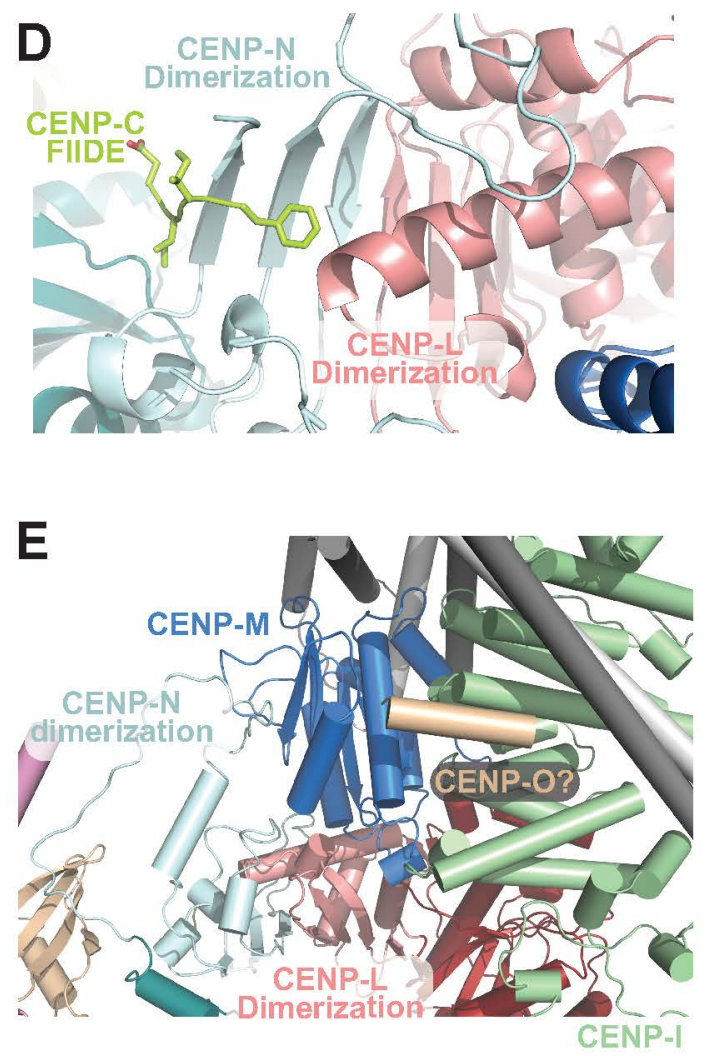

$\mathbf{F}$

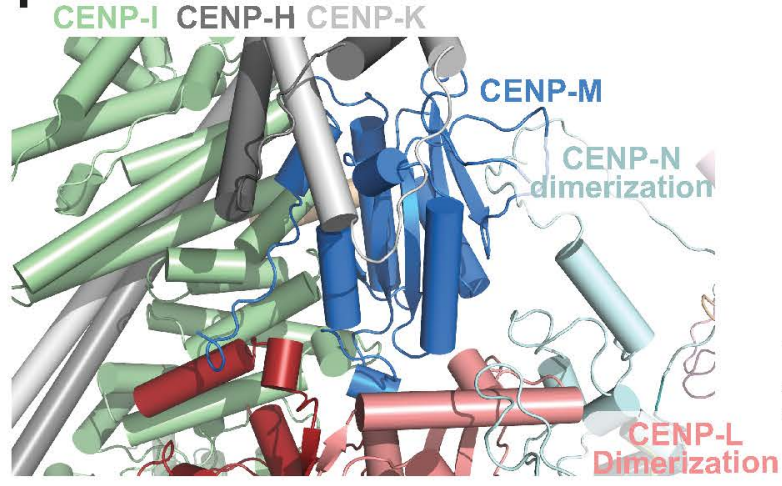

B

G

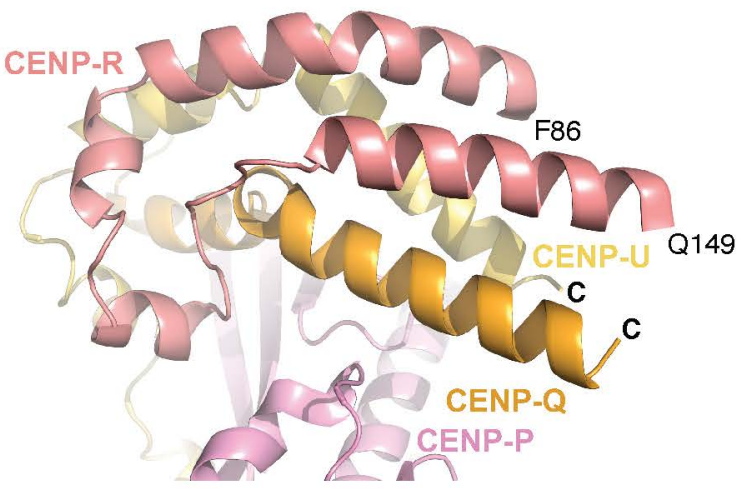

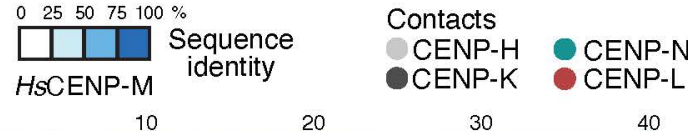

MSVLRPLDKLPGLNTATILLVGTEDALLQ'́LADSMLKEDCASEL $\begin{array}{llll}n 50 & 60 & \text { P-loop } & 70\end{array}$ KVHLAKSLPLPSSVNRPRIDL IVFVV'NLHSKYSLQNंTEESLRHV - -

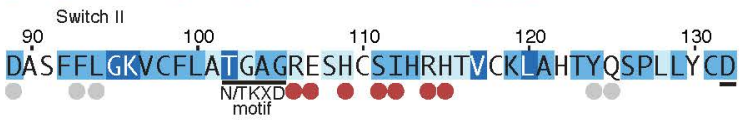
$140 \quad 150 \quad 160 \quad 170$

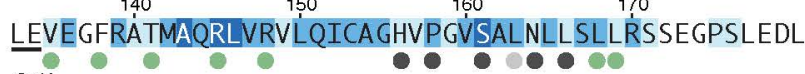
SAK
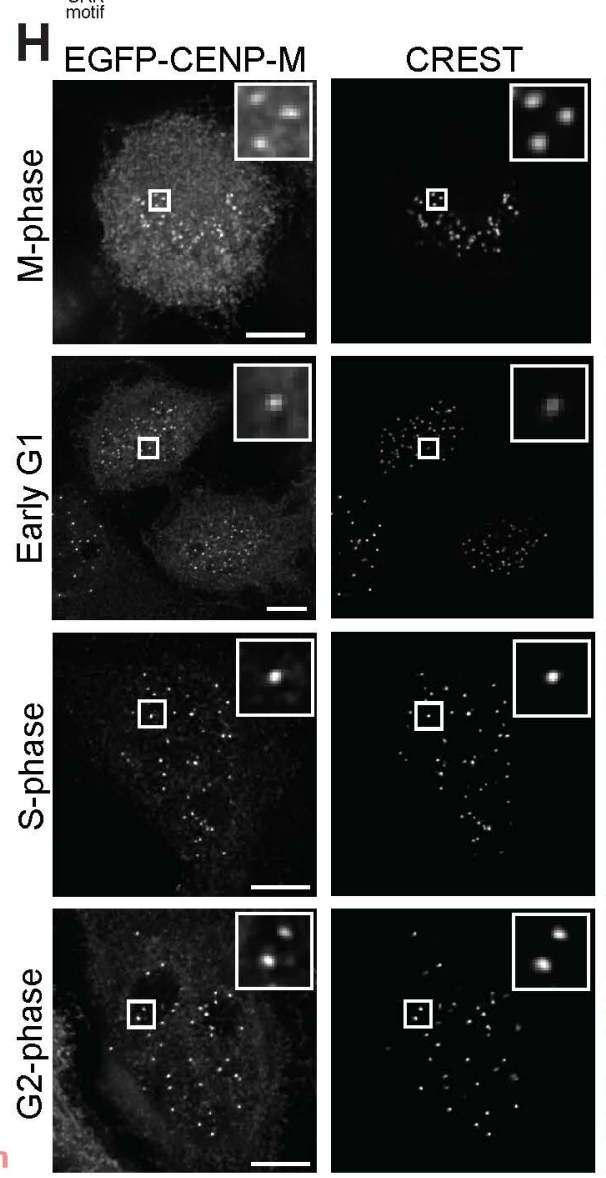
EGFP-CENP-M
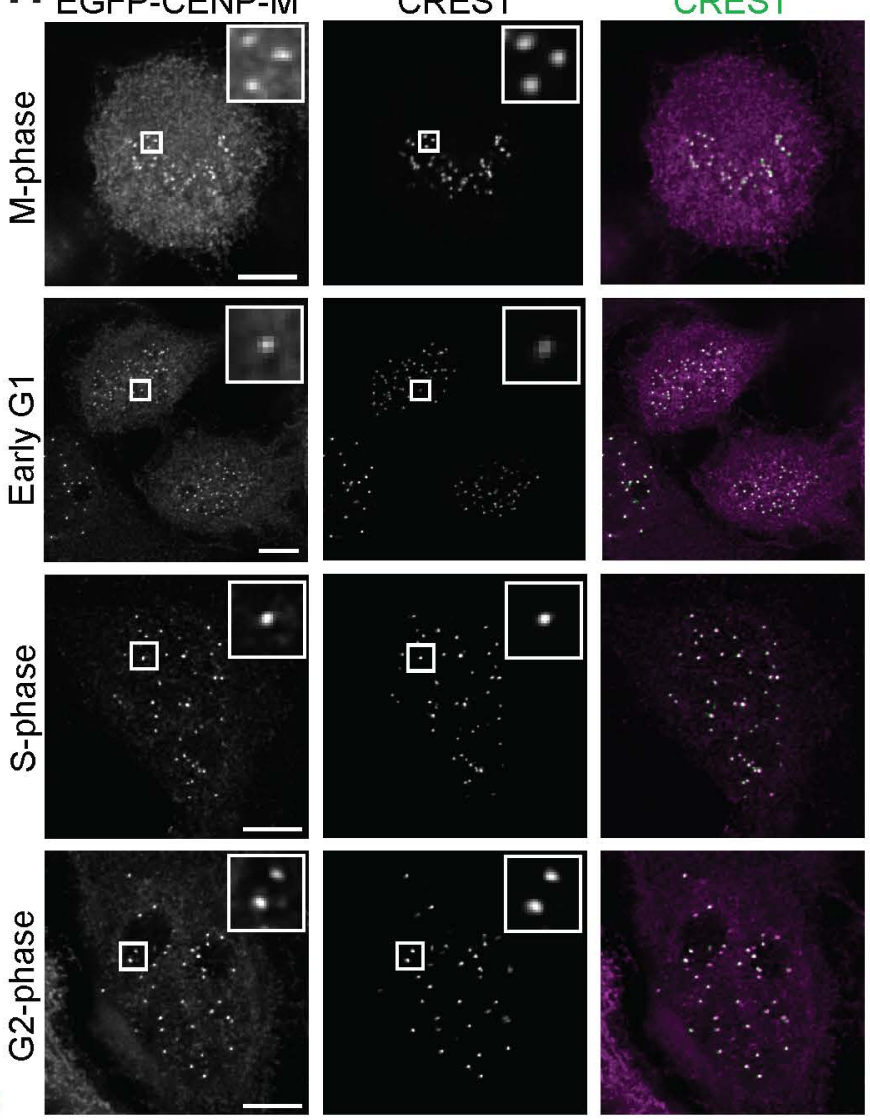

Figure 2 
bioRxiv preprint doi: https://doi org/10.1101/2022 01 06 475204 this version posted January 6, 2022. The copyright holder for this preprint

(which was not certified by peer review) is the author/funder, who has granted bioRxiv a license to display the preprint in perpetuity. It is made available under aCC-BY-NC 4.0 International license.
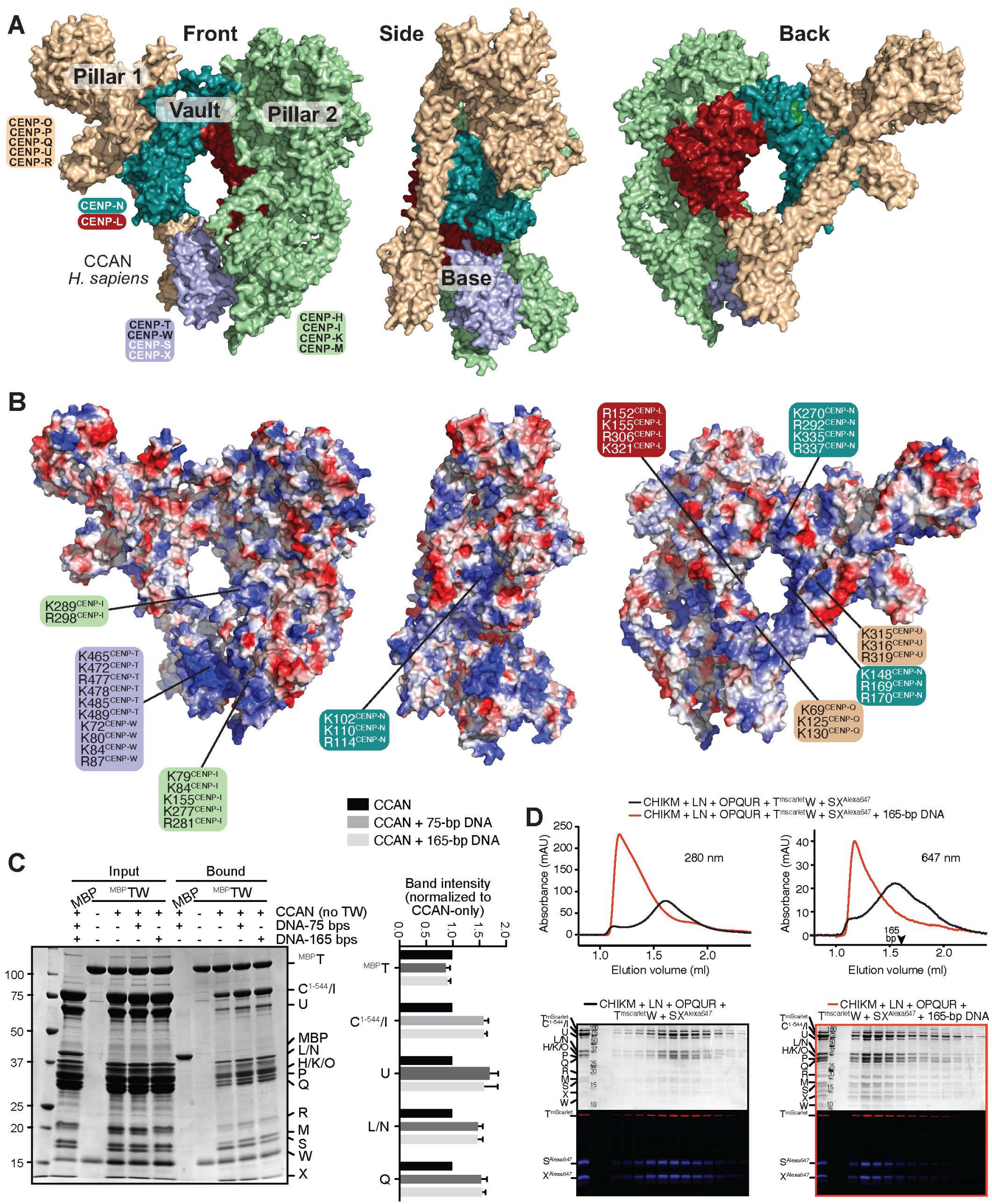

Figure 3 
bioRxiv preprint doi: https://doi.org/10.1101/2022 01.06 475204; this version posted January 6, 2022. The copyright holder for this preprint

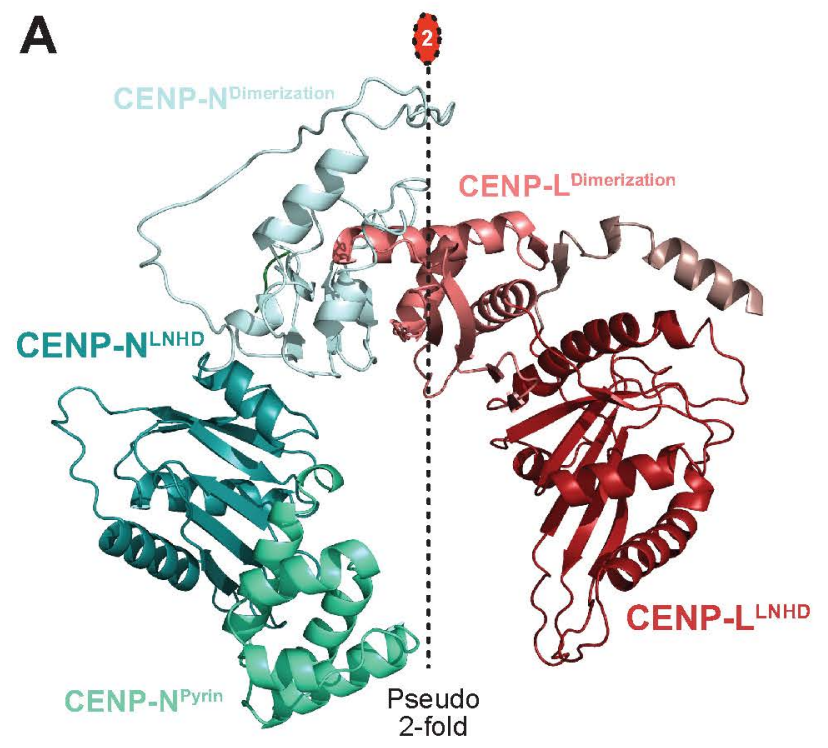

C

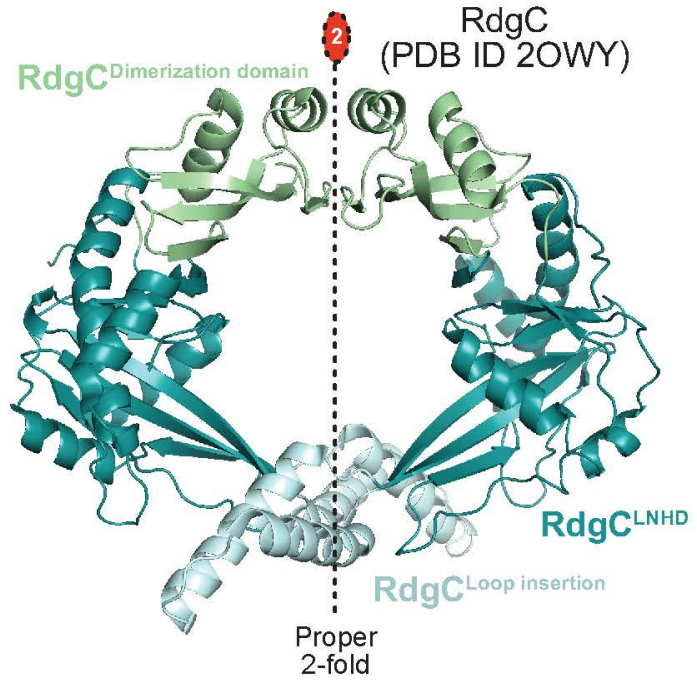

D

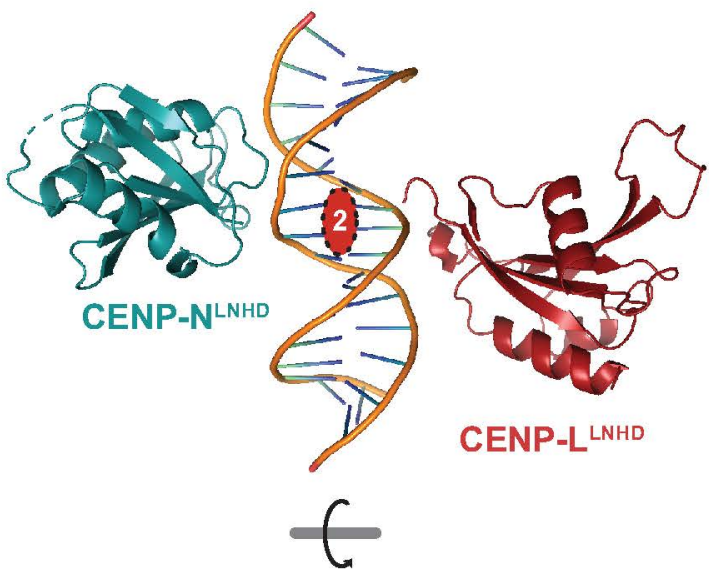

E

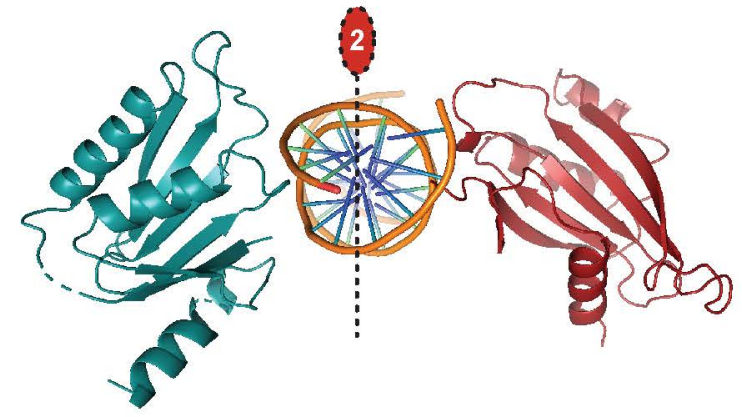

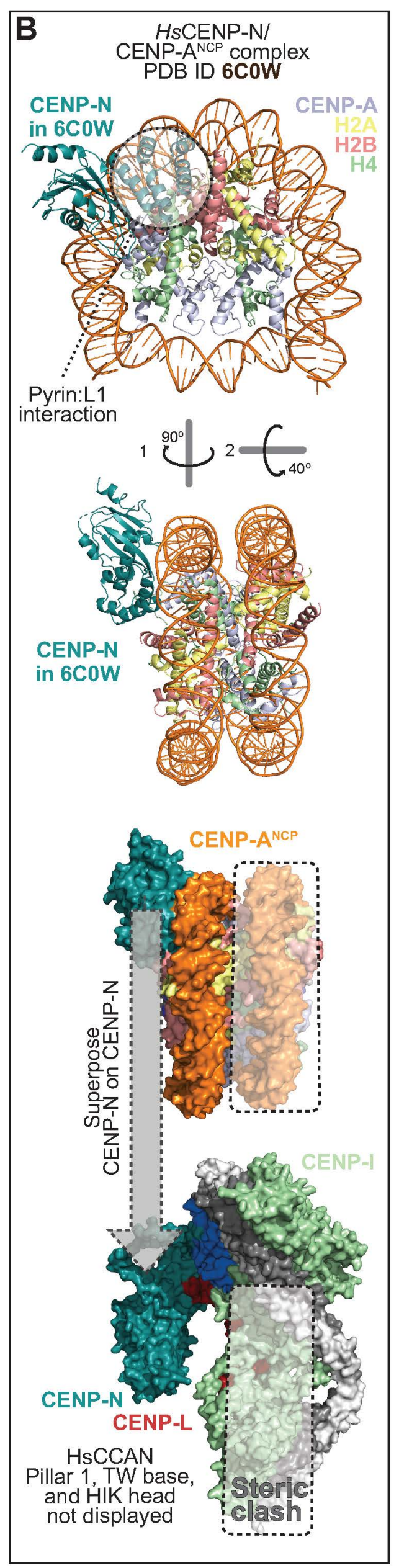



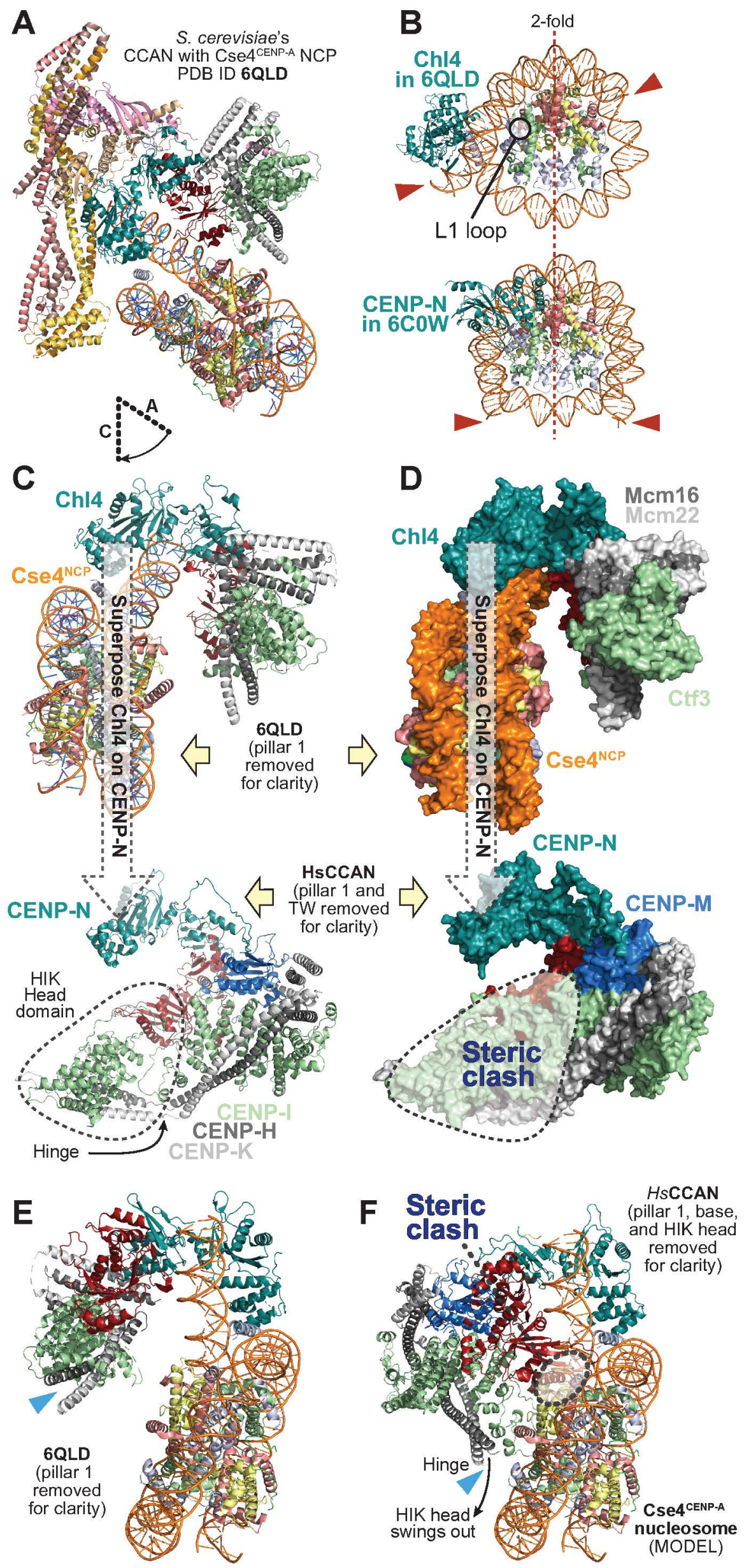

Figure 5 

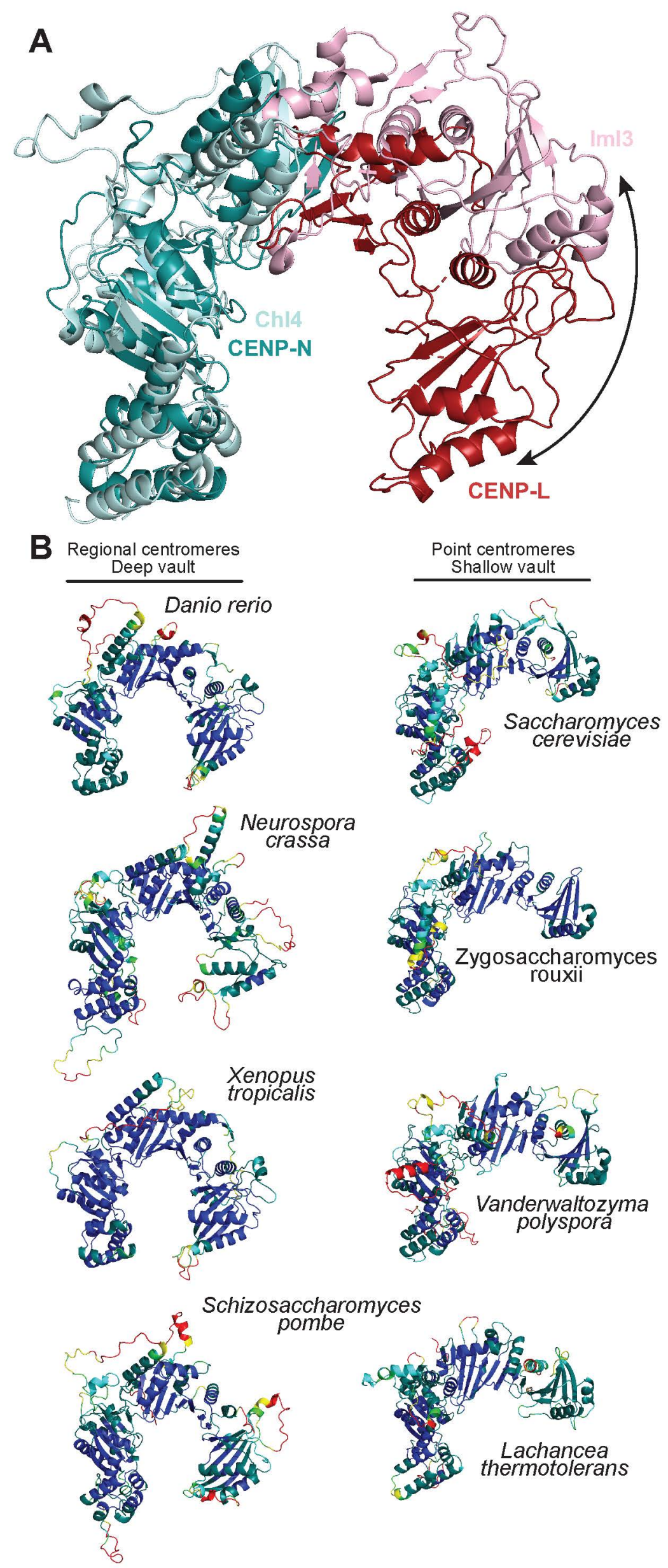

Figure 6 
bioRxiv preprint doi $\mathrm{https}$ ://doi. org/10.1101/2022 01.06 475204 this version posted January 6, 2022. The copyright holder for this preprint

A
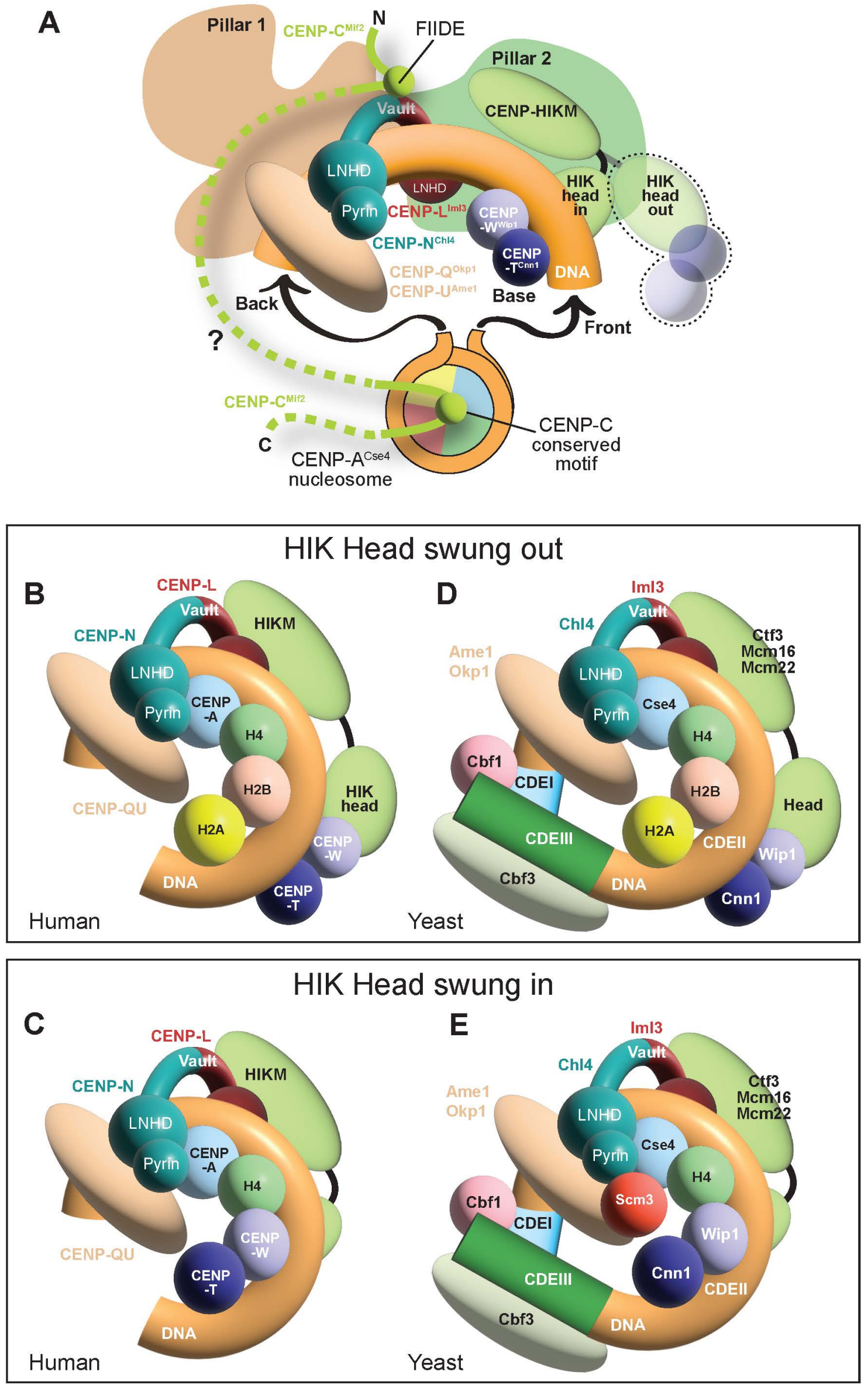

Figure 7 
Supplementary Table 1 - Cryo-EM data collection, refinement and validation statistics

\begin{tabular}{|l|l|l|}
\hline CCAN Krios2 EMDB-14098 & $\begin{array}{l}\text { CCAN Krios1 EMDB-14099 } \\
\text { ("dataset II") }\end{array}$ \\
\hline
\end{tabular}

\section{Data collection and processing}

Magnification

$130000 \mathrm{x}$

300

76.8

-0.6 to -1.2

$0.7 / 0.35$

C1

140910

22853

4.6

0.143
$105000 \mathrm{x}$

300

55.8

-0.6 to -1.2

$0.68 / 0.34$

C1

233598

44216

10

0.143

\section{Refinement}

Initial model used:

Alphafold,6EQT,4WAU,6WUC, 6QLD, 6QLE

Model resolution $(\AA)$

3.8

FSC threshold

0.143

Model composition

Non-hydrogen atoms

24952

Protein residues

3086

B-factors $\left(\AA^{2}\right)$

Protein

47.8

R.m.s. deviations

Bond length $(\AA)$

0.0035

Bond angles $\left({ }^{\circ}\right)$

0.84

Validation

MolProbity score

1.61

Clashscore

5.14

Poor rotamers (\%)

1.53

Ramachandran plot

Favored (\%)

96.8

Allowed (\%)

3.13

Disallowed (\%)

0.07 

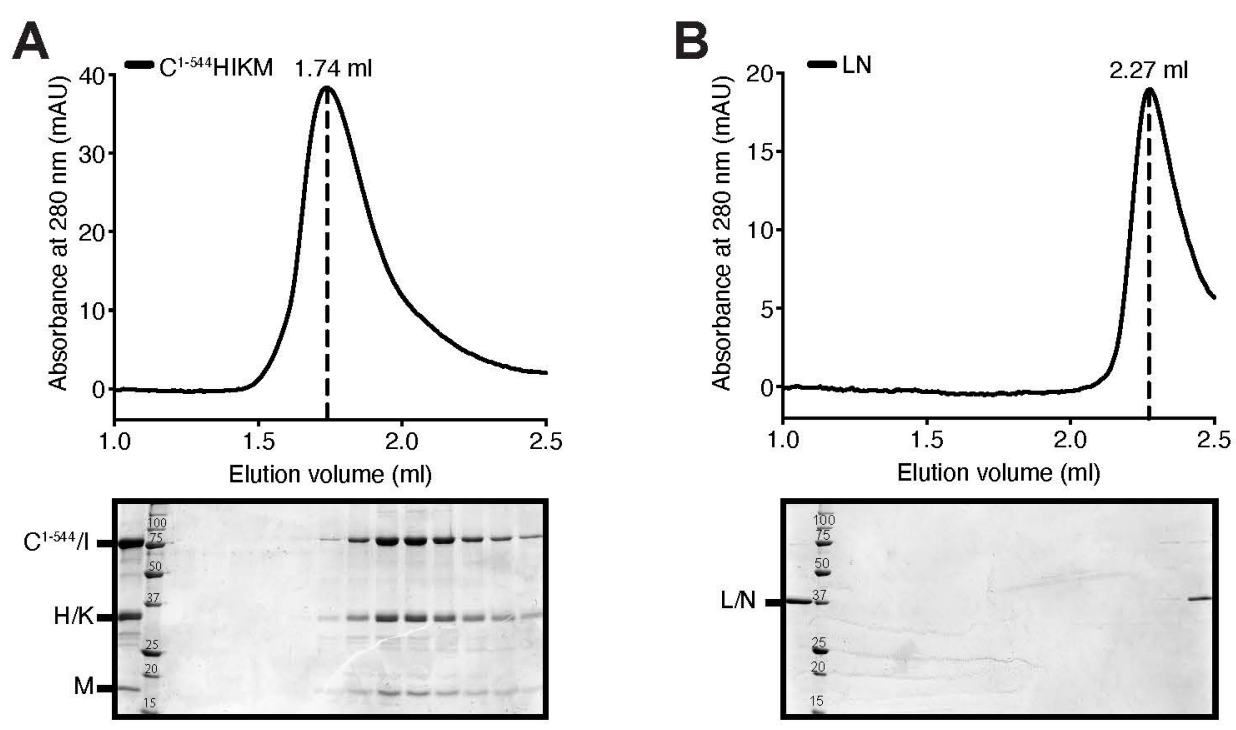

C
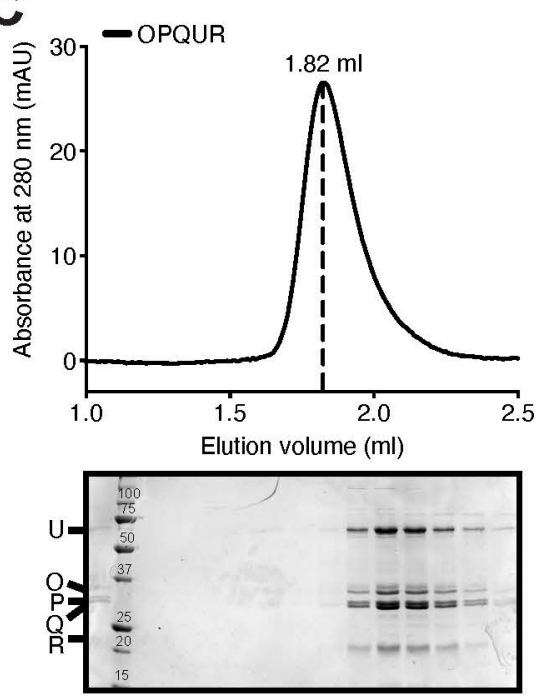

D

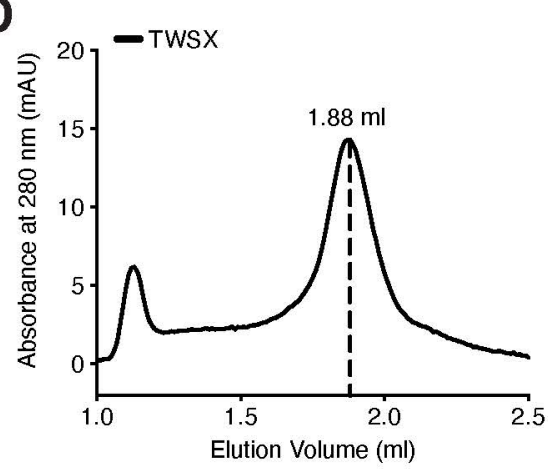

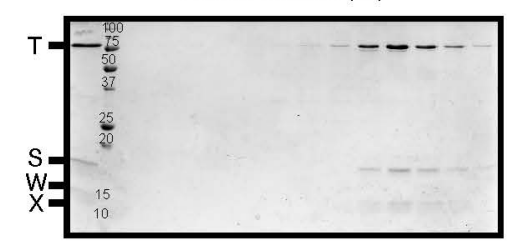

E $-\mathrm{C}^{1-544} \mathrm{HIKM}+\mathrm{LN}+\mathrm{OPQUR}+\mathrm{TWSX}$

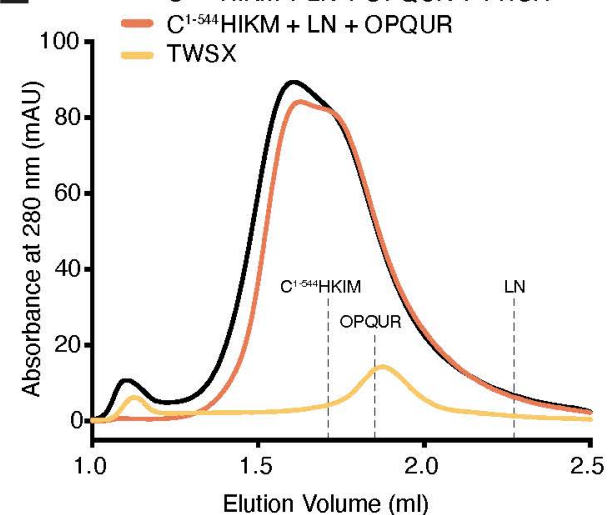

$\mathbf{F}$

- 1 CHIKMLNOPQUR

-3 CHIKMLNOPQUR $\times$ TW
-6 CHIKMLNOPQUR $\times$ SX

$=7$ CHIKMLNOPQUR $x$ TW $x$ SX
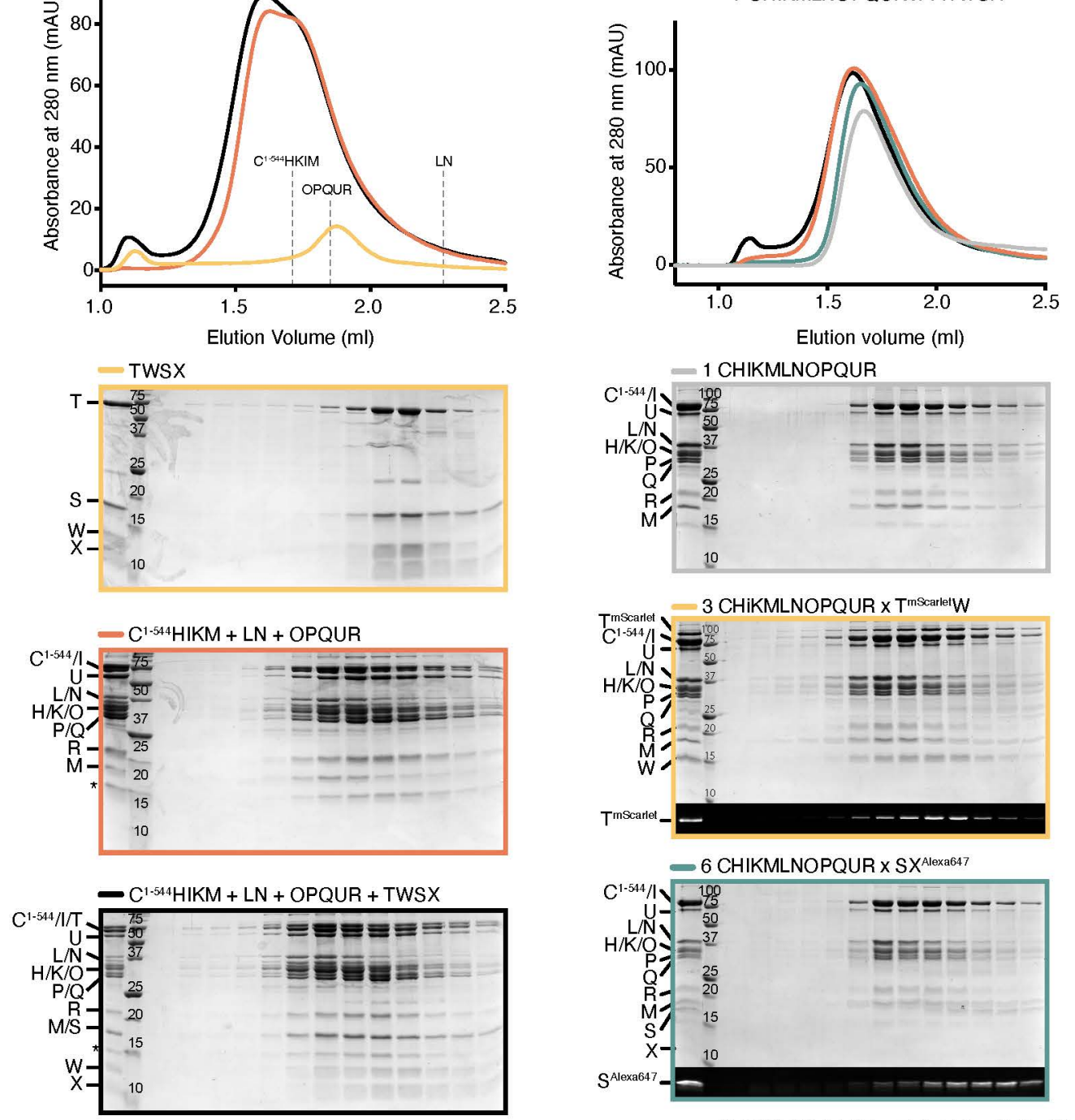

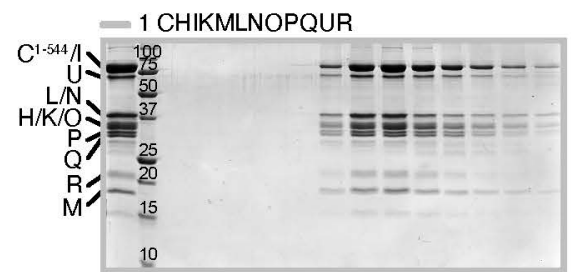

-3 CHIKMLNOPQUR $\times T^{\text {mscarlet } W}$

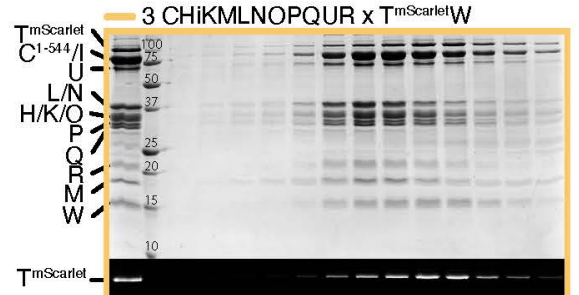

-6 CHIKMLNOPQUR $x$ SX $X^{\text {Alexa647 }}$

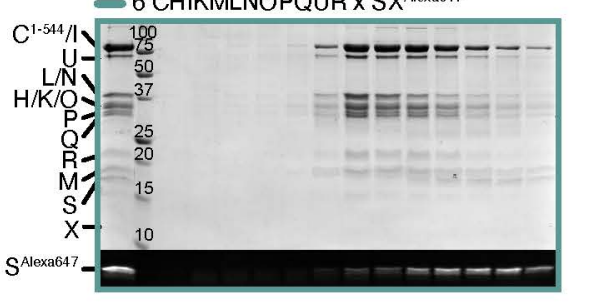

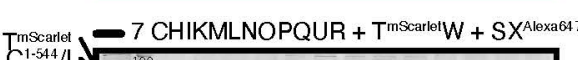

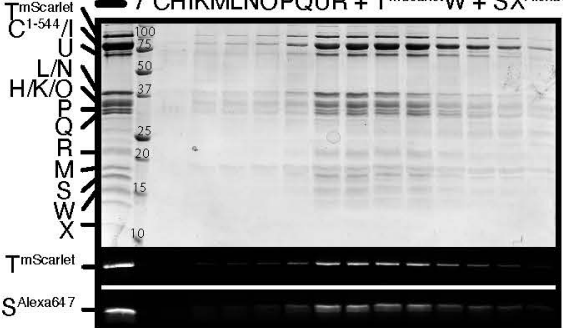

Figure 1 - Supplement 1 
bioRxiv preprint doi: https://doi.org/10.1101/2022 01 06 475204 this version posted January 6, 2022. The copyright holder for this preprint (which was not certified by peer review) is the author/funder, who has granted bioRxiv a license to display the preprint in perpetuity. It is made available under aCC-BY-NC 4.0 International license.

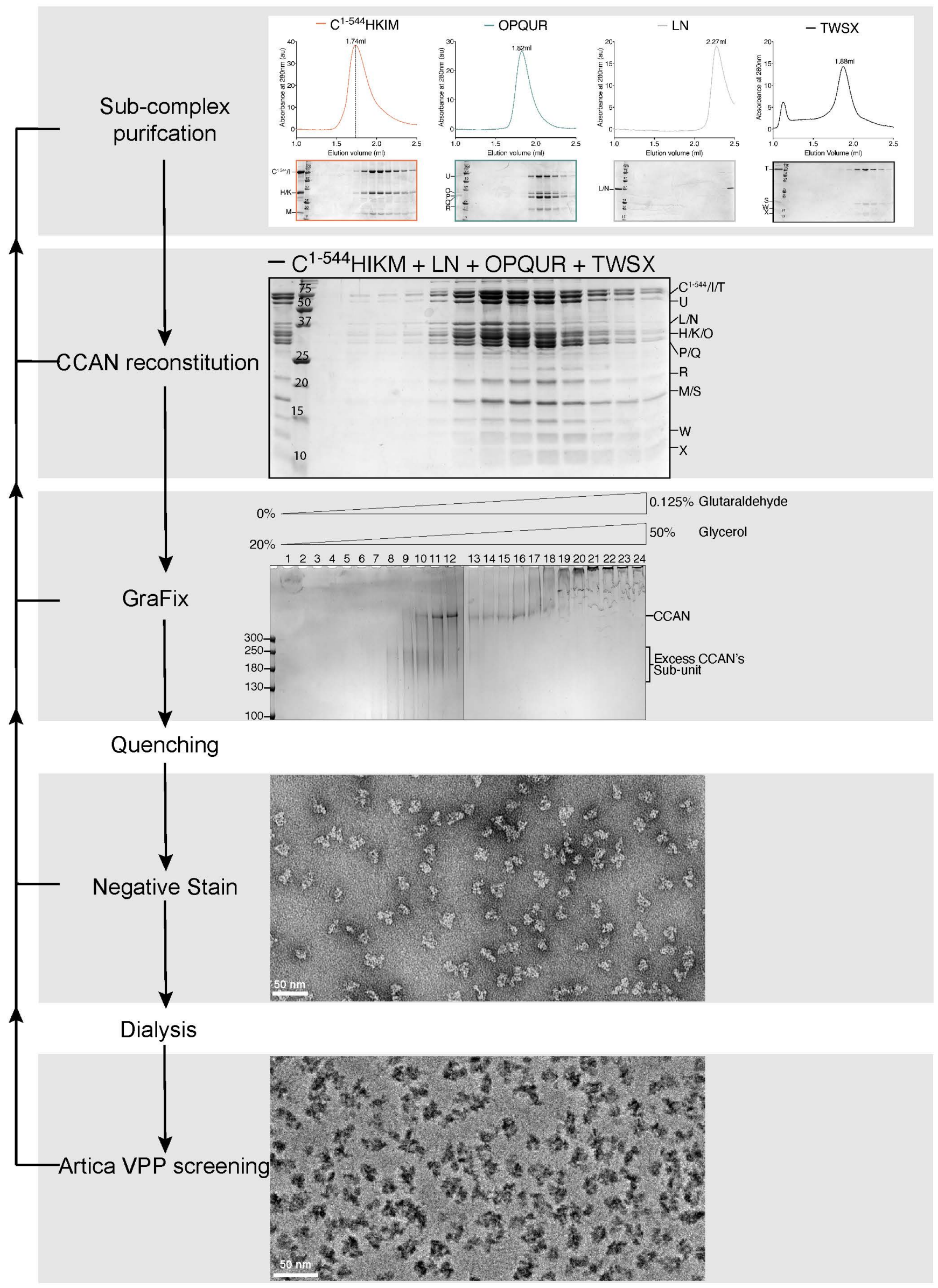

Figure 1 - Supplement 2 
bioRxiv preprint doi: https://doi.org/10.1101/2022.01.06.475204; this version posted January 6, 2022. The copyright holder for this preprint

(which was not certified by peer review) is the author/funder, who has granted bioRxiv a license to display the preprint in perpetuity. It is made available under aCC-BY-NC 4.0 International license.

A

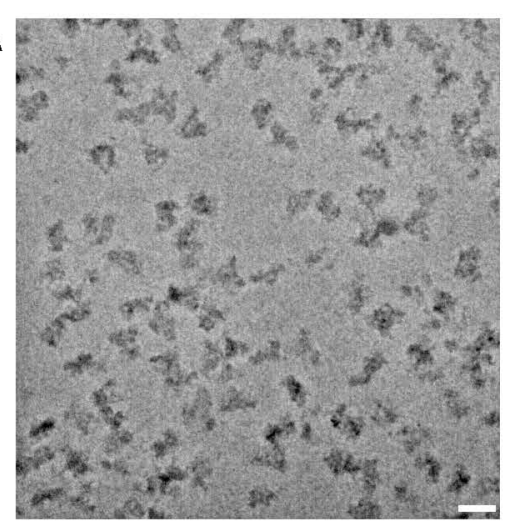

Dataset I

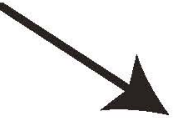

140910 particles

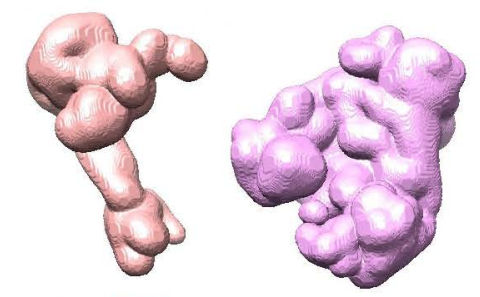

multibody submasks
Multibody refinement (2 groups)

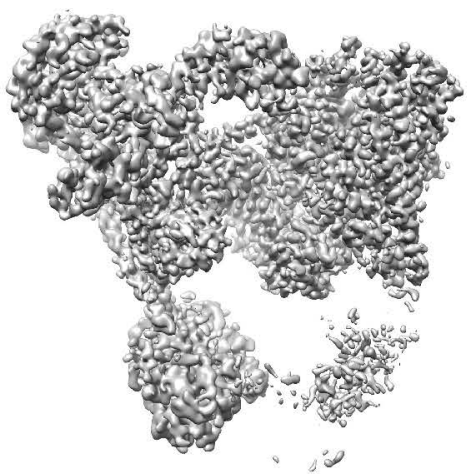

D

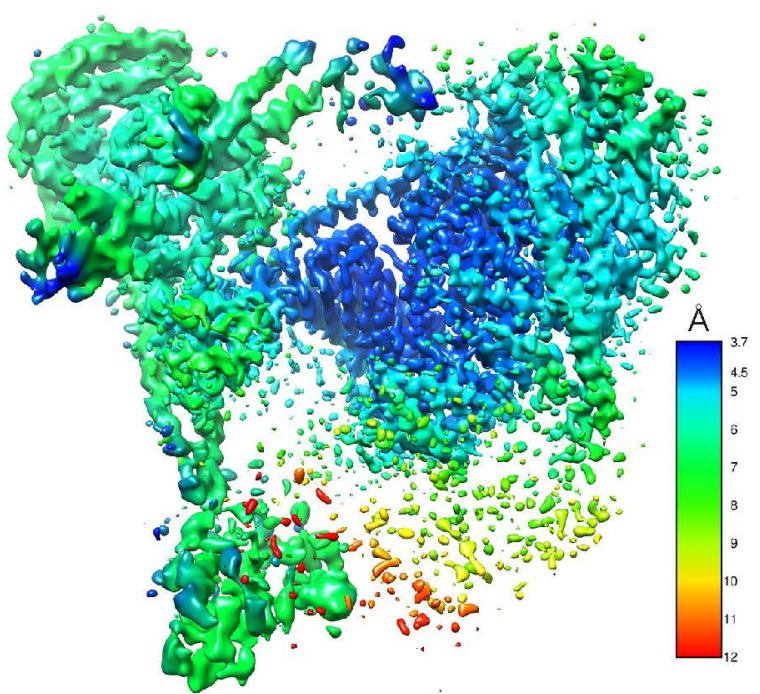

B

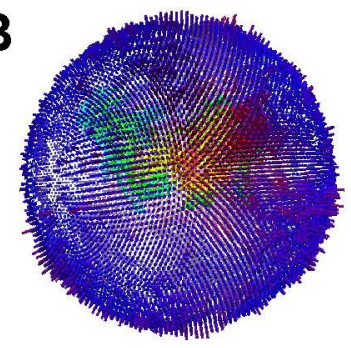

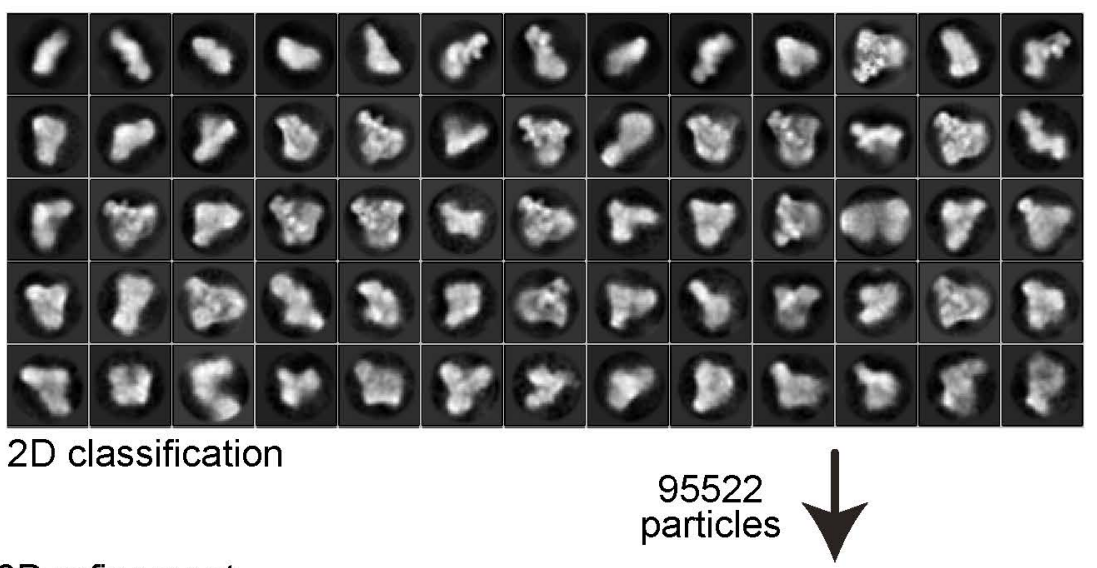

3D refinement

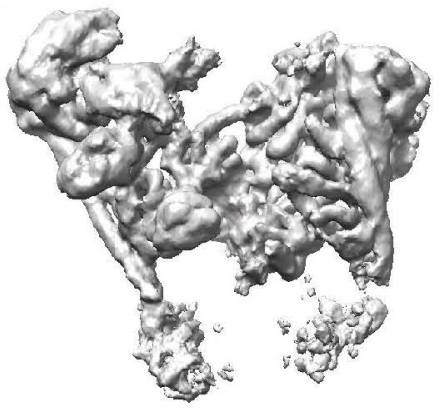

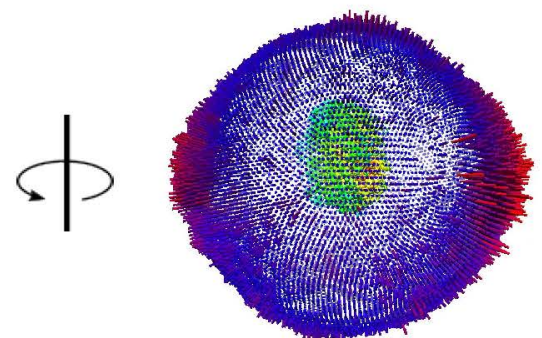

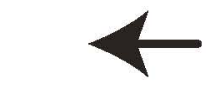

3D classification 25206 particles

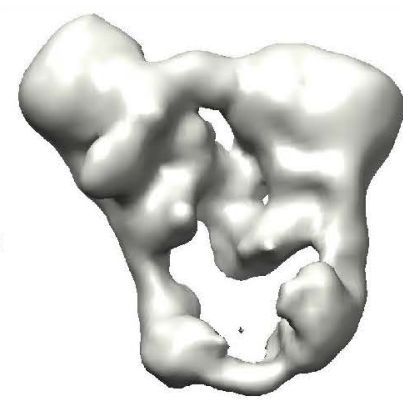

initial model
C
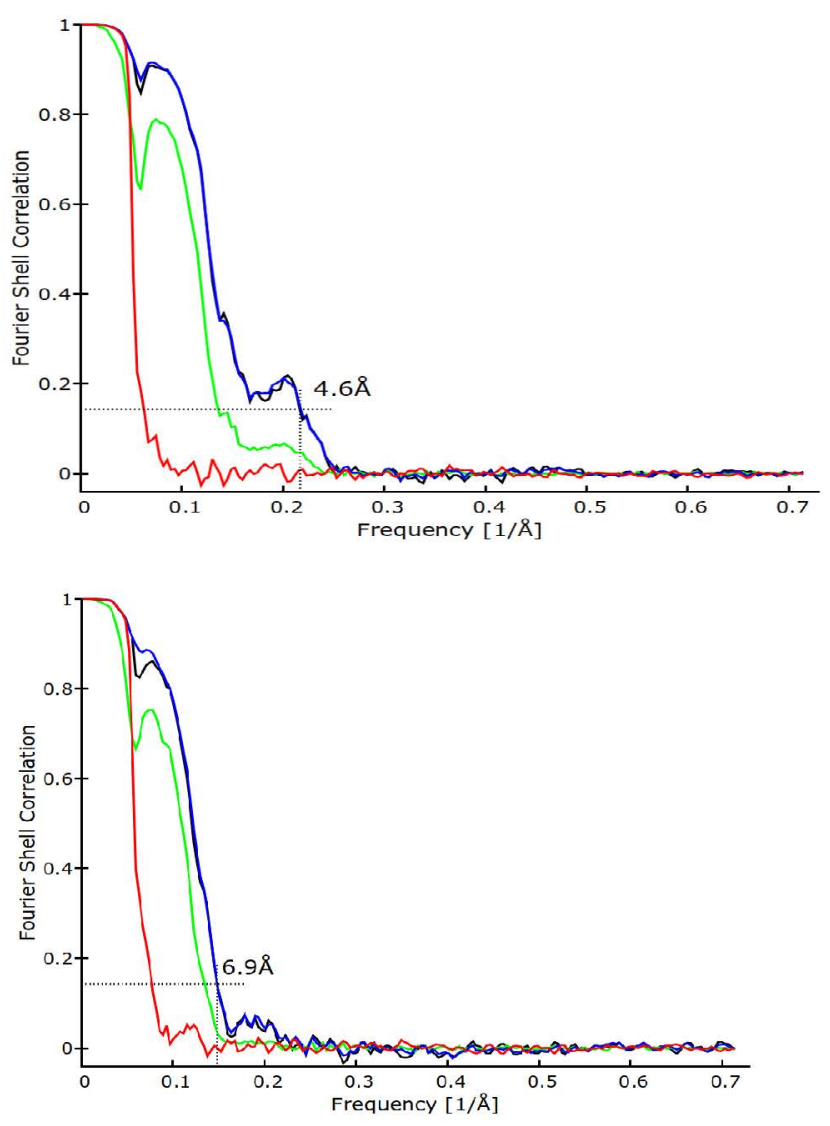
bioRxiv preprint doi: https://doi.org/10.1101/2022.01.06.475204 this version posted January 6, 2022. The copyright holder for this preprint

(which was not certified by peer review) is the author/funder, who has granted bioRxiv a license to display the preprint in perpetuity. It is made available under aCC-BY-NC 4.0 International license.

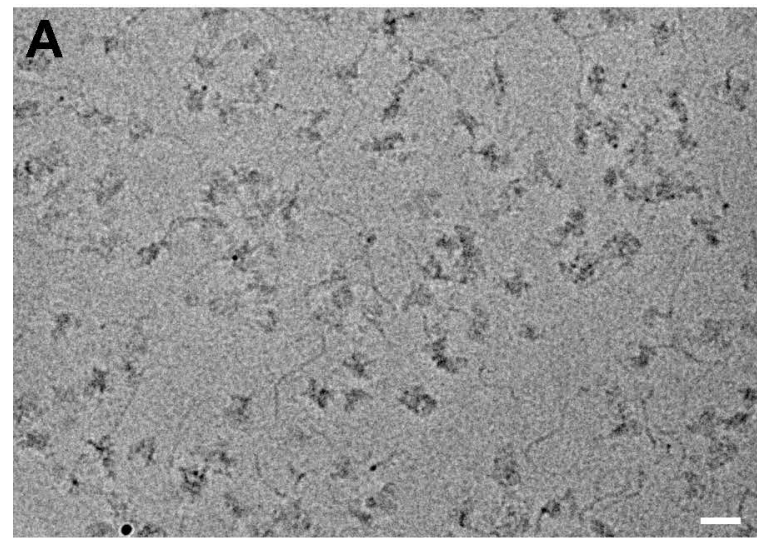

Dataset II
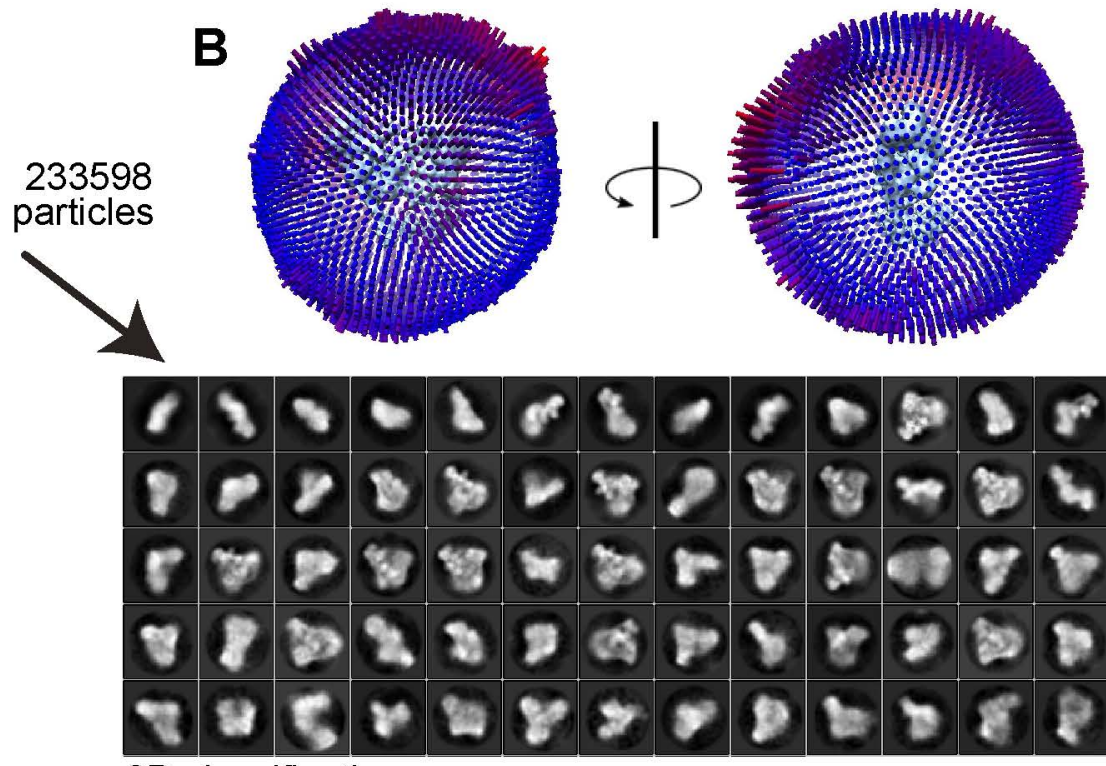

Multibody

refinement

(3 groups)

2D classification:
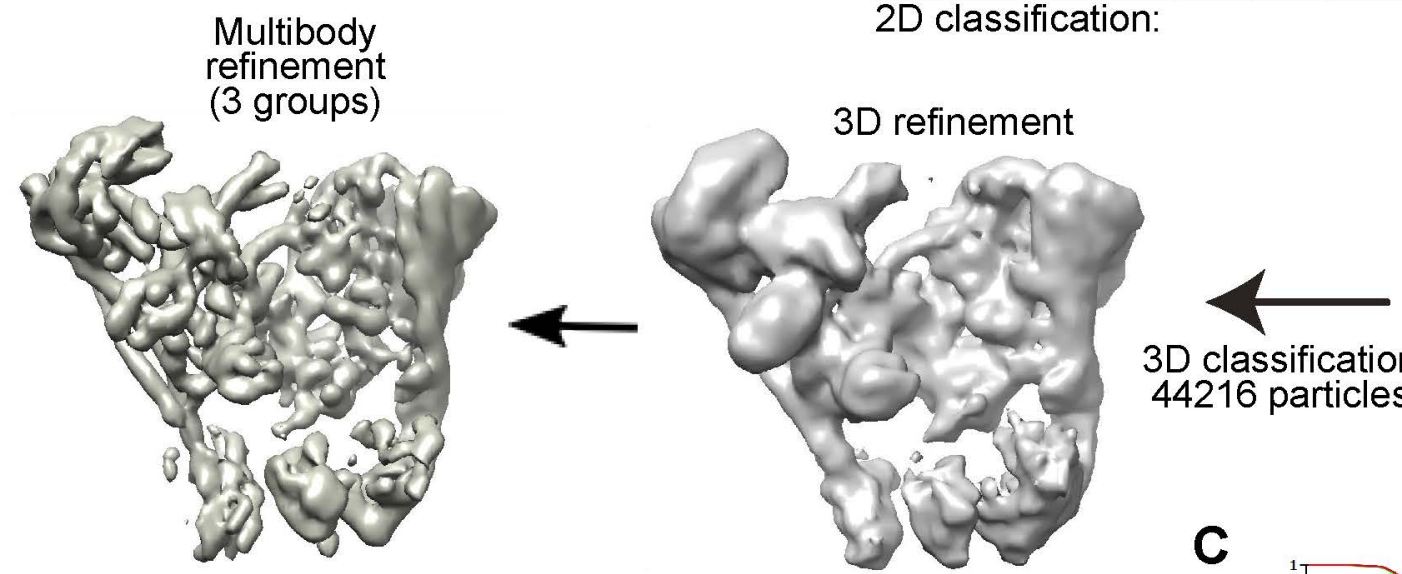

3D classification

44216 particles

initial

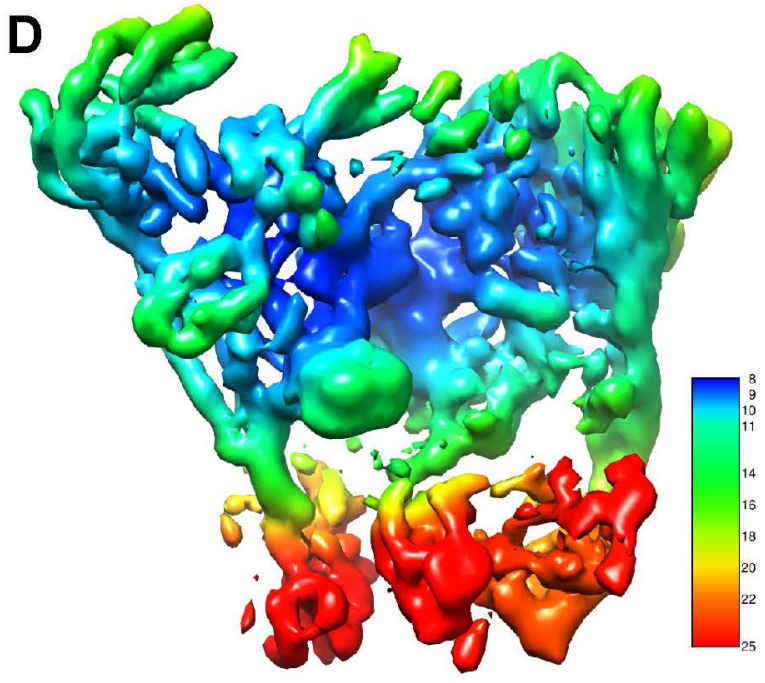

E

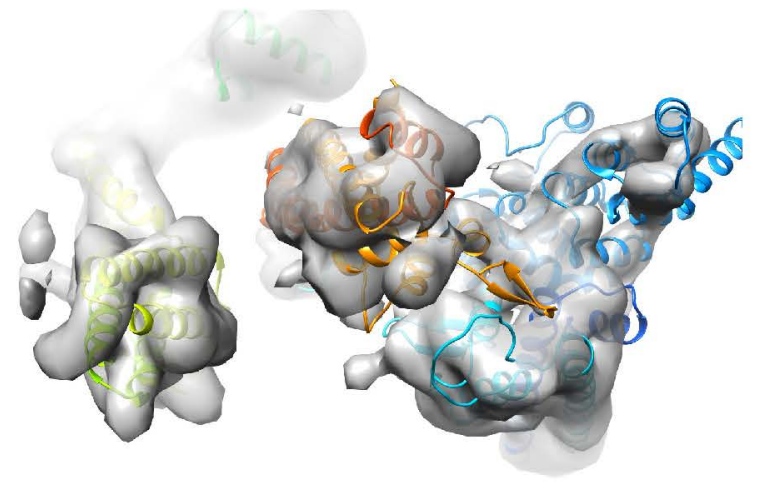

C
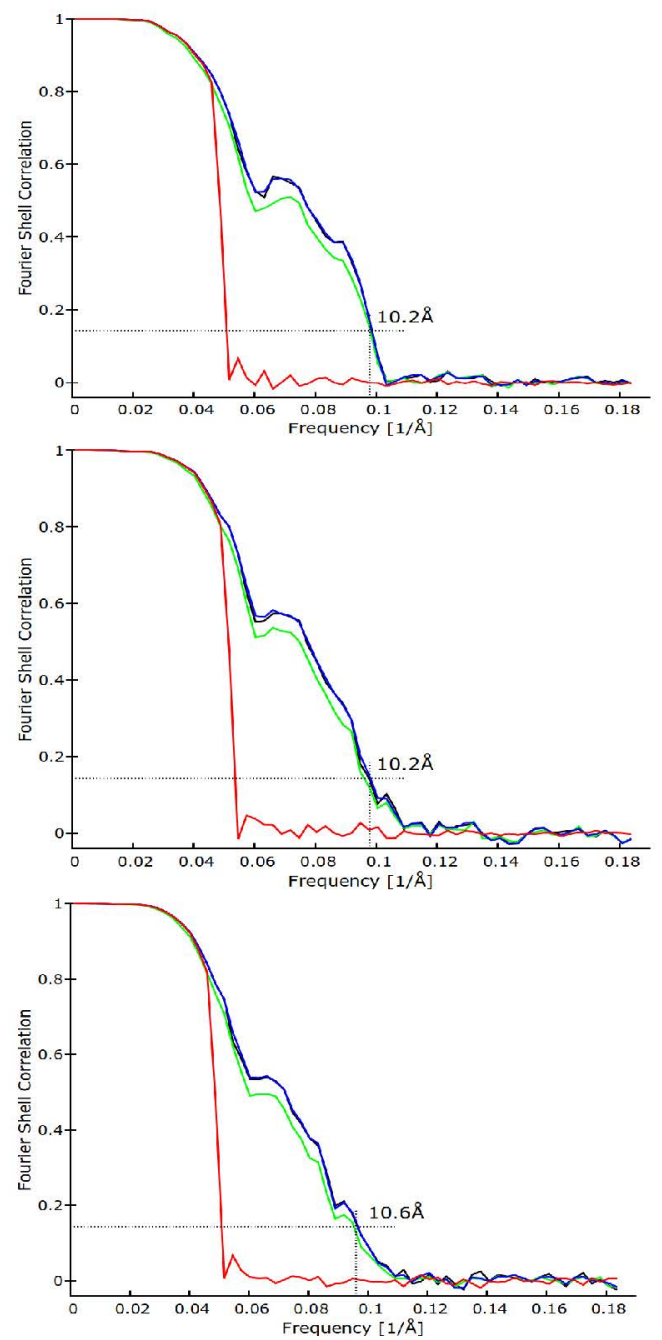
bioRxiv preprint doi: https://doi.org/10.1101/2022 0106 475204 this version posted January 6,2022 . The copyright holder for this preprint

(which was not certified by peer review) is the author/funder, who has granted bioRxiv a license to display the preprint in perpetuity. It is made available under aCC-BY-NC 4.0 International license.
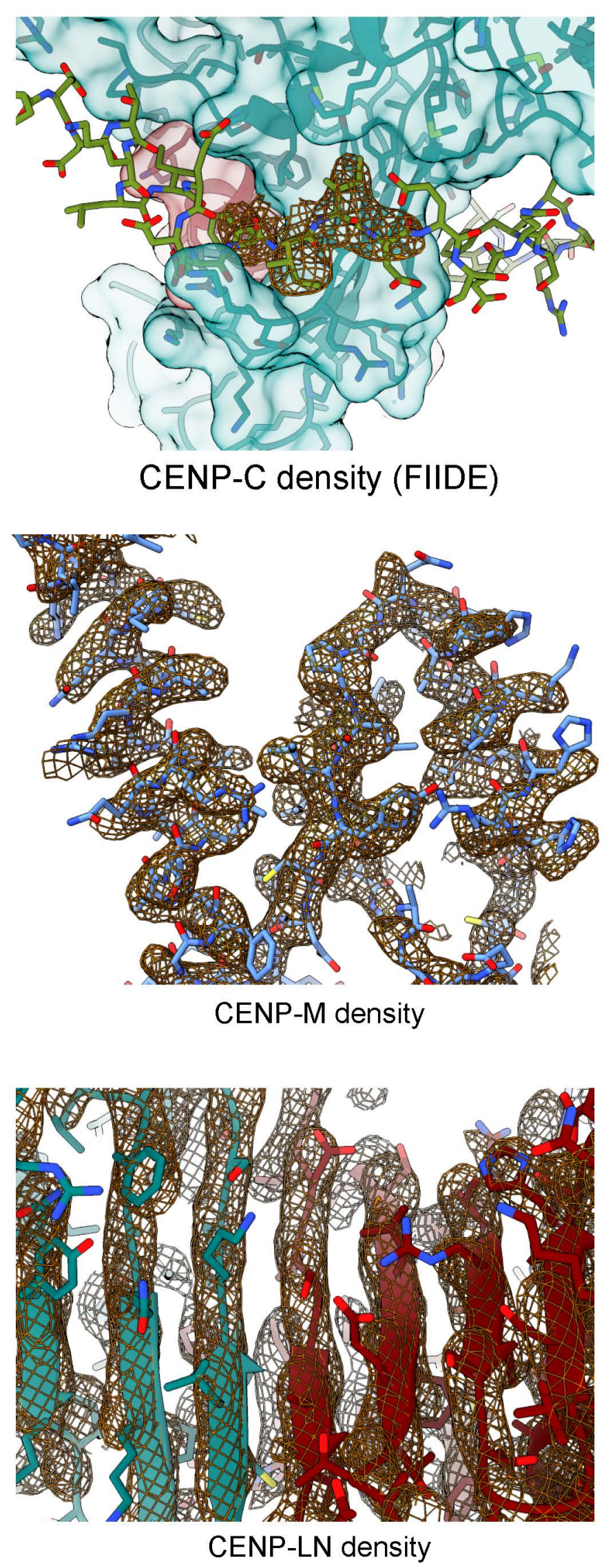

Figure 1 - Supplement 5 


\section{CENP-H}

CENP.H yeast secstruc
CNNP-H human secstruc CENP-H yeast

consensus
conservation score

CENP-H yeast secstruc
CNNP-H human secstruc

CENP-H yeast

conservation score

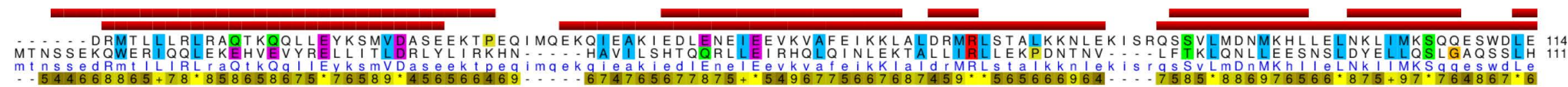

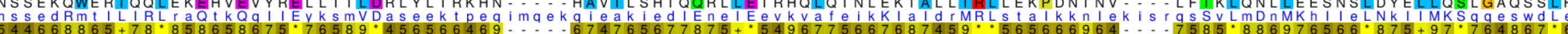

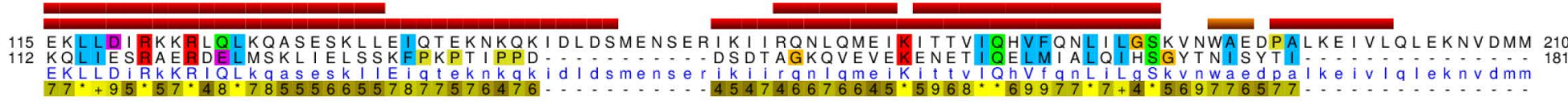

\section{CENP-I}

CENP-I yeast secstruc CENP-I human
CENP-I yeast

consensus
conservation score

CENP-I yeast secstruc
CENP-I human secstruc CENP-I yeast
consensus

consensus
conservation score

CENP-I yeast secstruc
CENP-I human secstruc CENP-I yeast

consensus
conservation score

CENP-I yeast secstruc
CENP-I human secstruc CENP-I yeas

consensus
conservation score

CENPPI yeast secstruc
CENP-I human secstruc CENP-I human
CENP-I yeast

consensus
conservation score

CENP-I yeast secstruc CENP-I human
CENP-I yeast

consensus
conservation score

CENP-I yeast secstruc
CENP-I human secstruc CENP-I human
CENP-I yeast

VGDYEHADDQAEEDALOMAVGYFE

A

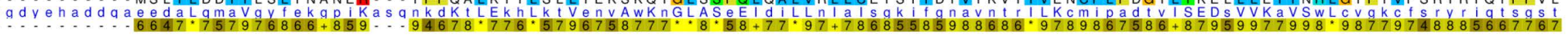

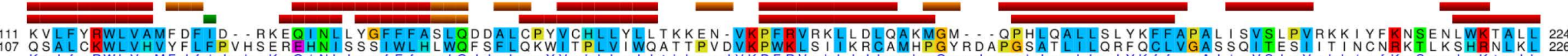

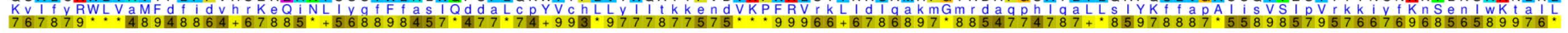

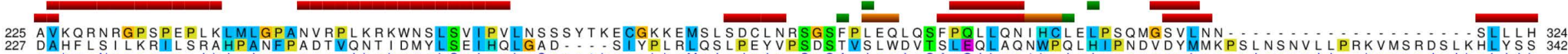

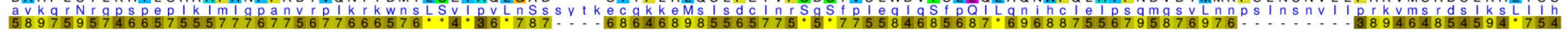

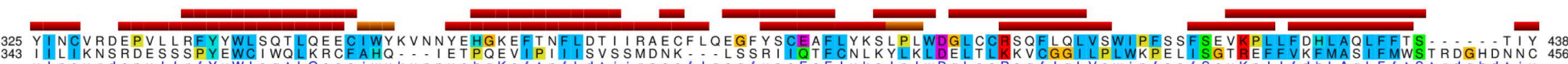

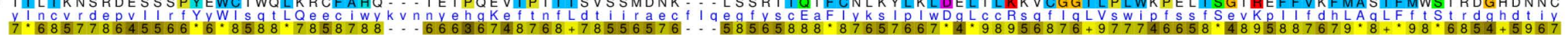

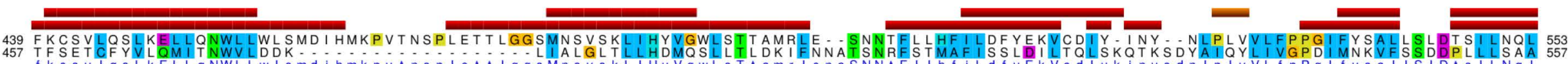

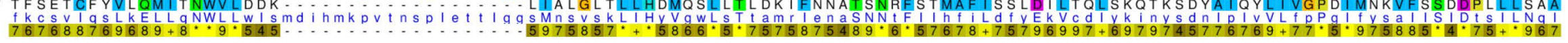

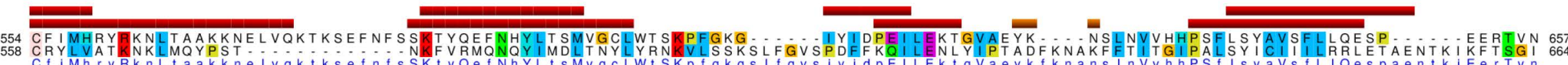

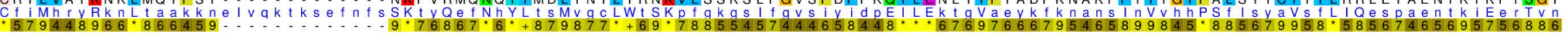

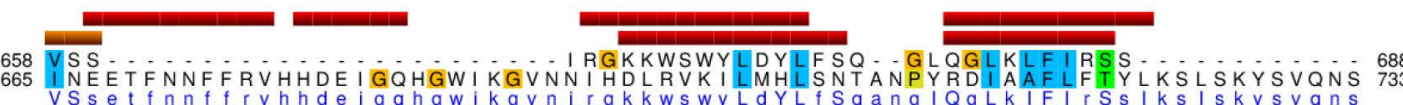

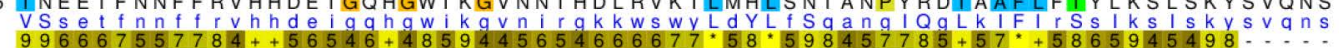

Figure 1 - Supplement 6 


\section{CENP-K}

CENP.K yeast secstruc
CENP.K human secstrux
CEn CENP-K yeast

consensus
conservation score

CENP-K yeast secstruc
CENP-K Kuman secstruc
CENP CENP-K yeast

consensus
conservation score

CENP-K yeast secstruc
CENP-K human secstruc

CENP-K human
CENP-K yeast

consensus
conservation score

\section{CENP-L}

CENP-L yeast secstruc
CENP-L human secstruc
Chen CENP-L human
CENP-L yeast
consensus

consensus
conservation score

CENP-L yeast secstruc
CNPP-L human secstruc CENP- L yeast
consensus

CENP-L yeast secstruc
CENP-L human secstruc
CENP-L human

CENP-L yeast

consensus
conservation scor

\section{CENP-N}

CENP-N yeast secstruc
CENP-N human secstruc CENP-N yeast
consensus
conservation score

CENP-N yeast sectruc CENP-N human
CENP-N yeast consensus
conservation score

CENP-N yeast secstruc CENP-N human
CENP-N yeast consensus
conservation score

CENP-N yeast secctruc
CENP-N human secstruc

CENP-N human
CENP-N yeast
consensus

consensus
conservation score

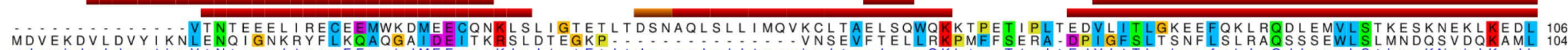

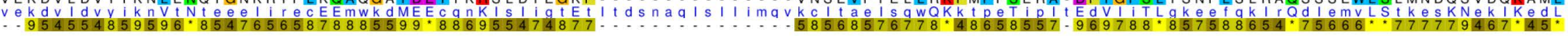

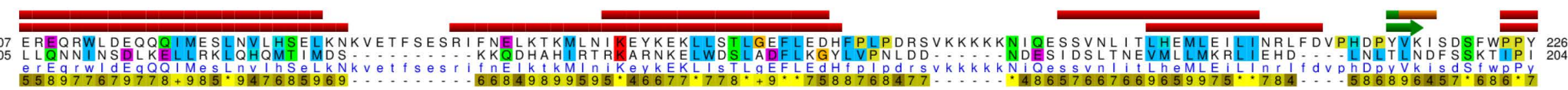

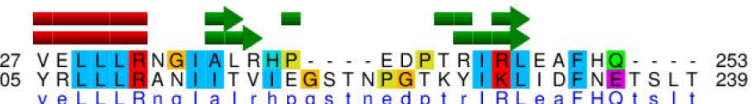

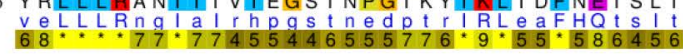

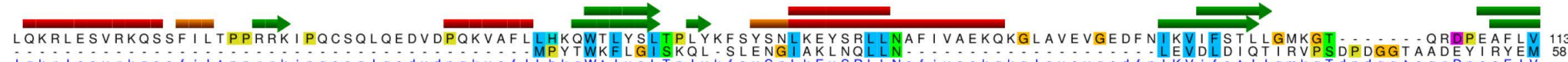

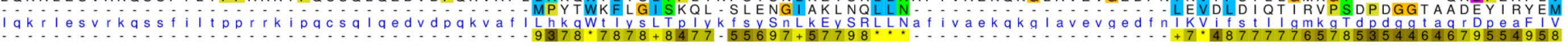

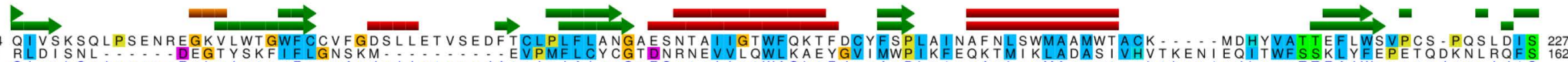

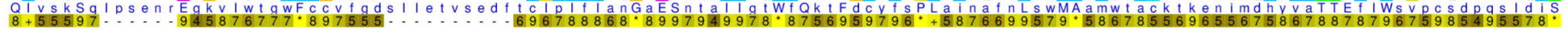

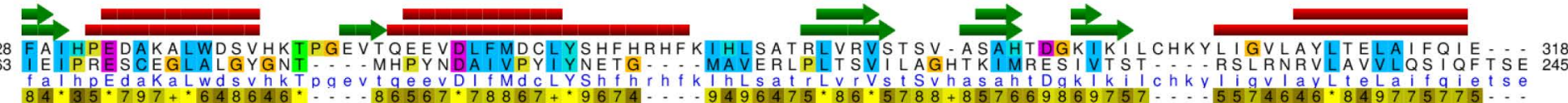

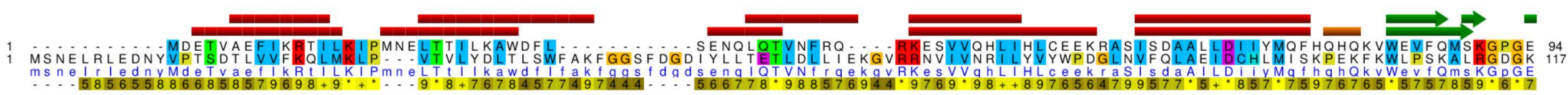

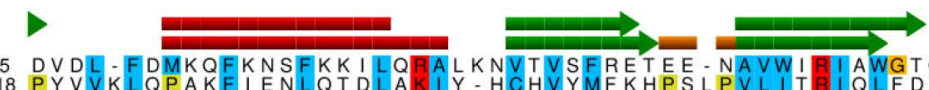

$\Rightarrow \vec{\longrightarrow} \longrightarrow$

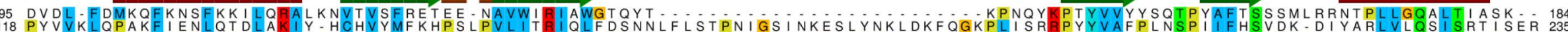

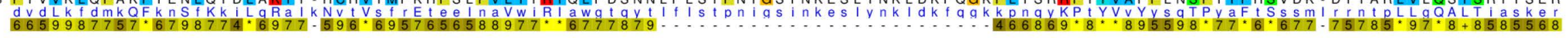

\section{- \\ $\Rightarrow$ \\ - \\ -}

ANTVERERQRITOETFE

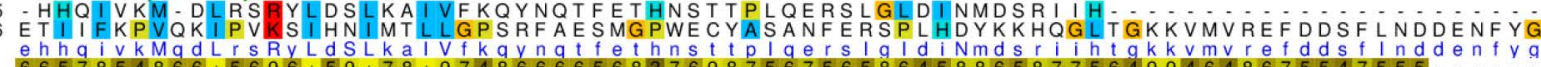

ent

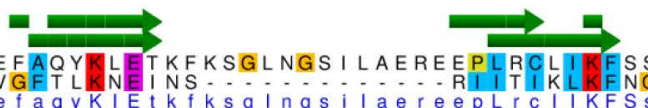

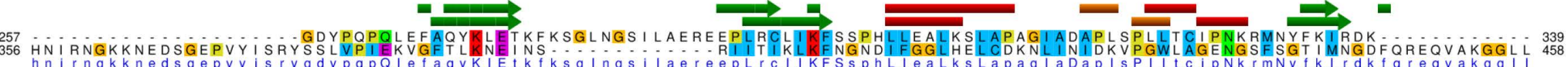

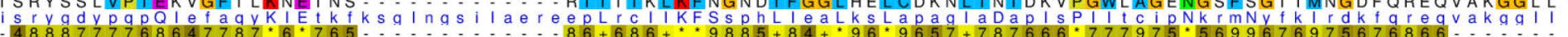

CCAN

Figure 1 - Supplement 6

(continued) 


\section{CENP-O}

CENP.O yeast secstruc
CENP-O human secstruc CENP-O human
CENP-O yeast consensus
conservation score

CENPPO yeast secstruc
CENP-O human secstruc CENP-O yeast

consensus
conservation score

CENP-O yeast secstruc
CENPPO human secstruc

CENP.O human

consensus
conservation score

CENP-O yeast secstruc
CENP-O human secstruc

CENP-O human

consensus
conservation score

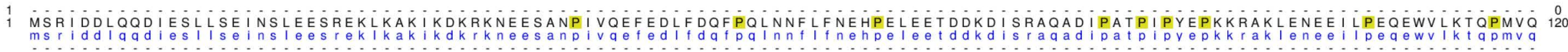

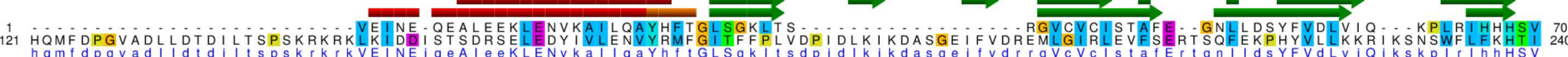

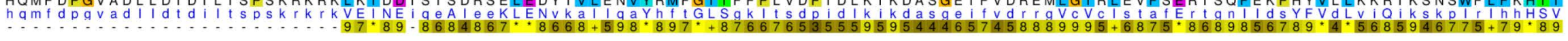

71 PVFIPLEEIAAKYLQT

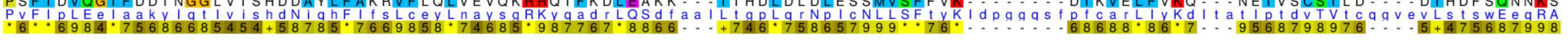

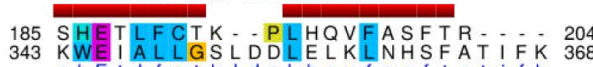

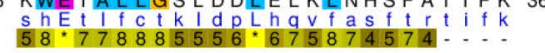

\section{CENP-P}

CENPP yeast secstruc CENPP P human
CENP-P yeast consensus
conservation score

CENP-P yeast secstruc

CENP-P human
CENPP.P yeast

consensus
conservation score

CENP.P yeast secstruc
CENP.P human secstruc

CENP-P human
CENP-P yeast

consensus
conservation score

CENP-P yeast secstruc

CENP-P yeast

consensus
conservation score

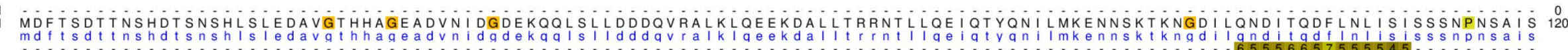

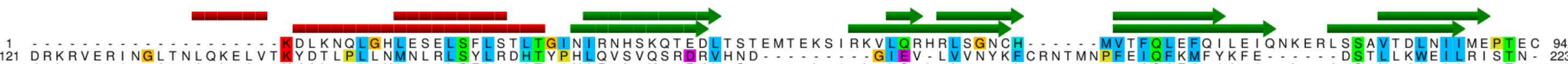

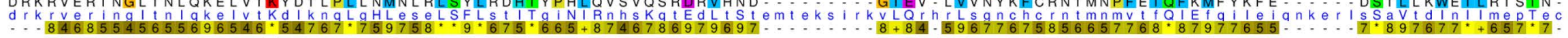

95 SELSEFVSRAEERKDLFMFFRSLFFVEWFEYRKRTFKHLKEKYPDAVYLSEGPSSCSMGIRSASRPG

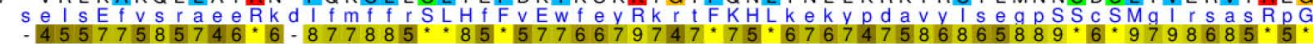

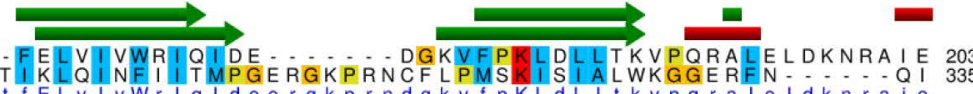
DEA

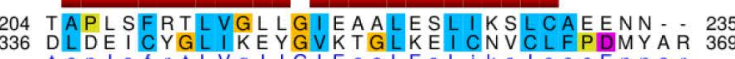

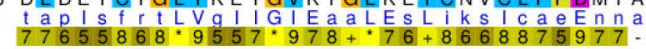




\title{
CENP-Q
}

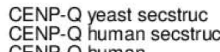
CENP-Q human
CENP-Q yeast consensus
conservation score

CENP-Q yeast secstruc CENP.Q human consensus
conservation score

CENP-Q yeast secstruc
CENP-Q human secstruc CENPPQ human
CENP-Q yeast
consensus consensus
conservation score

CENP-Q yeast secstruc
CENP-Q human secstruc CENP-Q human
CENP-Q yeast

consensus
conservation score

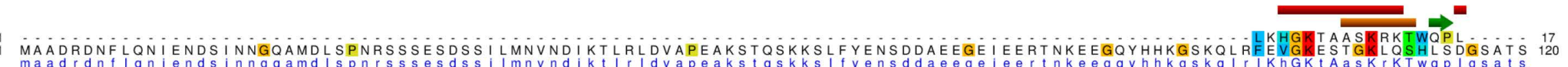

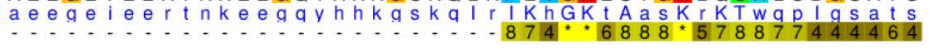

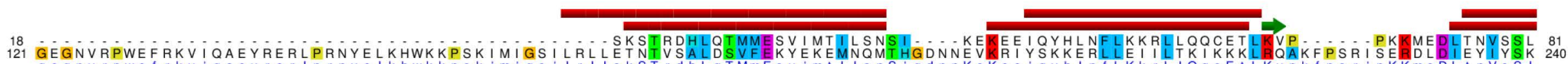

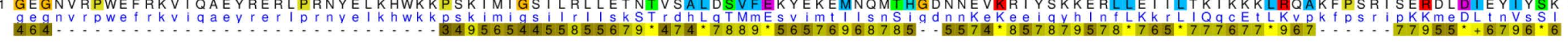

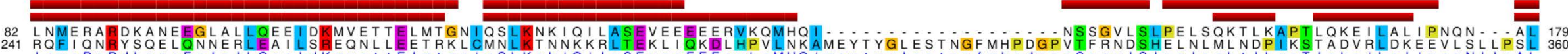

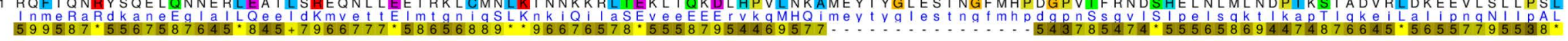

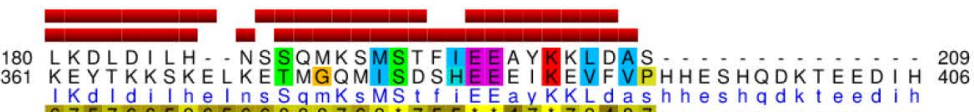

\section{CENP-T}

CENP-T yeast secstruc CENP-T human

consensus
conservation score

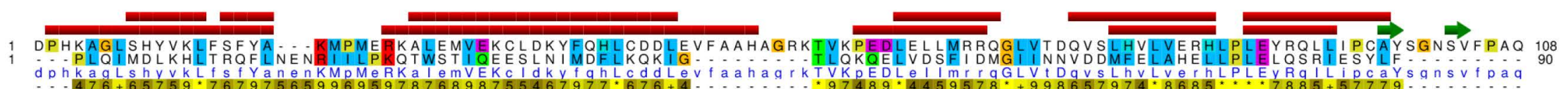

\section{CENP-U}

CENP-U yeast secstruc
CENP-U human secstruc CENP-U human
CENP-U yeast consensus
conservation score

CENP-U yeast secstruc CENP.U human
CENP.U yeast consensus
conservation score

CENP-U yeast secstruc
CENP-U human secstruc CENP.U human
CENPU yeast

consensus
conservation score

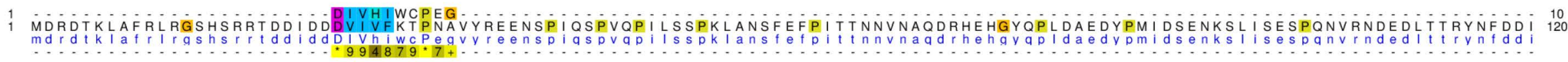

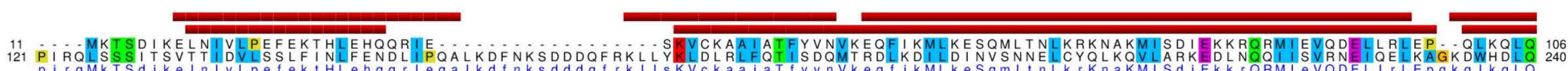

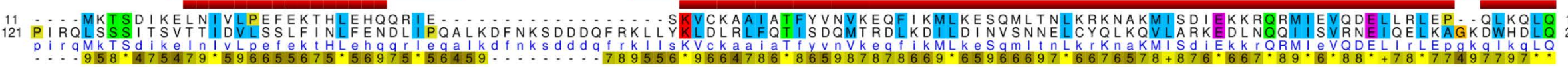

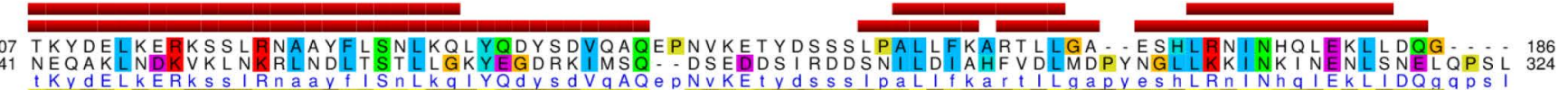

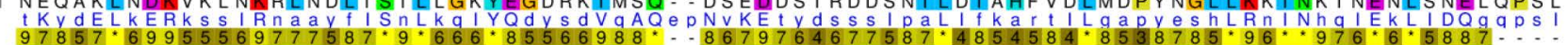

\section{CENP-W}

CENP-W yeast secstruc
CENP-W human secstruc
CENP-W human CENP.W yeast
consensus consensus
conservation score

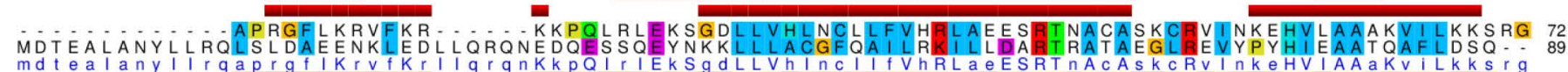

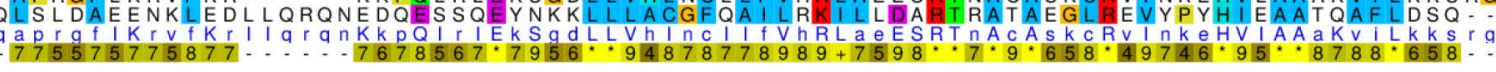

\author{
Figure 1 C SçN \\ (continued)
}


bioRxiv preprint doi: https://doi.org/10.1101/2022 01 06.475204 this version posted January 6, 2022. The copyright holder for this preprint (which was not certified by peer review) is the author/funder, who has granted bioRxiv a license to display the preprint in perpetuity. It is made available under aCC-BY-NC 4.0 International license.
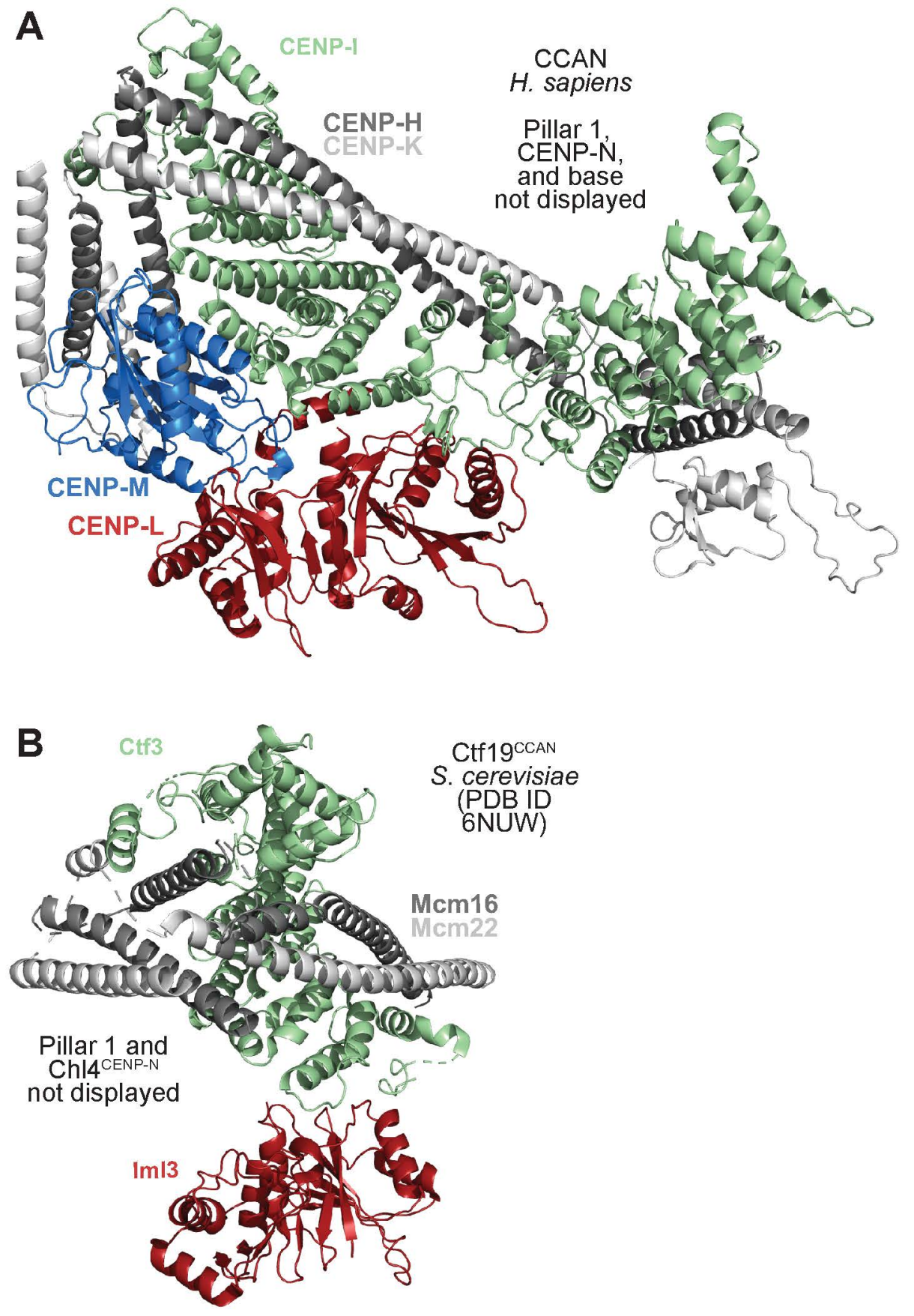

Figure 2 - Supplement 1 
bioRxiv preprint doi: https://doi.org/10.1101/2022.01.06.475204; this version posted January 6, 2022. The copyright holder for this preprint

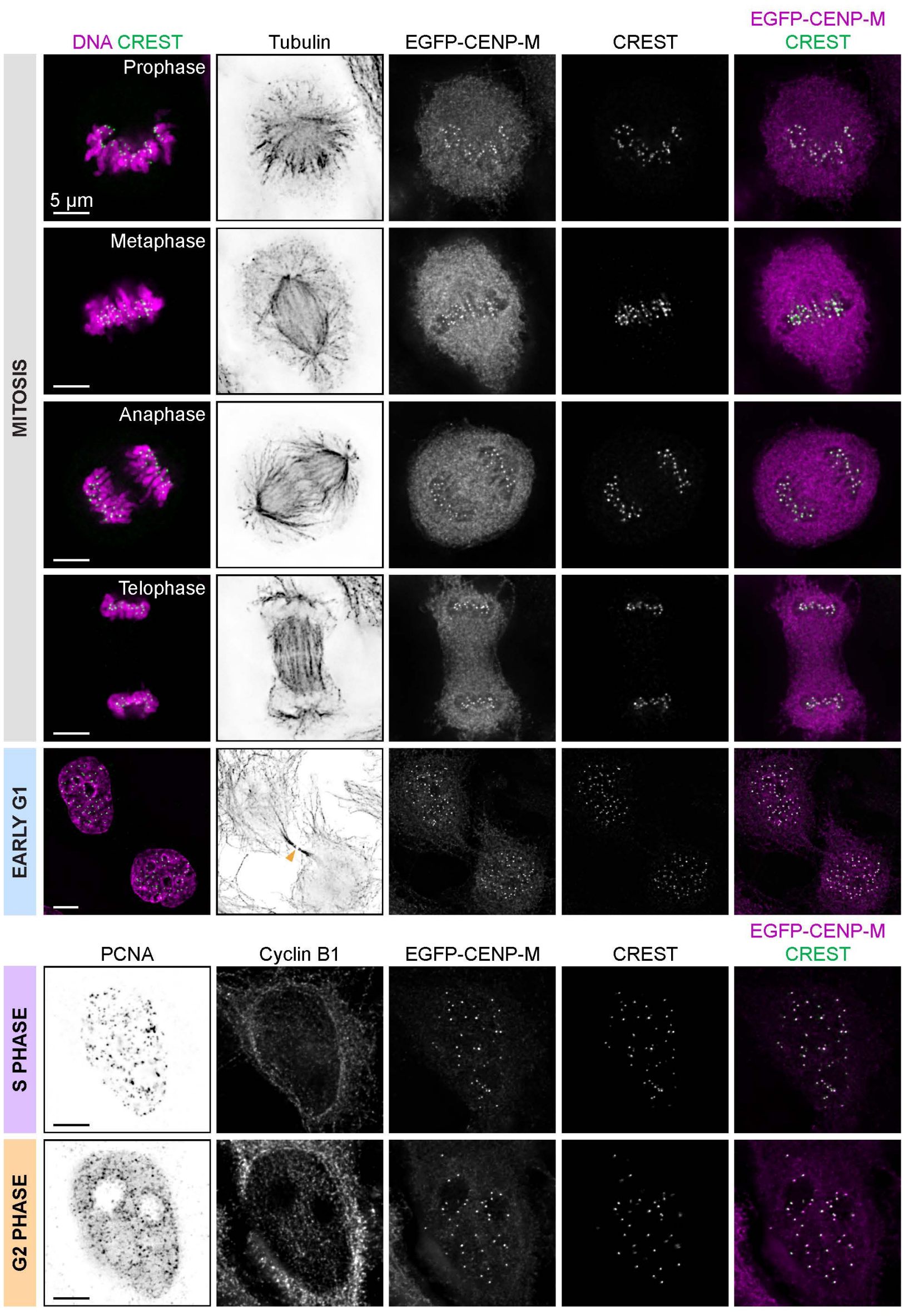

Figure 2 - Supplement 2 
bioRxiv preprint doi: https://doi.org/10.1101/2022.01.06.475204; this version posted January 6, 2022. The copyright holder for this preprint

(which was not certified by peer review) is the author/funder, who has granted bioRxiv a license to display the preprint in perpetuity. It is made available under aCC-BY-NC 4.0 International license.

A
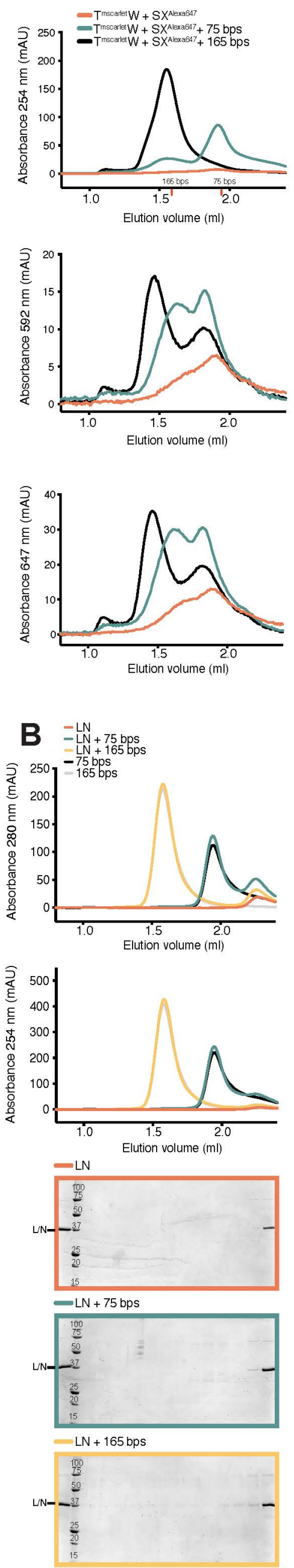
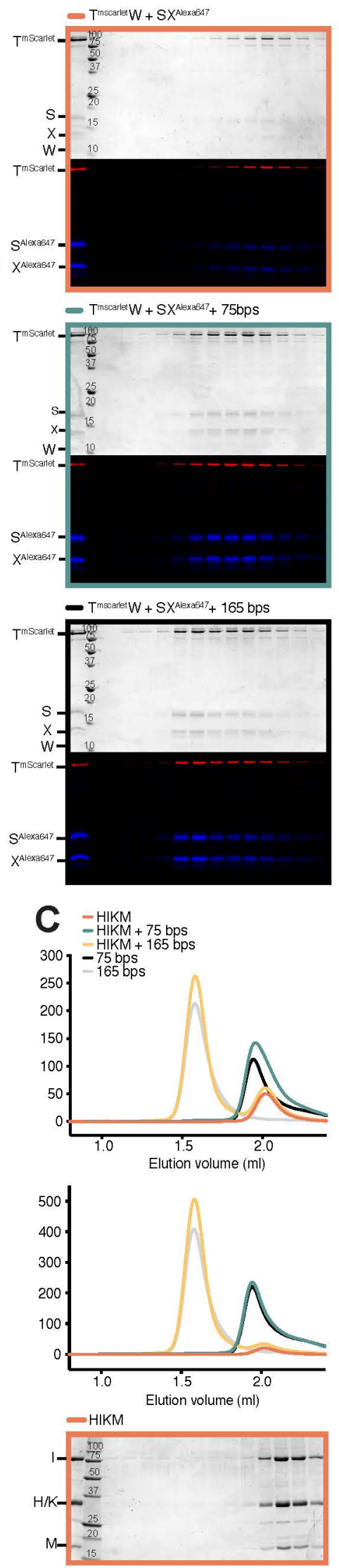

$$
-\mathrm{HIKM}+75 \text { bps }
$$

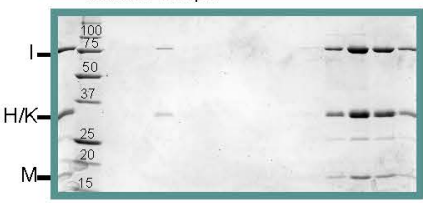

$-\mathrm{HIKM}+165 \mathrm{bps}$

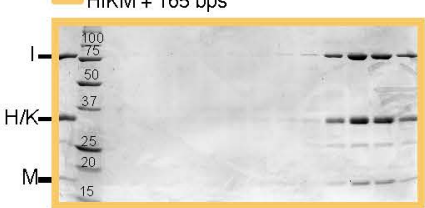

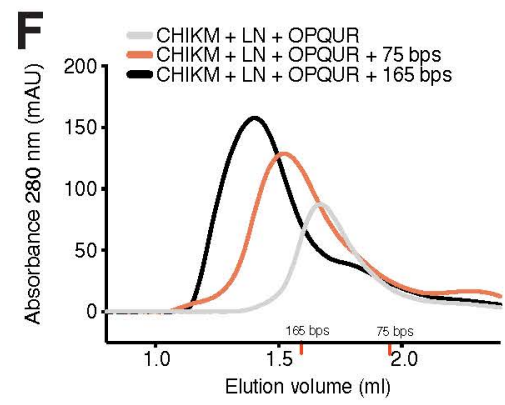
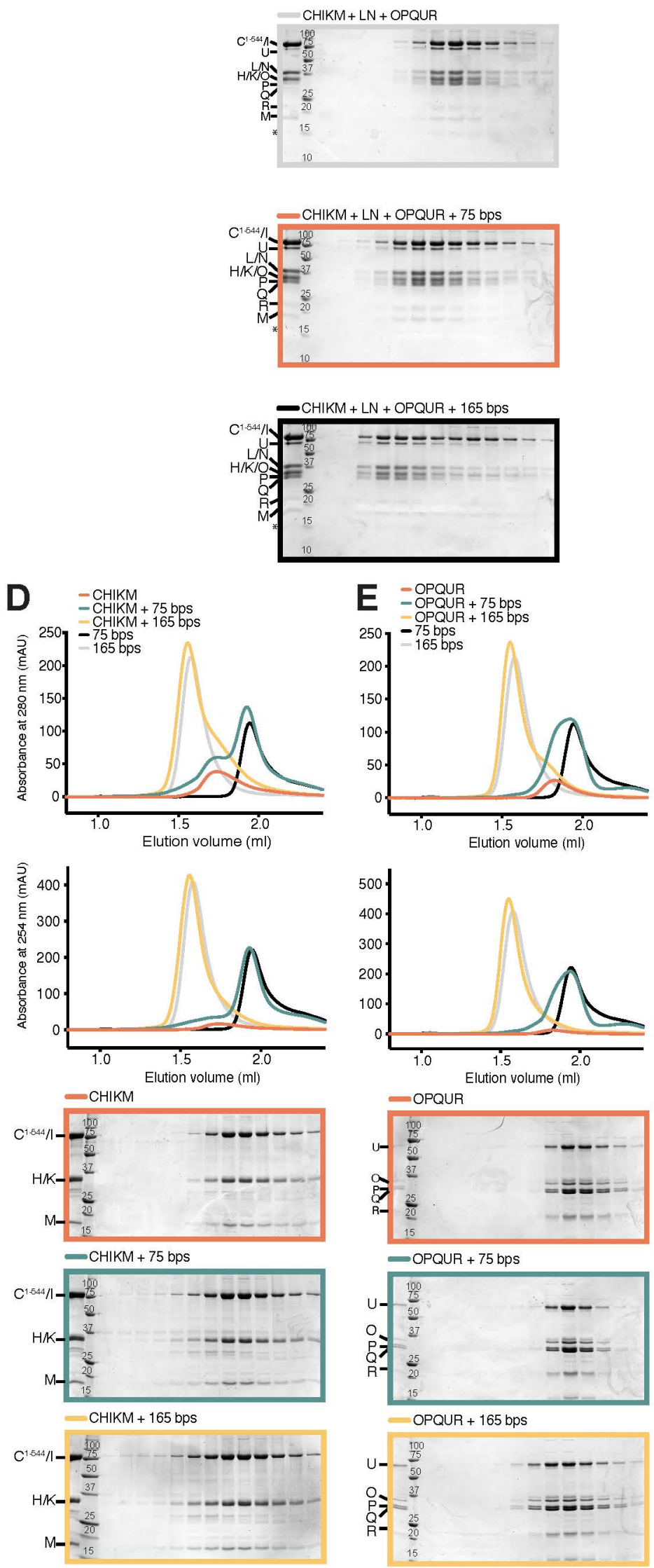

Figure 3 - Supplement 1 
bioRxiv preprint doi: https://doi.org/10.1101/2022 01.06.475204; this version posted January 6, 2022. The copyright holder for this preprint

(which was not certified by peer review) is the author/funder, who has granted bioRxiv a license to display the preprint in perpetuity. It is made available under aCC-BY-NC 4.0 International license.
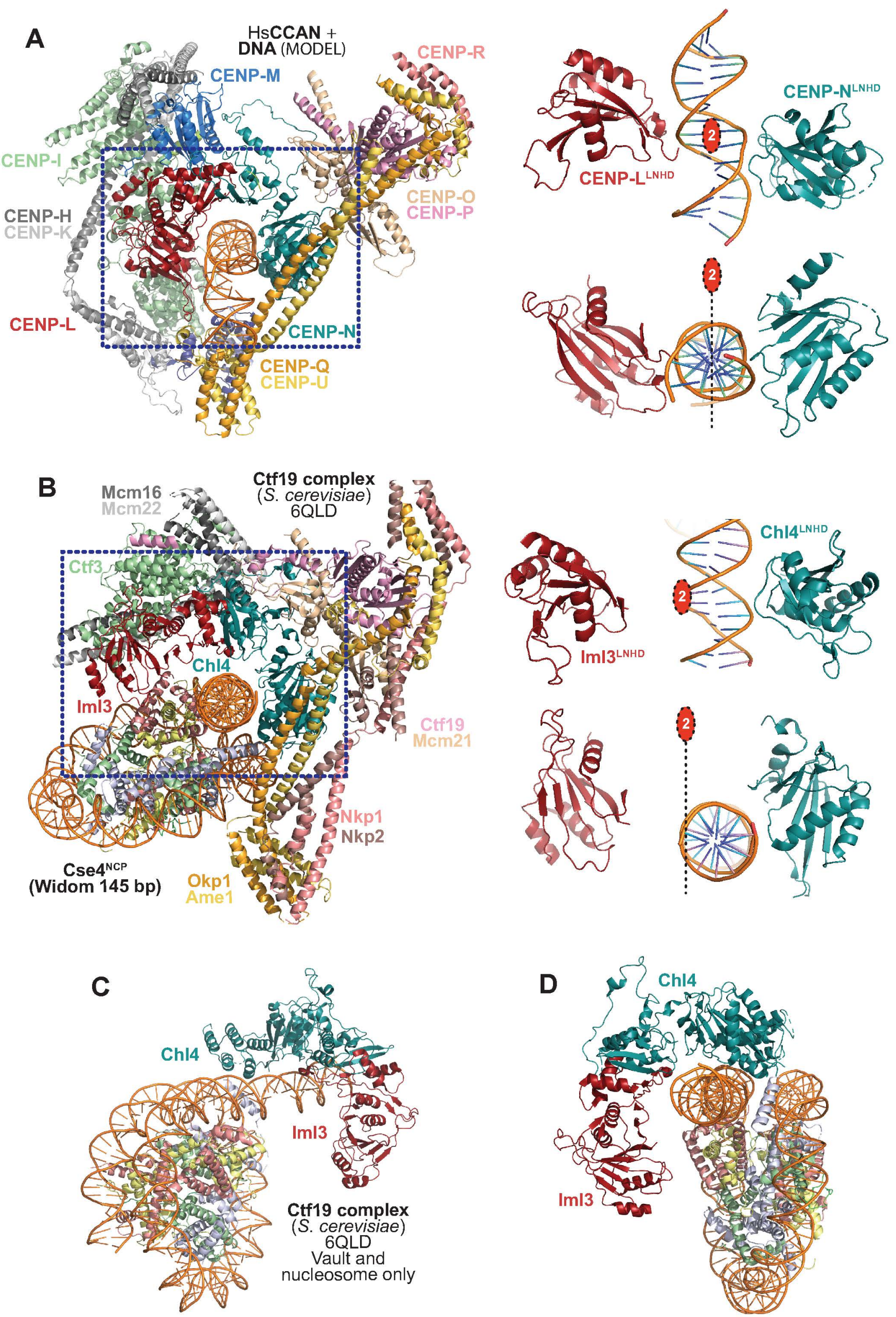

Figure 4 - Supplement 1 